\title{
Bandgap Engineering of Lead-Free Halide Double Perovskites
}

Fuxiang Ji
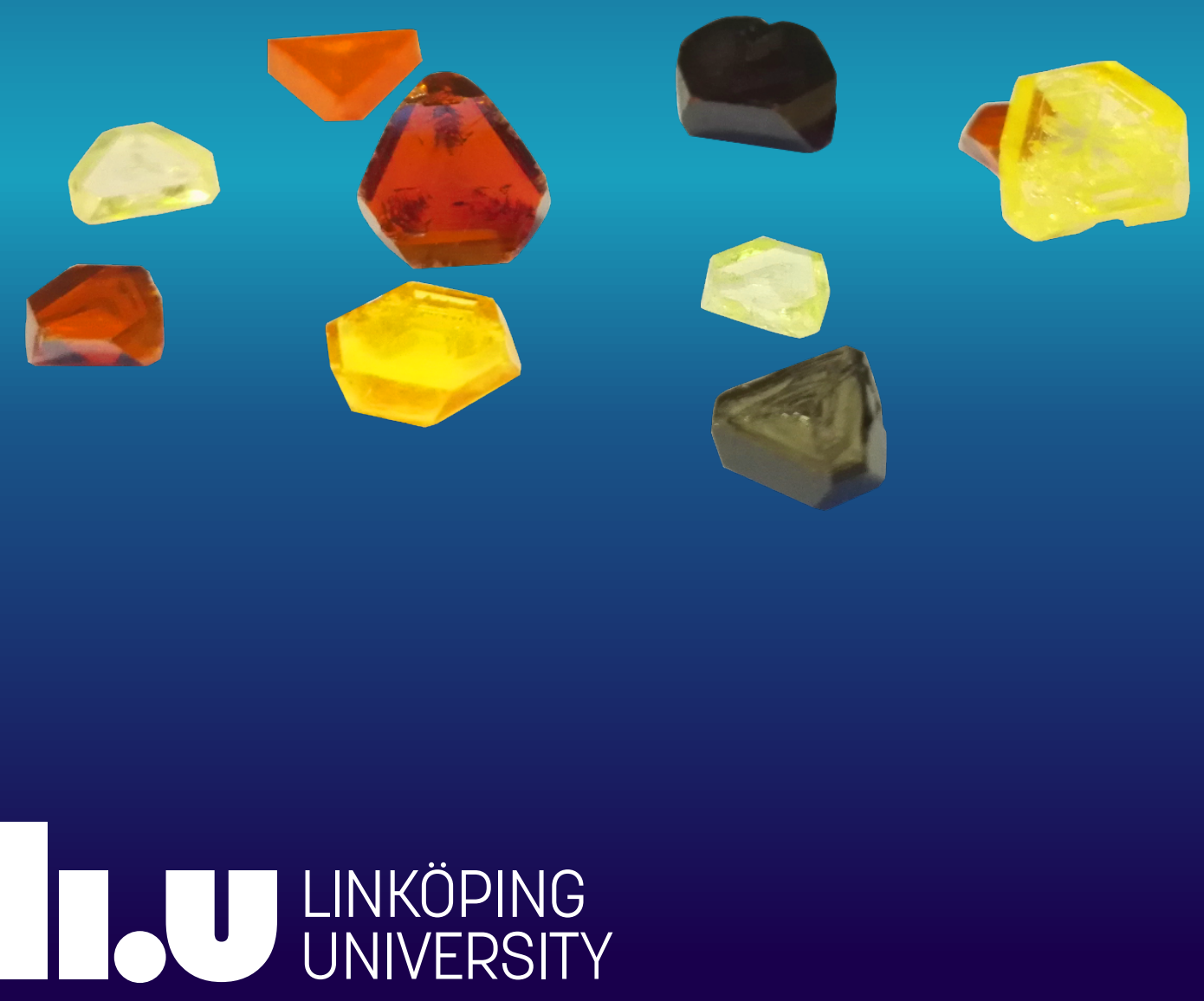

Linköping Studies in Science and Technology.

Dissertations No. 2156

\title{
Bandgap Engineering of Lead-Free Halide Double Perovskites
}

\author{
Fuxiang Ji
}

Electronic and Photonic Materials (EFM)

Department of Physics, Chemistry and Biology (IFM) Linköpings universitet, SE-581 83 Linköping, Sweden Linköping 2021 
During the course of research underlying the thesis, Fuxiang Ji was enrolled in Agora Materiae, a multidisciplinary doctoral program at Linköping University, Sweden.

(oc) $\mathrm{EY}$ This work is licensed under a Creative Commons Attribution 4.0 International License.

https://creativecommons.org/licenses/by/4.0/

(C) Fuxiang Ji, 2021

Printed in Sweden by Liu-Tryck, 2021

ISSN 0345-7524

ISBN 978-91-7929-606-3 


\begin{abstract}
Lead-free halide double perovskites (HDPs, $\mathrm{A}_{2} \mathrm{~B}^{\mathrm{I}} \mathrm{B}^{\mathrm{III}} \mathrm{X}_{6}$ ) with attractive optical and electronic features are regarded as one of the most promising alternatives to overcome the toxicity and stability issues of lead halide perovskites. They provide a wide range of possible combinations and rich substitutional chemistry with interesting properties for various optoelectronic devices. However, the performance of state-of-the-art lead-free HDPs is not yet comparable to that of lead halide perovskites, especially in the photovoltaic field. One of the main reasons for this is that HDPs usually have large and/or indirect bandgaps, which limit their optical and optoelectronic properties in the visible and infrared region. In this thesis, we attempt to modify the bandgap and optical properties of HDPs using metal doping/alloying and crystallization control, as well as provide detailed understanding of the alloying at the atomic level. We also observe significant changes of the bandgap of HDPs at different temperatures (i.e., thermochromism) and uncover the reasons behind it.
\end{abstract}

We first adopt the metal doping/alloying strategy to alter the absorption properties of benchmark HDPs $\mathrm{Cs}_{2} \mathrm{AgBiBr}_{6}$. By introducing $\mathrm{Cu}$ as the dopant in $\mathrm{Cs}_{2} \mathrm{AgBiBr}_{6}$, we significantly broaden the absorption edge from around $610 \mathrm{~nm}$ to around $860 \mathrm{~nm}$. Systematic characterizations indicate that $\mathrm{Cu}$ doping introduces defect states (sub-bandgap states) in the bandgap, without changing the bandgap of $\mathrm{Cs}_{2} \mathrm{AgBiBr}_{6}$. Interestingly, these sub-bandgaps can generate considerable amount of band carriers upon optical excitation, making these double perovskites promising for near-infrared light detection.

In parallel with the material modification using the metal doping/alloying strategy, the fundamental understanding of these doped/alloyed double perovskite is also of critical importance. In the second paper, we reveal the atomic-level structure of alloyed double perovskites by presenting a series of double perovskite alloys with the chemical formula $\mathrm{Cs}_{2} \mathrm{AgIn}_{1-\mathrm{x}} \mathrm{Fe}_{\mathrm{x}} \mathrm{Cl}_{6}(\mathrm{x}=0-1)$ showing tunable bandgaps in the range of 2.8-1.6 $\mathrm{eV}$. Our results show that $\mathrm{Fe}^{3+}$ substitutes $\mathrm{In}^{3+}$ in the lattice with the formation of $\left[\mathrm{FeCl}_{6}\right]^{3-} \cdot\left[\mathrm{AgCl}_{6}\right]^{5-}$ domains, which grow larger gradually as the $\mathrm{Fe}^{3+}$ concentration increases. It is noted that these domains could be further connected to form microscopically segregated $\mathrm{Fe}^{3+}$-rich phases in the double perovskite alloys.

To narrow the bandgap of $\mathrm{Cs}_{2} \mathrm{AgBiBr}_{6}$, we also develop a crystallization control approach, where high temperature is employed to assist the single crystal growth. By simply increasing the crystal growth temperature from $60{ }^{\circ} \mathrm{C}$ to $150{ }^{\circ} \mathrm{C}$, the bandgap of 
$\mathrm{Cs}_{2} \mathrm{AgBiBr}_{6}$ crystals can be reduced from $1.98 \mathrm{eV}$ to $1.72 \mathrm{eV}$, which is the lowest reported bandgap for $\mathrm{Cs}_{2} \mathrm{AgBiBr}_{6}$ at ambient conditions. The underlying reason is hypothesized to be related to the increased level of $\mathrm{Ag}-\mathrm{Bi}$ disorder in the crystal structure.

Lastly, we observe an interesting reversible thermochromic behavior in HDPs $\mathrm{Cs}_{2} \mathrm{NaFeCl}_{6}$. Specifically, the optical bandgap of $\mathrm{Cs}_{2} \mathrm{NaFeCl}_{6}$ is reduced from $2.06 \mathrm{eV}$ to $1.86 \mathrm{eV}$ when the temperature increases from $\mathrm{RT}$ to $150{ }^{\circ} \mathrm{C}$ and turns back to its original value after cooling. Meanwhile, we observe lattice expansion during the heating/cooling process without phase transition. Our first-principles calculation indicates that the underlying mechanism for the thermochromic phenomenon in $\mathrm{Cs}_{2} \mathrm{NaFeCl}_{6}$ is mainly related to the electron-phonon coupling.

Although the development of HDPs is in its early stages, we believe that HDPs with impressive optical and electronic properties and rich substitutional chemistry have a bright future in optoelectronic and multifunctional applications. Our findings shed new light to the absorption and bandgap modulation of HDPs and provide new insights into the atomic-level structures of DPAs, which can help to develop efficient optoelectronic devices.

Keywords: Lead-free halide double perovskites, Metal doping/alloying, Bandgap engineering, Atomic-level structure, Thermochromism 


\section{Populärvetenskaplig Sammanfattning}

Blyfria halid-dubbelperovskiter (HDP:er, $\mathrm{A}_{2} \mathrm{~B}^{\mathrm{I}} \mathrm{B}^{\mathrm{III}} \mathrm{X}_{6}$ ) med attraktiva optiska och elektroniska egenskaper betraktas som ett av de mest lovande alternativen för att övervinna de toxicitets- och stabilitetsproblem som bly-halidperovskiter för optoelektriska tillämpningar har. HDP:er ger upphov till en bredd av möjliga kombinationer och en rik möjlighet till substitutionskemi med intressanta egenskaper för olika optoelektriska komponenter. Prestandan hos vetenskapens bästa blyfria HDP:er är dock ännu inte jämförbar med bly-halidperovskiters, särskilt inte inom solcellsfältet. En av de främsta orsakerna till detta, är att HDP:er vanligtvis har stora och/eller indirekta bandgap, vilket begränsar deras optiska och optoelektroniska egenskaper i det synliga och infraröda området. I denna avhandling försöker vi modifiera bandgap och optiska egenskaper hos HDP:er med hjälp av metalldopning/legering och kristalliseringskontroll, så väl som ge en detaljerad förståelse för legeringen på atomnivå. Vi observerar även betydande förändringar av bandgap hos HDP:er vid olika temperaturer (dvs. Termokromism) och visar på orsakerna bakom detta.

$\mathrm{Vi}$ antar först metalldopning-/legeringsstrategin för att ändra absorptionsegenskaperna hos $\mathrm{HDP}$-utgångsmaterialet $\mathrm{Cs}_{2} \mathrm{AgBiBr}_{6}$. Genom att introducera $\mathrm{Cu}$ som dopämne i $\mathrm{Cs}_{2} \mathrm{AgBiBr}_{6}$ breddar vi absorptionskanten avsevärt, från cirka $610 \mathrm{~nm}$ till cirka $860 \mathrm{~nm}$. Systematiska karakteriseringar indikerar att $\mathrm{Cu}$-dopning introducerar defekttillstånd (sub-bandgap-tillstånd) i bandgapet, utan att ändra bandgapet för $\mathrm{Cs}_{2} \mathrm{AgBiBr}_{6}$. Intressant nog kan dessa subbandgap generera en betydande mängd bandbärare via optisk excitation, vilket gör dessa dubbelperovskiter lovande för ljusdetektering i det nära-infraröda området.

Parallellt med materialmodifieringen med hjälp av metalldopnings/legeringsstrategin är den grundläggande förståelsen av dessa dopade/legerade dubbelperovskiter också av avgörande betydelse. I den andra artikeln undersöker vi atomnivåstrukturen hos dopade dubbelperovskiter genom att presentera en serie dubbelperovskitlegeringar med den kemiska formeln $\mathrm{Cs}_{2} \mathrm{AgIn}_{1-\mathrm{x}} \mathrm{Fe}_{\mathrm{x}} \mathrm{Cl}_{6}(\mathrm{x}=0-1)$ som visar ett justerbart bandgap i intervallet 2.8-1.6 eV. Våra resultat visar att $\mathrm{Fe}^{3+}$ ersätter $\mathrm{In}^{3+} \mathrm{i}$ gitteret och bildar $\left[\mathrm{FeCl}_{6}\right]^{3-} \cdot\left[\mathrm{AgCl}_{6}\right]^{5-}$ domäner som gradvis växer sig större när $\mathrm{Fe}^{3+}$ koncentrationen ökar. Det är observerat att dessa domäner kan sammanföras ytterligare för att bilda mikroskopiskt segregerade $\mathrm{Fe}^{3+}$-rika faser i dubbelperovskitlegeringarna. 
För att minska $\mathrm{Cs}_{2} \mathrm{AgBiBr}_{6}-\mathrm{HDP}$ :ernas bandgap utvecklade vi även en kristalliseringskontrollmetod, där hög temperatur används för att främja enkristallin tillväxt. Genom att öka kristalltillväxttemperaturen från $60^{\circ} \mathrm{C}$ till $150^{\circ} \mathrm{C}$ kan bandgapet för $\mathrm{Cs}_{2} \mathrm{AgBiBr} 6$ minskas från 1,98 eV till 1,72 eV, vilket är det minsta bandgap som har rapporterats för $\mathrm{Cs}_{2} \mathrm{AgBiBr}_{6}$ i rumsförhållanden. Den underliggande orsaken antas vara relaterad till den ökade nivån av Ag-Bi-oordning i kristallstrukturen.

Slutligen har vi observerat ett intressant reversibelt termokromatiskt beteende i $\mathrm{Cs}_{2} \mathrm{NaFeCl}_{6}-\mathrm{HDP}$ :er. Mer specifikt, reduceras det optiska bandgapet för $\mathrm{Cs}_{2} \mathrm{NaFeCl}_{6}$ från $2.06 \mathrm{eV}$ till $1.86 \mathrm{eV}$ när temperaturen ökar från RT till $150{ }^{\circ} \mathrm{C}$ och återgår till sitt ursprungliga värde efter kylning. Under tiden observerar vi gitterexpansion under uppvärmnings-/kylprocessen utan fasövergång. Vår första-princip-beräkning visar att den underliggande mekanismen för det termokromatiska fenomenet i $\mathrm{Cs}_{2} \mathrm{NaFeCl}_{6}$ främst är relaterade till elektron-fonon-koppling.

Även om utvecklingen av HDP:er är i ett tidigt skede, tror vi att HDP:er med imponerande optiska och elektroniska egenskaper och rik substitutionskemi har en ljus framtid inom optoelektroniska och multifunktionella applikationer. Våra resultat kastar nytt ljus över absorption- och bandgapmoduleringen av HDP:er och ger nya insikter gällande atomnivåstrukturer av dubbelperovskitlegeringar, vilket kan bidra till utvecklingen av effektiva optoelektroniska komponenter. 


\section{Acknowledgement}

This thesis would not have been completed without the support of my supervisors, colleagues, collaborators, friends, and families.

Firstly, I would like to express my sincere gratitude to my main supervisor Prof. Feng Gao. Thank you for giving me this precious opportunity to do my $\mathrm{PhD}$ in our wonderful group, which has changed my life. Before joining you, I had almost lost my confidence to study abroad due to my poor English. You gave me enough freedom, patient encouragement, useful guidance, and endless support during my research. I have also learned a lot of solid knowledge, rigorous academic style, and sincere character from you. It is a great pleasure to be your student.

I would like to give my special thanks to my co-supervisor Dr. Feng Wang and colleague Dr. Weihua Ning. Thank you for the tremendous help and support in experiment design, data analysis, and paper writing. Dr. Feng Wang, thank you for your endless and selfless help and support during my whole doctoral journey. You have taught me not only how to publish scientific papers but also how to become a qualified scientific researcher. You have also been providing me a lot of selfless help, such as revising my doctoral thesis and curriculum vitae, etc. I really appreciate everything you have done for me. I also want to thank you and your wife Mei Yang for the delicious food. Dr. Weihua Ning, thank you for providing me the research direction and teaching me how to synthesize single crystals by hydrothermal method. You have made a lot of contributions to these published papers. Special thanks also go to my co-supervisor Prof. Niclas Solin and mentor Dr. Jianwu Sun for their support and discussion, which have made my study easier.

My sincere thanks go to my collaborators: Dr. Johan Klarbring, Prof. Sergei I. Simak, and Prof. Igor A. Abrikosov. Thank you for the kind discussions and professional support in the first-principles calculations. Dr. Libor Kobera, Dr. Sabina Abbrent, and Dr. Jiri Brus, thank you for your detailed and professional solid-state NMR measurements and analysis. Dr. Yuqing Huang, Prof. Irina A. Buyanova, and Prof. Weimin M. Chen, thank you for the help with photoconductivity measurement. Dr. Linqin Wang and Prof. Licheng Sun, thank you for the measurement support in single crystal XRD. Dr. Chunyang Yin, Dr. José Silvestre Mendoza Figueroa, Dr. Christian Kolle Christensen, Dr. Martin Etter, Dr. Xianje Liu, Dr. Amgalanbaatar Baldansuren, Dr.Yuttapoom Puttisong, Prof. Fangyan Xie, Prof. Thomas Ederth, Prof. Martin Magnuson and Prof. Mats Fahlman, thank you for the professional measurement support. Thank you all for your cooperation and contribution to make these works successfully published.

I would like to express my sincere thanks to all my current and previous colleagues in our group; to Xiang $\mathrm{Xu}$, who was the first person I met at Linkoping and helped me rent me a comfortable room; to Julia Morát, Max Karlsson, and Shan Anjum, who helped me to translate the abstract into Swedish; to Hongling Yu, who provided lots of useful comments and help in the preparation process of the doctoral dissertation, English learning and acknowledgement writing; to Jibin Zhang for the help in discarding leadbased waste in the lab; to Linlong Deng, Chang Yi, Chunxiong Bao, Jie Yang, Weidong $\mathrm{Xu}$, Sai Bai, Xiaoke Liu, Zhongcheng Yuan, Heyong Wang, Mengyun Chen, Tiankai Zhang, Chaoyang Kuang, Huotian Zhang, Tiqiang Pang, Naresh Kumar, Haifeng Zhao, 
Xinyi Cai, Pengpeng Teng, Xiyu Luo, Yuming Wang, Deping Qian, Rui Zhang, Junjie Xie, Jiajun Qin, Xuehong Zhou, Yong Wang, Zhan Chen, Muyi Zhang, David Hardy, Bei Yang, Yatao Zou, Hongting Chen, Ziyue Yi, Yan Xu, Xin Wang, Yu Wang, Fanglong Yuan, Zhiqi Li, Jia Zhang, Yonghong Wang, Tianjun Liu, Li Wan, Tao Zhang and Nakul Jain, who have provided me lots of help, support, encouragement, and advices in my research and life.

I also want to express my sincere thanks to our food sharing team: Xin Zheng, Tingting Tian, Chao Cui, Yuequn Shang, Hongwei Lei, Shanpeng Wang, and Yusheng Yuan. I really enjoyed the time that we spent together to share food, travel, play games and have fika. Thank you all for bringing me a lot of fun, laughter, happiness, memories, and delicious Chinese food. Thank Weidong Cai and his wife for giving me lots of delicious food and snacks. Thank Yanyan Cui for your help in designing the cover of my dissertation. In addition, I would like to thank Zhixing Wu, Xin Zhang and Lingying Meng for playing badminton and pingpong with me.

My sincere thanks also go to my colleagues and friends from Linköping University; to our administrators (Anna-Maria Uhlin, Ann-Charlotte Svensson Holm, Lena Martinsson and Iryna Yakymenko); to Caroline Brommesson and all Agora members; to my contact person at LiU-Tryck Martin Pettersson; to Prof. Fengling Zhang, Zhangjun Hu, Meijia, Yong Yu, Chunxia Du, Quanzheng Tao, Danfeng Cao, Lianlian Liu, Jinhao Xu, Xiaoyu Sun, Luqing Cui, Rui Shu, Jiwen Hu, Yuchen Shi, Hongfang Zhang, Binbin Xin, Lei Wang, Nannan Yao, Yanfeng Liu, Jie Zhou, Yuxin Xia, Husseindante, Yuanbin Zhou, Xiane Li, Shangzhi Chen, Ye Yuan, and Mingduo Zhao. Thank you very much for your help and support in my daily life.

I express great gratitude to my previous supervisors Prof. Shuping Pang and Prof. Guangwen Xie. Without your guidance and support, I could never start my journey in science and research.

Special thanks to China Scholarship Council (CSC) for the financial support.

Last but not least, I would like to express my sincere gratitude to my parents for your love and support. Thanks to my aunt and cousin for your help and support. My deepest gratitude goes to my maternal grandfather, who is the most important person in my life. I cannot grow up healthy without your care and support. Words cannot express my gratitude at all. Your passing is a truth that I cannot accept, and it is a regret in my life that I have lost the opportunity to take care of you.

The four-year study abroad is a very exciting journey, which has changed me a lot. Thanks again to all friends in Sweden and China for your kind help!

Fuxiang Ji

July 2021 at Linköping University 


\section{List of Publications Included in the Thesis}

1. Near-Infrared Light-Responsive $\mathrm{Cu}-\mathrm{Doped} \mathrm{Cs}_{2} \mathrm{AgBiBr}_{6}$.

Ji, F.; Huang, Y.; Wang, F.; Kobera, L.; Xie, F.; Klarbring, J.; Abbrent, S.; Brus, J.; Yin, C.; Simak, S. I.; Abrikosov, I. A.; Buyanova, I. A.; Chen, W. M.; Gao, F. Adv. Funct. Mater. 2020, 30 (51), 2005521.

2. The Atomic-Level Structure of Bandgap Engineered Double Perovskite Alloys $\mathrm{Cs}_{2} \mathrm{AgIn}_{1-\mathrm{x}} \mathrm{Fe}_{\mathrm{x}} \mathrm{Cl}_{6}$.

Ji, F.; Wang, F.; Kobera, L.; Abbrent, S.; Brus, J.; Ning, W.; Gao, F.

Chem. Sci. 2021, 10.1039.

3. Lead-Free Halide Double Perovskite $\mathrm{Cs}_{2} \mathrm{AgBiBr}_{6}$ with Decreased Band Gap.

Ji, F.; Klarbring, J.; Wang, F.; Ning, W.; Wang, L.; Yin, C.; Figueroa, J. S. M.; Christensen, C. K.; Etter, M.; Ederth, T.; Sun, L.; Simak, S. I.; Abrikosov, I. A.; Gao, F. Angew. Chem. 2020, 132 (35), 15303-15306.

4. Strong electron-phonon coupling induced thermochromism in the double perovskite $\mathrm{Cs}_{2} \mathrm{NaFeCl}_{6}$.

Ji, F.; Klarbring, J.; Zhang, B.; Wang, F.; Ning, W.; Ren, X.; Buyanova, I. A.; Chen, W. M., Simak, S. I.; Abrikosov, I. A.; Gao, F.

Manuscript

\section{Author contribution}

Paper 1: Synthesized the $\mathrm{Cu}$-doped $\mathrm{Cs}_{2} \mathrm{AgBiBr}_{6}$ single crystals, carried out most of the characterizations and data analysis, except for the photoconductivity measurement and analysis, wrote the manuscript and revised it together with co-authors.

Paper 2: Synthesized the $\mathrm{Cs}_{2} \mathrm{AgIn}_{1-\mathrm{x}} \mathrm{Fe}_{\mathrm{x}} \mathrm{Cl}_{6}$ double perovskite alloys, carried out most of the characterizations and data analysis, except for the solid-state nuclear magnetic resonance (ssNMR) measurements and analysis, wrote the manuscript and revised it together with co-authors.

Paper 3: Synthesized the $\mathrm{Cs}_{2} \mathrm{AgBiBr}_{6}$ single crystals, carried out most of the characterizations and data analysis, except for First-principle DFT calculations, wrote the manuscript and revised it together with co-authors.

Paper 4: Synthesized the $\mathrm{Cs}_{2} \mathrm{NaFeCl}_{6}$ single crystals, carried out most of the characterizations and data analysis, wrote the manuscript and revised it together with co-authors. 


\section{List of Publications not Included in the Thesis}

1. Thermochromic Lead-Free Halide Double Perovskites.

Ning, W.; Zhao, X.-G.; Klarbring, J.; Bai, S.; Ji, F.; Wang, F.; Simak, S. I.; Tao, Y.; Ren, X.-M.; Zhang, L.; Huang, W.; Abrikosov, I. A.; Gao, F.

Adv. Funct. Mater. 2019, 29 (10), 1807375.

2. Stable, High-Sensitivity and Fast-Response Photodetectors Based on Lead-Free $\mathrm{Cs}_{2} \mathrm{AgBiBr}_{6}$ Double Perovskite Films.

Yang, J.; Bao, C.; Ning, W.; Wu, B.; Ji, F.; Yan, Z.; Tao, Y.; Liu, J.; Sum, T. C.; Bai, S.; Wang, J.; Huang, W.; Zhang, W.; Gao, F.

Adv. Opt. Mater. 2019, 1801732.

3. Dimensional Tailoring of Ultrahigh Vacuum Annealing-Assisted Quantum Wells for the Efficiency Enhancement of Perovskite Light-Emitting Diodes.

Yu, Y.; Wang, H.; Xu, W.; Kuang, C.; Ji, F.; Braun, S.; Liu, X.; Yi, C.; Gao, F.; Fahlman, $\mathrm{M}$.

ACS Appl. Mater. Interfaces 2020, 12 (22), 24965-24970.

4. Intermediate-Phase-Assisted Low-Temperature Formation of $\gamma-\mathrm{CsPbI}_{3}$ Films for High-Efficiency Deep-Red Light-Emitting Devices.

Yi, C.; Liu, C.; Wen, K.; Liu, X.-K.; Zhang, H.; Yu, Y.; Fan, N.; Ji, F.; Kuang, C.; Ma, B.; Tu, C.; Zhang, Y.; Xue, C.; Li, R.; Gao, F.; Huang, W.; Wang, J.

Nat Commun 2020, 11 (1), 4736.

\section{Author contribution}

For these papers not included in the thesis, I contributed to partial experiment preparation, characterization, and data analysis. 


\section{Abbreviations}

\begin{tabular}{|c|c|}
\hline Abbreviation & Meaning \\
\hline HDPs & Halide double perovskites \\
\hline 3D & Three-dimensional \\
\hline 2D & Two-dimensional \\
\hline OD & Zero-dimensional \\
\hline $\mathbf{P b}$ & Lead \\
\hline MA & Methylammonium \\
\hline FA & Formamidinium \\
\hline Cs & Cesium \\
\hline PCE & Power conversion efficiency \\
\hline LED & Light emitting diode \\
\hline EQEs & External quantum efficiency \\
\hline IEC & International Electrotechnical Commission \\
\hline CBM & Conduction band minimum \\
\hline VBM & Valence band maximum \\
\hline PL & Photoluminescence \\
\hline PLQY & Photoluminescence quantum yield \\
\hline STEs & Self-trapped excitons \\
\hline GS & Ground state \\
\hline $\mathbf{F E}$ & Free exciton state \\
\hline FC & Free carrier state \\
\hline$E_{\mathrm{g}}$ & Bandgap energy \\
\hline $\boldsymbol{E}_{\mathbf{b}}$ & Exciton binding energy \\
\hline$E_{\text {st }}$ & Self-trapping energy \\
\hline$E_{\mathrm{d}}$ & Lattice deformation energy \\
\hline$E_{\mathrm{PL}}$ & Emission energy \\
\hline DMSO & Dimethyl sulfoxide \\
\hline ETL & Electron transport layer \\
\hline $\mathrm{TiO}_{2}$ & Titanium oxide \\
\hline m- $\mathrm{TiO}_{2}$ & Mesoscopic titanium oxide \\
\hline \multirow[t]{2}{*}{ Spiro-OMeTAD } & 2,2',7,7'-tetrakis(N,N-dipmethoxyphenylamine)- \\
\hline & $9,9^{\prime}$-spirobifluorene \\
\hline
\end{tabular}




\begin{tabular}{|c|c|}
\hline Au & Gold \\
\hline Ag & Sliver \\
\hline $\mathbf{B i}$ & Bismuth \\
\hline $\mathbf{C u}$ & Copper \\
\hline $\mathbf{F e}$ & Iron \\
\hline $\mathbf{N a}$ & Sodium \\
\hline In & Indium \\
\hline $\mathbf{C l}$ & Chlorine \\
\hline $\mathbf{B r}$ & Bromine \\
\hline ITO & Indium doped tin oxide \\
\hline $\mathrm{SnO}_{2}$ & Tin oxide \\
\hline NIR & Near infrared \\
\hline XRD & X-ray diffraction \\
\hline PXRD & Powder X-ray diffraction \\
\hline SCXRD & Single-crystal diffraction \\
\hline RT & Room temperature \\
\hline RT-Cooling & Cooling to room temperature \\
\hline SOC & Spin-orbit coupling \\
\hline GBL & $\gamma$ - butyrolactone \\
\hline UV-Vis & Ultraviolet-visible spectrophotometry \\
\hline NMR & Nuclear magnetic resonance \\
\hline ssNMR & Solid-state nuclear magnetic resonance \\
\hline ppm & Part per million \\
\hline $\mathbf{R F}$ & Radiofrequency \\
\hline MAS & Magic-angle spinning \\
\hline PRE & Paramagnetic relaxation enhancements \\
\hline
\end{tabular}




\section{Table of Contents}

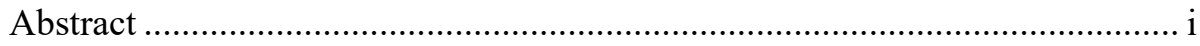

Populärvetenskaplig Sammanfattning ........................................................ii

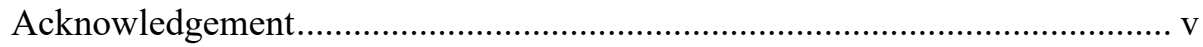

List of Publications Included in the Thesis ....................................................... vii

List of Publications not Included in the Thesis ............................................... viii

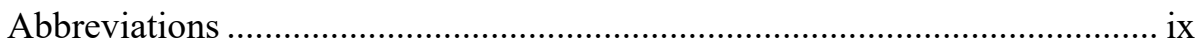

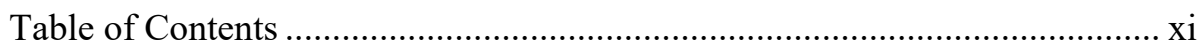

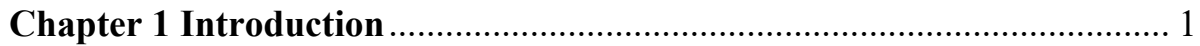

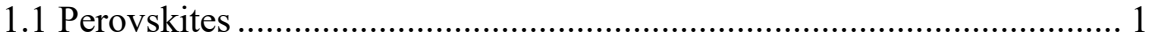

1.2 Crystal Structure of Perovskite ............................................................... 1

1.3 Lead Halide Perovskites................................................................... 2

1.3.1 Applications of Lead Halide Perovskites ................................. 2

1.3.2 Challenges and Solutions ..................................................... 3

Chapter 2 Lead-free Halide Perovskites ……............................................. 9

2.1 Three-Dimensional Lead-Free Halide Perovskites ............................... 9

2.2 Three-Dimensional Lead-Free Halide Double Perovskites ...................... 9

2.2.1 Basic Properties................................................................... 10

2.2.2 Applications of Lead-free Halide Double Perovskites........... 16

2.2.3 Challenges ....................................................................... 20

Chapter 3 Bandgap Engineering of Halide Double Perovskites ............... 23

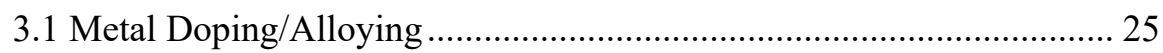

3.1.1 Monovalent Metal Doping/Alloying …………........................ 26

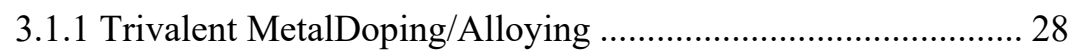

3.1.3 Heterovalent Metal Doping/Alloying ...................................... 31

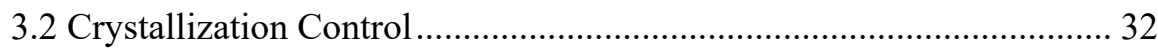

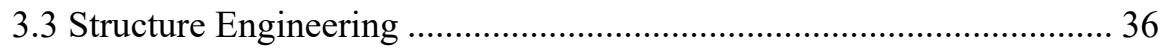

3.3.1 High-Pressure Treatment ..................................................... 36

3.3.2 High-Temperature Treatment................................................ 38

Chapter 4 Crystal Synthesis and Characterization Methods ..................... 43

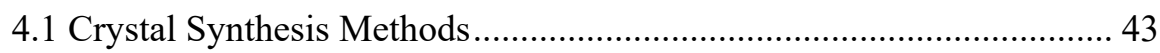

4.1.1 Hydrothermal (Solvothermal) Method...................................... 43

4.1.2 Slow Evaporation Method........................................................ 44 
4.1.3 Inversion Temperature Crystallization Method .........................44

4.1.4 Antisolvent Vapor Assisted Method .........................................45

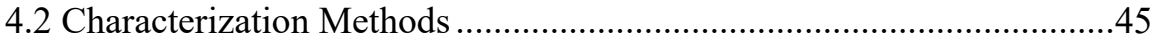

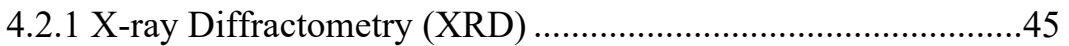

4.2.2 Ultraviolet and Visible Spectrophotometry (UV-Vis) ...............46

4.2.3 Photoluminescence spectroscopy …………..............................47

4.2.4 Solid-State Unclear Magnetic Resonance (ssNMR) ..................48

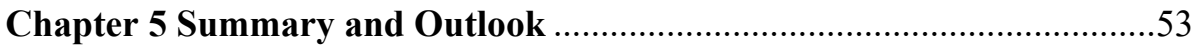

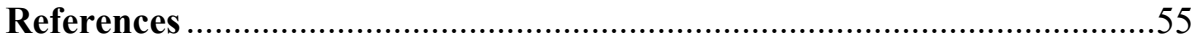




\section{Chapter 1 Introduction}

\subsection{Perovskites}

Perovskite originally referred to the naturally occurring calcium titanate mineral $\left(\mathrm{CaTiO}_{3}\right)$. This mineral was first discovered in Russia by Gustary Rose in 1839 and named after the Russian mineralogist Lev Perovski. ${ }^{1,2}$ Now, the name perovskite is generally applied to the class of compounds that have the same type of crystal structure as $\mathrm{CaTiO}_{3}{ }^{2}$ The general chemical formula for perovskite materials can be described as $\mathrm{ABX}_{3}$, where $\mathrm{A}$ and $\mathrm{B}$ are cations, and $\mathrm{X}$ is an anion. Perovskites are a large family of materials with many interesting and amazing properties, such as ferroelectricity, superconductivity, charge ordering, spin-dependent transport and high thermopower. These properties have enabled perovskites to be successfully applied in different fields, including catalysis, ${ }^{3}$ ferroelectrics ${ }^{4}$ spintronics,${ }^{5}$ piezoelectric ${ }^{6}$ and optoelectronics. In this thesis, we mainly focus on the optoelectronic applications of halide perovskites.

\subsection{Crystal Structure of Perovskite}

Figure 1.1a shows the unit cell of the typical $\mathrm{ABX}_{3}$ perovskite structure. The central Bsite cation bonds with six $\mathrm{X}$-site anions to form $\mathrm{BX}_{6}$ octahedron, and A-site cations stay in the corner position. These $\mathrm{BX}_{6}$ octahedrons are connected by the corner-sharing mode to form a three-dimensional (3D) structure, where A-site cations occupy the cavities formed by four $\mathrm{BX}_{6}$ octahedrons (Figure 1.1 b). Apart from the common single perovskite structure, there is another interesting perovskite structure named double perovskite structure. Double perovskite has a similar structure as single perovskite, but two different cations are ordered on $\mathrm{B}$ site. The general chemical formula of double perovskites can be written as $\mathrm{A}_{2} \mathrm{BB}^{\prime} \mathrm{X}_{6}$ (Figure $1.1 \mathrm{c}$ ). Considering a wide range of possibilities for two different B-site cations, double perovskites offer immense opportunities in terms of combinatorial chemistry.

\section{a}

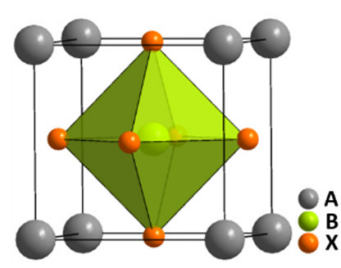

b

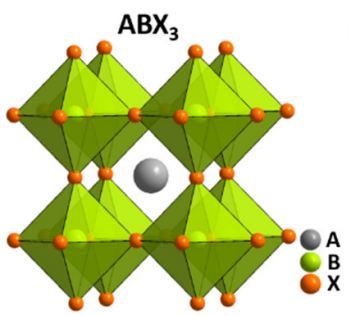

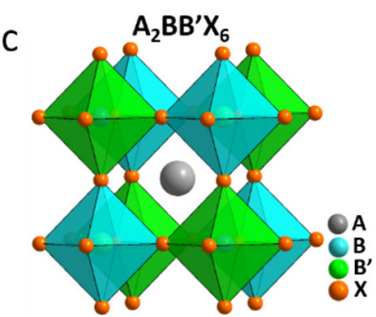

Figure 1.1 a) Unit cell of the general perovskite. b) Schematic diagram of the structure of common single perovskite $\mathrm{ABX}_{3}$ and double perovskite $\mathrm{A}_{2} \mathrm{BB}^{\prime} \mathrm{X}_{6}$. 
In theory a series of compounds can satisfy the chemical formula of $\mathrm{ABX}_{3}$ or $\mathrm{A}_{2} \mathrm{BB}^{\prime} \mathrm{X}_{6}$; however not all of them are stable in crystallography. There are two factors to predict the crystallographic stability of perovskites crystal structure, the Goldschmidt tolerance factor $t$ (equation 1.1) 7 and octahedral factor $\mu$ (equation 1.2):

$$
\begin{gathered}
t=\frac{\left(R_{\mathrm{A}}+R_{\mathrm{B}}\right)}{\sqrt{2\left(R_{\mathrm{B}}+R_{\mathrm{X}}\right)}} \\
\mu=\frac{R_{\mathrm{B}}}{R_{\mathrm{X}}}
\end{gathered}
$$

where $R_{\mathrm{A}}$ and $R \mathrm{x}$ represent the ionic radii of $\mathrm{A}$ and $\mathrm{X}$ ions. $R_{\mathrm{B}}$ is the radii of $\mathrm{B}$ cation in single perovskite and refers to the average radius of $\mathrm{B}$ and $\mathrm{B}$ ' cations in double perovskite. To form a stable perovskite structure, the Goldschmidt tolerance factor $t$ and octahedral factor $\mu$ are usually in the range of $0.81<t<1.11$ and $0.41<\mu<0.90$, respectively. ${ }^{8,9}$ When the tolerance factor $t$ is equal to 1.0 , it will form an ideal symmetrical cubic crystal structure with high stability, such as $\mathrm{SrTiO}_{3}$. Perovskites usually maintain the major cubic structure when the tolerance factor $t$ is between 0.9 and 1.0 . When $t$ is reduced to the range of 0.89 to 0.81 , the cubic crystal structure would possibly be distorted into an orthorhombic or rhombohedral structure. If $t$ is further decreased, the crystal cannot retain the perovskite structure. When $t>1$, a hexagonal or tetragonal structure is most likely to form. Besides the consideration of $t$, the value of octahedral factor $\mu$ should be between 0.41 and 0.90 for the formation of a stable $\mathrm{BX}_{6}$ octahedra. ${ }^{9}$ Both the tolerance factor $t$ and octahedral $\mu$ are necessary to predict the stability of perovskite structure.

\subsection{Lead Halide Perovskites}

Lead $(\mathrm{Pb})$ halide perovskites with the formula of $\mathrm{APbX}_{3}$ is one of the most famous perovskite materials, where $\mathrm{A}$ is the organic cation methylammonium $\left(\mathrm{MA}^{+}\right)$, formamidinium $\left(\mathrm{FA}^{+}\right)$or inorganic cation cesium $\left(\mathrm{Cs}^{+}\right)$, and $\mathrm{X}$ is the halogen anion $\mathrm{Cl}^{-}, \mathrm{Br}^{-}$or $\mathrm{I}^{-}$. As a new generation of semiconductors, $\mathrm{Pb}$ halide perovskites have achieved great success in various optoelectronic applications.

\subsubsection{Applications of Lead Halide Perovskites}

One of the most successful applications of $\mathrm{Pb}$ halide perovskite is solar cells. ${ }^{10}$ The first perovskite solar cells was fabricated by Miyasaka and colleagues in 2009 and achieved a power conversion efficiency (PCE) of 3.8\%. ${ }^{10}$ In 2012, Snaith and coworkers first adopted the solid-state perovskite solar cell structure and enhanced the PCE to $10.9 \% .{ }^{11}$ After that, halide perovskites have achieved significant breakthroughs, with the PCE of $25.5 \%$ now, ${ }^{12}$ which has surpassed commercial polycrystalline silicon solar cells and is 
comparable to the monocrystalline silicon solar cells. The excellent performance is mainly due to their superior optoelectronic properties, such as suitable and tunable direct band gap, high absorption coefficient, balanced and small carrier effective masses, long carrier lifetime and diffusion length, small exciton binding energy and high defect tolerance (Figure 1.2). ${ }^{11,13-17}$
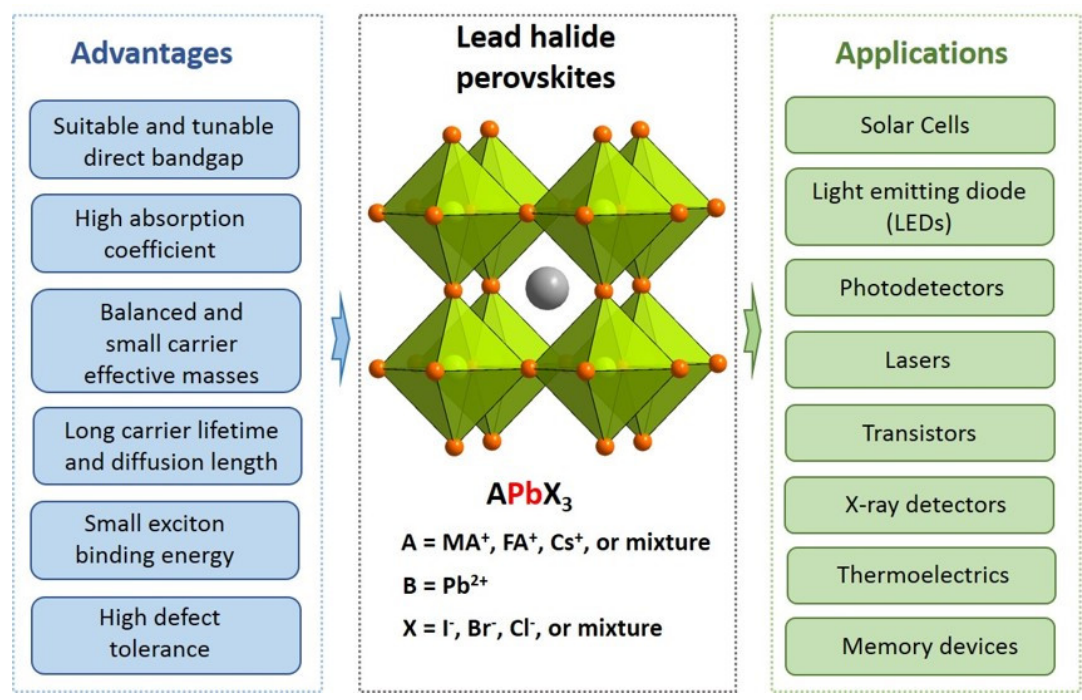

Figure 1.2 Advantages and optoelectronic applications of lead halide perovskites.

In contrast to solar cell devices, $\mathrm{Pb}$ halide perovskites can also convert electricity into light by light emitting diode (LED) devices. The room temperature perovskite LED was first reported by R. H. Friend and coworkers in 2014 and achieved an external quantum efficiency (EQEs) of $0.76 \% .{ }^{18}$ Since then, many effects have been focused on this direction, and the EQEs of perovskite LEDs have increased dramatically. Up to now, the EQEs of green, red and near-infrared perovskite LEDs have been improved to more than $20 \% .{ }^{19-21}$ Even for the more challenging blue perovskite LEDs, the best EQE has reached $12.3 \% .^{22}$

In addition to the successful application of $\mathrm{Pb}$ halide perovskite in solar cells and LEDs, its unique and remarkable optoelectronic properties make it also employed in other optoelectronic applications, such as photodetectors, ${ }^{23}$ lasers, ${ }^{24}$ transistors, ${ }^{25} \mathrm{X}$-ray detectors, ${ }^{26}$ thermoelectrics, ${ }^{27}$ and memory devices (Figure 1.2).${ }^{28}$

\subsubsection{Challenges and Solutions}

Although Pb-based perovskites have achieved great success in optoelectronics field, the issues of poor stability and toxic $\mathrm{Pb}$ hinder their further development. In this section, we 
identify challenges in $\mathrm{Pb}$-based perovskites and discuss possible solutions: improving its stability and solving the toxicity of $\mathrm{Pb}$.

Stability is a key concern for the commercialization of perovskite photoelectric devices. Unfortunately, $\mathrm{Pb}$ halide perovskites are chemically unstable after exposure to light, oxygen, moisture, and heat. ${ }^{29}$ Different factors degrade perovskite materials in different mechanisms, such as polymorphic transformation, hydration and decomposition (Figure 1.3) ${ }^{30}$ It is also highly dependent on the specific perovskite composition. For example, $\mathrm{MAPbI}_{3}$ is the most famous and popularly studied hybrid $\mathrm{Pb}$ halide perovskite, which is easily decomposed into $\mathrm{PbI}_{2}$ and MAI under a humid environment. This is because water molecules can easily form strong hydrogen bonds with organic cation $\left(\mathrm{MA}^{+}\right)$and weaken the hydrogen-bonding interaction between organic cation and $\mathrm{PbX}_{6}$ octahedra, causing the degradation of perovskite. ${ }^{31}$ Meanwhile, the $\mathrm{MAPbI}_{3}$ perovskite cannot withstand at high temperature $\left(140{ }^{\circ} \mathrm{C}\right)$ and can be decomposed into $\mathrm{PbI}_{2}$ even at $85^{\circ} \mathrm{C}$ for a long time, ${ }^{32}$ which is highly related to the volatile organic compound $\mathrm{MA}^{+}$. Other effects such as irradiation and oxygen can also cause the decomposition of perovskite materials. In addition, the formation enthalpy of $\mathrm{MAPbI}_{3}$ measured by Navrotsky and coworkers is positive, implying that $\mathrm{MAPbI}_{3}$ is thermodynamically unstable and prone to decomposition even without external influences. ${ }^{33}$

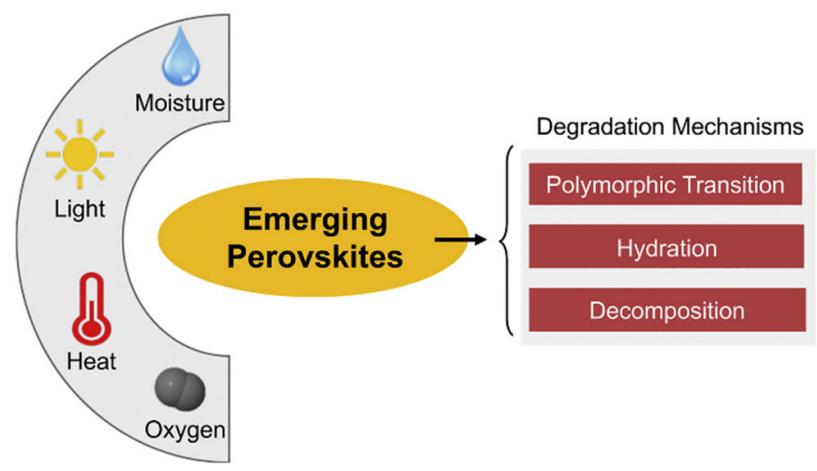

Figure 1.3 Schematic illustration of the environmental factors and mechanisms that are responsible for the degradation of emerging perovskites. ${ }^{30}$

The stability can be enhanced by substituting organic cations with inorganic cations such as $\mathrm{Cs}^{+}$, which could result in an intrinsic or thermodynamic stable compound. Correspondingly, the all-inorganic perovskite $\mathrm{CsPbI}_{3}$ shows improved tolerance to oxygen and heat than $\mathrm{MAPbI}_{3}$. However, it has a poor phase stability. The perovskite phase ('black' phase) of $\mathrm{CsPbI}_{3}$ would easily transform to the nonperovskite phase ('yellow' phase) that is thermodynamically more stable at room temperature. ${ }^{34}$ This is possibly originating from the relatively low tolerance factor $t(t<0.8)$ of $\mathrm{CsPbI}_{3}$, making $\mathrm{CsPbI}_{3}$ 
tend to form the nonperovskite orthorhombic phase ('yellow' phase). It is noted that this stable 'yellow' phase has poor absorption and low carrier mobility, which is not suitable for photoelectronic applications. Therefore, phase stability is also very important and needs to be considered before utilizing these inorganic halide perovskites.

To stabilize the perovskite phase of $\mathrm{CsPbI}_{3}$, one approach is to increase its Goldschmidt tolerance factor $t$ by incorporating larger A-site cations. Since $\mathrm{Cs}^{+}$is already the largest nonradioactive Group-I element, larger organic cations (such as $\mathrm{MA}^{+}$and $\mathrm{FA}^{+}$) become the only suitable choice for A-site doping. However, there is a tradeoff between phase stability and environmental stability regarding the ratio of inorganic and organic cations. Another approach is to replace $\mathrm{I}^{-}$by a part of the smaller-size $\mathrm{Br}^{-}$with the formation of alloyed perovskites, which could increase the tolerance factor $t$ and retain the all-inorganic composition, as indicated by some reports. ${ }^{35}$ Meanwhile, $\mathrm{Br}^{-}$alloying can enlarge the bandgap, and thus making final perovskites suitable for tandem solar cells. A critical issue for these alloys is the segregation of halides during devices operation, which could cause emission color instability issues in LED devices.

In addition to the instability of perovskites, the presence of toxic $\mathrm{Pb}$ is another concern for practical applications. In the case of encapsulant failure, the leakage of $\mathrm{Pb}$ would cause damage to human health and the environment. As shown in Figure 1.4, when accidental exposed to $\mathrm{Pb}$, the human body possibly ingests $\mathrm{Pb}$ through the gastrointestinal, respiratory, and dermal. Meanwhile, the blood can transport the $\mathrm{Pb}$ ions to various organs of the human body, and eventually the skeleton is the major depository for $\mathrm{Pb}$ in the body. $\mathrm{Pb}$ compounds could interfere with heme activity and cause damage to our renal, reproductive, and central nervous systems. Finally, $\mathrm{Pb}$ resides in all of the three compartments with a certain organ-specific retention time, after which it is excreted from the body through urine, gastrointestinal secretion, hair, sweat, nails and breast milk (Figure 1.4) ${ }^{36}$ In addition to toxic $\mathrm{Pb}$, several other ways such as acidification and nanotoxicity of perovskite materials are also potentially harmful to the environment and human health. ${ }^{36,37}$ 


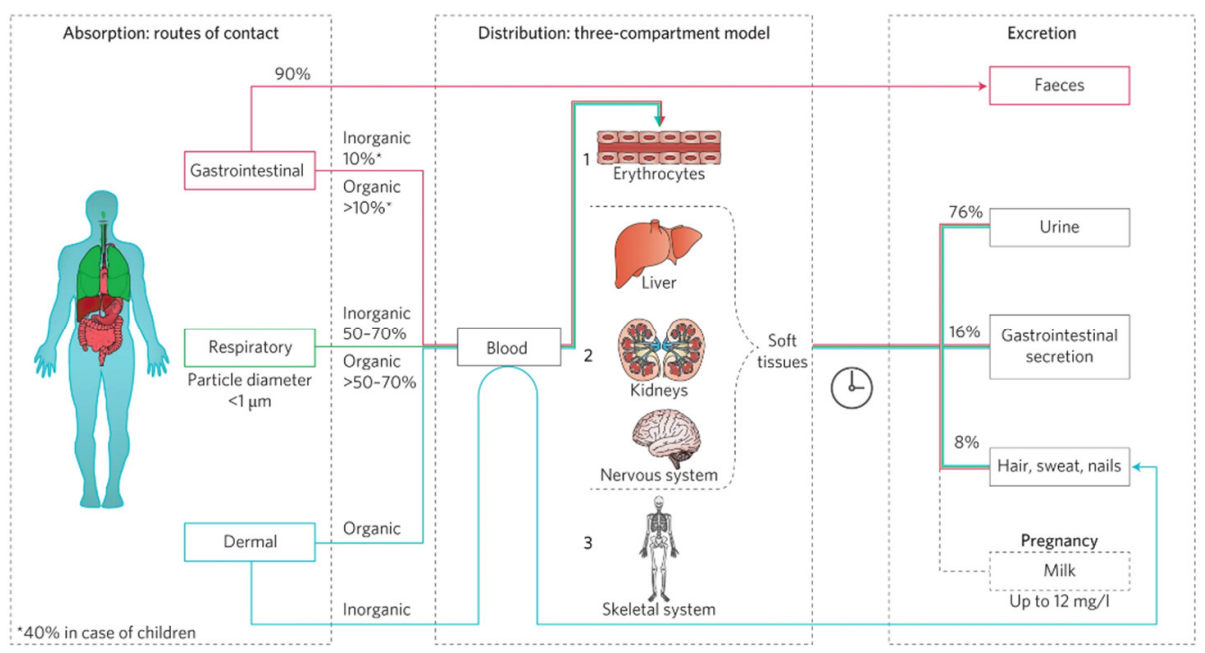

Figure 1.4 Schematic overview of absorption, distribution, and excretion of $\mathrm{Pb}$ compounds in the human body. For each route of intakes, a percentage indicates the overall amount that can be absorbed. $\mathrm{Pb}$ not absorbed upon gastrointestinal intake leaves the body via the faeces (as indicated); $\mathrm{Pb}$ not absorbed by respiratory or dermal routes is assumed to have left the body directly by exhalation or to have lost contact through natural body movement, respectively (not indicated in the figure). ${ }^{36}$

Device encapsulation is an effective approach to address the toxicity and instability issues of $\mathrm{Pb}$ halide perovskites, as it can isolate the perovskites materials from oxygen and moisture and can effectively avoid the leakage of toxic $\mathrm{Pb}$. It has found that the polymer/glass stack encapsulation can make $\mathrm{Pb}$ halide perovskite solar cells pass the International Electrotechnical Commiss on (IEC) 61215:2016 photovoltaic module standard tests. ${ }^{38}$ Even though encapsulation can suppress the decomposition of perovskites, the fundamental instability and toxicity of hybrid $\mathrm{Pb}$ halide perovskites are not resolved.

Comparing with device encapsulation, the straightforward approach for the toxicity issue is to replace the toxic $\mathrm{Pb}^{2+}$ with other low-toxic or non-toxic elements. $\mathrm{Sn}^{2+}$ and $\mathrm{Ge}^{2+}$ are natural substitution candidates with the formation of similar three-dimensional structure as $\mathrm{Pb}$-based perovskite, because they are in the same group as $\mathrm{Pb}^{2+}$ in the periodic table. As expected, these materials have achieved a relatively high PCE than other alternatives. However, both $\mathrm{Sn}^{2+}$ and $\mathrm{Ge}^{2+}$ are easily oxidized to their tetravalent state, resulting in the instability of these perovskite materials. ${ }^{39,40}$ In contrast, heterovalent cations such as $\mathrm{In}^{3+}, \mathrm{Bi}^{3+}, \mathrm{Sb}^{3+}, \mathrm{Ti}^{4+}, \mathrm{Pd}^{4+}$, and $\mathrm{Eu}^{3+}$ are relatively stable, which provide more possibilities for searching nontoxic and stable candidates. ${ }^{41-45}$ Unfortunately, to maintain the charge neutrality, the chemical formulas of these new compounds have 
changed significantly compared to $\mathrm{APbX}_{3}$ perovskites. Correspondingly, their crystal structures have become a low-dimensional structure to accommodate heterovalent substitution, including zero-dimensional (0D) $)^{41,42,46}$ and two-dimensional (2D). ${ }^{47-51}$ Therefore, we consider these new lead-free materials as perovskite derivatives. Although these derivatives are nontoxicity and relativity stable in ambient environment, they exhibit indirect bandgaps, poor carrier transport, deep defects, and high exciton binding energies due to their low structural and electronic dimensionality, which hinder their applications in optoelectronic field. It is highly desirable to explore new lead-free candidates with high structure and electronic dimensionality. 
Chapter 1 Introduction 


\section{Chapter 2 Lead-free Halide Perovskites}

\subsection{Three-Dimensional Lead-Free Halide Perovskites}

One critical parameter for promising lead-free perovskite candidates is $3 \mathrm{D}$ crystal structure with high electronic dimensionality. To meet this requirement, the candidates should have suitable Goldschmidt tolerance factor $t$ and octahedral factor $\mu$ to form a stable 3D crystal structure. Meanwhile, the B-site cation should be bivalent $(+2)$ to keep electrical neutrality for metal halide perovskite $\mathrm{ABX}_{3}$, as the A-site cation is monovalent $(+1)$ and the anion $\mathrm{X}$ is negatively monovalent $(-1)$. Another feasible and attractive approach is the combination of $\mathrm{B}^{+}\left(\mathrm{B}^{\mathrm{I}}\right)$ and $\mathrm{B}^{3+}\left(\mathrm{B}^{\mathrm{III}}\right)$ cations to replace two $\mathrm{B}^{2+}$, forming a $3 \mathrm{D}$ double perovskite. While a special kind of compounds formed by replacing two $\mathrm{B}^{2+}$ cations with a $\mathrm{B}^{4+}$ and a vacancy was previously described as quasi-3D vacancy ordered double perovskites, it is more appropriate to view these $\mathrm{A}_{2} \mathrm{~B}^{4+} \mathrm{X}_{6}$-type compounds as $0 \mathrm{D}$ perovskite derivatives considering that their octahedrons are completely isolated. Therefore, strictly speaking, there are mainly two types of $3 \mathrm{D} \mathrm{Pb}$-free perovskites, $\mathrm{AB}^{2+} \mathrm{X}_{3}$ and $\mathrm{A}_{2} \mathrm{~B}^{\mathrm{I}} \mathrm{B}^{\mathrm{III}} \mathrm{X}_{6}$.

$\mathrm{ASn}^{2+} \mathrm{X}_{3}$ and $\mathrm{AGe}^{2+} \mathrm{X}_{3}$ based $3 \mathrm{D} \mathrm{AB}^{2+} \mathrm{X}_{3}$-type $\mathrm{Pb}$-free perovskites have been discussed in Section 1.3.2. A big disadvantage of these materials is their poor stability issues since $\mathrm{Sn}^{2+}$ and $\mathrm{Ge}^{2+}$ are easily oxidized to $\mathrm{Sn}^{4+}$ and $\mathrm{Ge}^{4+}$. Here, I will focus on halide double perovskites (HDPs) $\mathrm{A}_{2} \mathrm{~B}^{\mathrm{I}} \mathrm{B}^{\mathrm{III}} \mathrm{X}_{6}$, which are considered as the most promising candidates for stable $3 \mathrm{D} \mathrm{Pb}$-free perovskites.

\subsection{Three-Dimensional Lead-Free Halide Double Perovskites}

The typical ordered halide double perovskite structure contains alternating $\left[\mathrm{B}^{\mathrm{I}} \mathrm{X}_{6}\right]^{5-}$ and $\left[\mathrm{B}^{\mathrm{III}} \mathrm{X}_{6}\right]^{3-}$ octahedra, and A site cations are in the cavities formed by octahedrons (Figure 2.1a). The alternating arrangement of $\left[\mathrm{B}^{\mathrm{I}} \mathrm{X}_{6}\right]^{5-}$ and $\left[\mathrm{B}^{\mathrm{III}} \mathrm{X}_{6}\right]^{3-}$ octahedra in the $3 \mathrm{D}$ structure is termed rock-salt ordering. As I have just highlighted, a big advantage of double perovskite is their similar 3D structure to that of the common single perovskite. Besides, double perovskites allow more kinds of cations to be incorporated into the $\mathrm{B}^{\mathrm{I}} / \mathrm{B}^{\mathrm{III}}$ sites, which could enable access to an expansive range of alternative components. Feliciano Giustino and Henry J. Snaith highlighted the elements in the periodic table which belong to halide double perovskites, as shown in Figure 2.1b. The numbers of elements that can be occupied in $\mathrm{A}^{+}, \mathrm{B}^{\mathrm{I}}, \mathrm{B}^{\mathrm{III}}$ and $\mathrm{X}^{-}$sites are 7, 8, 34 and 5, respectively. By simply multiplying these numbers together, we can obtain around 9520 compounds without considering the phase stability. ${ }^{52}$ Even though the majority of these compounds are unstable due to their unsuitable octahedral factor $\mu$, it is believed that there are still more than 600 structurally stable compounds that have never been exploited. ${ }^{52}$ 
The first reported double perovskite, $\mathrm{K}_{2} \mathrm{NaAlF}_{6}$, formerly known as elpasolites, was discovered in El Paso County, Colorado in 1883. When the time came to 2016, three groups reported the new double perovskites $\mathrm{Cs}_{2} \mathrm{AgBiX}{ }_{6}\left(\mathrm{X}=\mathrm{Br}^{-}, \mathrm{Cl}^{-}\right)$with exciting optoelectronic properties, ${ }^{53-55}$ which stimulates the research interest into these HDPs for potential photovoltaic applications. Since then, an increasing number of new halide double perovskites have been synthesized, such as $\mathrm{Cs}_{2} \mathrm{AgInCl}_{6},{ }^{56} \mathrm{Cs}_{2} \mathrm{AgTlX}_{6}\left(\mathrm{X}=\mathrm{Br}^{-}\right.$, $\left.\mathrm{Cl}^{-}\right),{ }^{57,58} \mathrm{Cs}_{2} \mathrm{AgSbCl}_{6}{ }^{59}$ and $\mathrm{Cs}_{2} \mathrm{AgFeCl}_{6},{ }^{60}$ etc.

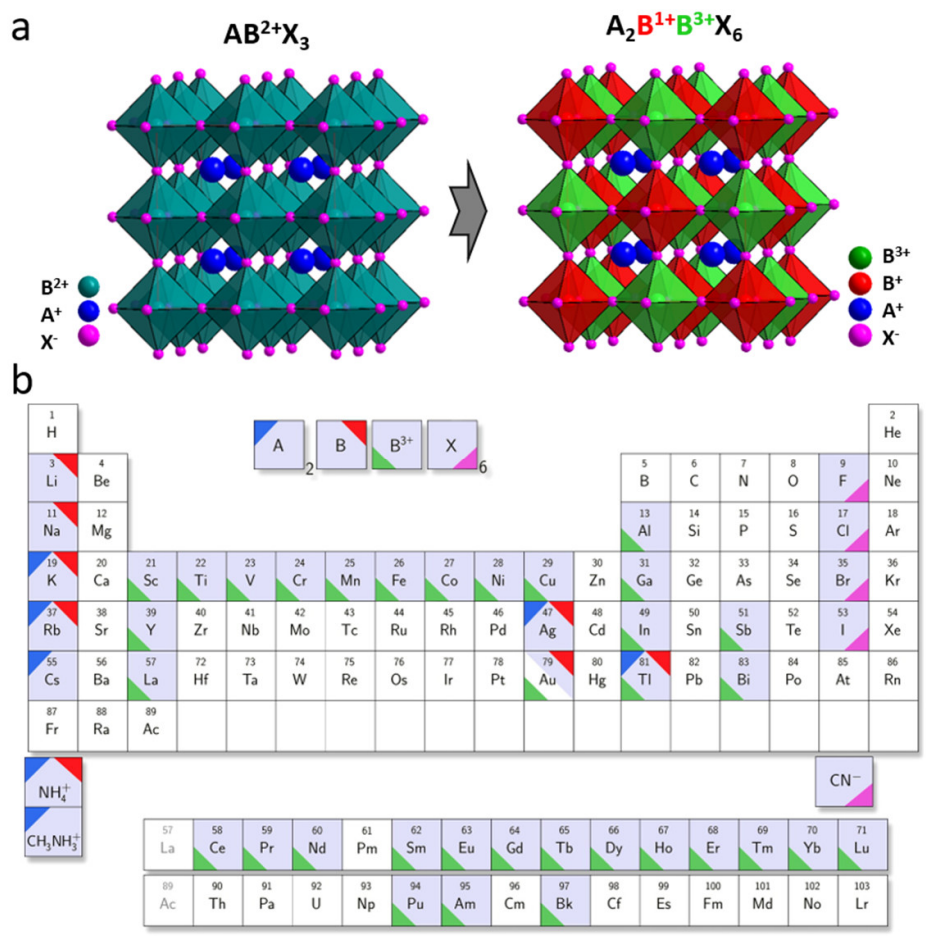

Figure 2.1 (a) Schematic view of $\mathrm{B}^{+} / \mathrm{B}^{3+}$ cation substitution from halide perovskites $\left(\mathrm{AB}^{2+} \mathrm{X}_{3}\right)$ to double perovskites $\left(\mathrm{A}_{2} \mathrm{~B}^{1+} \mathrm{B}^{3+} \mathrm{X}_{6}\right)$. (b) Composition available for lead-free double perovskites $\left(\mathrm{A}_{2} \mathrm{~B}^{1+} \mathrm{B}^{3+} \mathrm{X}_{6}\right)$. The triangular tags with different colors specify the site occupied by the element, illustrated as the legend at the top-middle site. ${ }^{52}$

\subsubsection{Basic Properties}

Up to now, $\mathrm{Cs}_{2} \mathrm{AgBiBr}_{6}$ and $\mathrm{Cs}_{2} \mathrm{AgInCl}_{6}$ are the most famous and widely studied double perovskites. $\mathrm{Cs}_{2} \mathrm{AgBiBr}_{6}$ crystallizes as red truncated octahedra in cubic space group Fm-3m (No. 225) at room temperature (Figure 2.2f inset) and can be easily synthesized by the hydrothermal method. As shown in Figure 2.2a,b, its conduction band minimum $(\mathrm{CBM})$ is mainly derived from $\mathrm{Bi} 6 \mathrm{p}-\mathrm{Br} 4 \mathrm{p}$ antibonding states, and the valence band 
maximum (VBM) is mainly derived from $\mathrm{Ag} 4 \mathrm{~d}-\mathrm{Br} 4 \mathrm{p}$ antibonding states. Since the $\mathrm{CBM}$ is located at the $L$ point and VBM is located at $\mathrm{X}$ point, $\mathrm{Cs}_{2} \mathrm{AgBiBr}_{6}$ shows an indirect bandgap. ${ }^{61}$ Based on the UV-Vis absorption spectrum, the calculated indirect optical bandgap of $\mathrm{Cs}_{2} \mathrm{AgBiBr}_{6}$ is in the range of 1.95-2.19 eV (Figure 2.2c). ${ }^{53,54}$
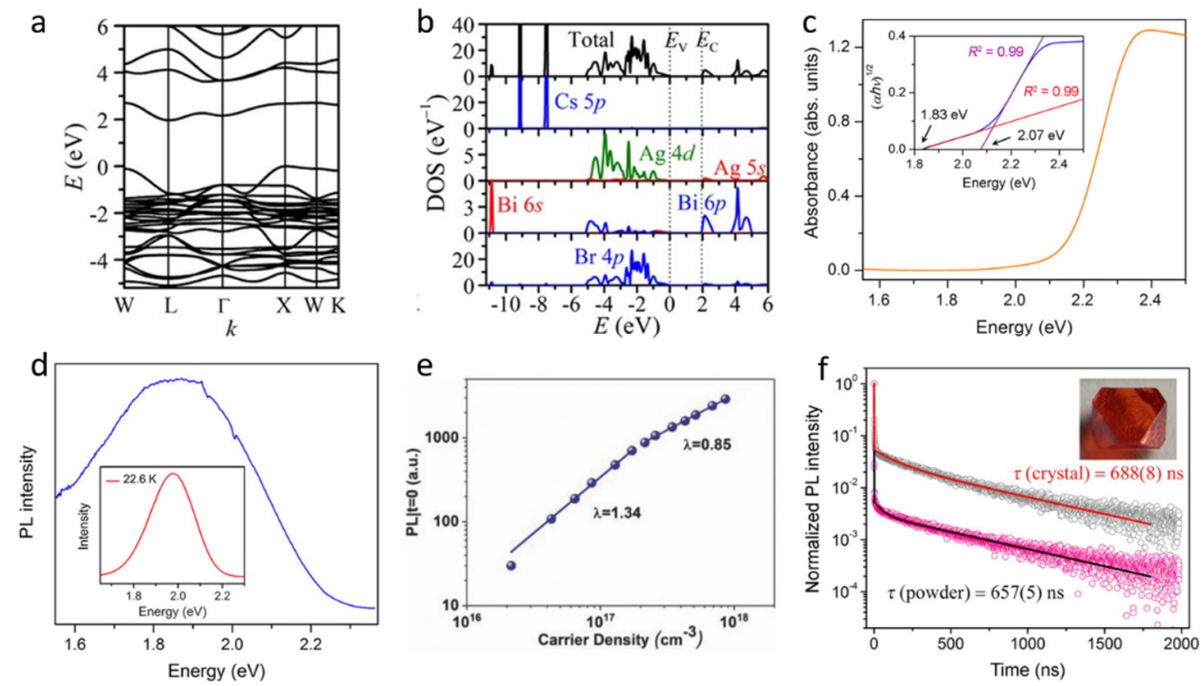

Figure 2.2 (a) Band structures and (b) total and projected densities of states (DOSs) of Cs2 $\mathrm{Ag}$ $\mathrm{BiBr}_{6}$ calculated with the HSE+SOC methods. ${ }^{61}$ (c) Absorbance spectrum of $\mathrm{Cs}_{2} \mathrm{AgBiBr} 6$ powder. Inset: Tauc plot showing the characteristics of an indirect band gap. ${ }^{53}$ (d) Steady-state room-temperature photoluminescence (PL) spectrum of a powdered $\mathrm{Cs}_{2} \mathrm{AgBiBr}_{6}$ sample upon $500 \mathrm{~nm}$ excitation. Inset: low-temperature PL spectrum. ${ }^{53}$ (e) PL intensity as a function of carrier density. The PL intensities were the values just after photoexcitation $(\mathrm{PL} \mid \mathrm{t}=0)$, rather than the integrated PL intensity. ${ }^{14}$ (f) Time-resolved room-temperature PL and fits for the PL decay time $(\tau)$ in powder and single-crystal samples. Inset: Photograph of a single crystal of $\mathrm{Cs}_{2} \mathrm{AgBiBr}_{6} .{ }^{53}$

The photoluminescence (PL) peak of $\mathrm{Cs}_{2} \mathrm{AgBiBr}_{6}$ centered at $1.87 \mathrm{eV}$ at room temperature and centered at $1.98 \mathrm{eV}$ at $22.6 \mathrm{~K}$ (Figure 2.2d). ${ }^{53}$ The measured PL quantum yield (PLQY) of $\mathrm{Cs}_{2} \mathrm{AgBiBr}_{6}$ is only around $0.08 \%$, since the radiative recombination in indirect bandgap materials requires phonon assistance. Besides, the coexistence of excitons and free carriers in $\mathrm{Cs}_{2} \mathrm{AgBiBr}_{6}$ was revealed by Tze Chien Sum and co-workers through measuring PL density in terms of different excitation intensities (Figure 2.2e). ${ }^{14}$ Interestingly, the carrier lifetimes of $\mathrm{Cs}_{2} \mathrm{AgBiBr}_{6}$ can be as long as $668 \mathrm{~ns}$ (Figure 2.2f) or even more than 1 us, ${ }^{53,62}$ which could be related to its indirect bandgap. Meanwhile, our group demonstrated that the high quality $\mathrm{Cs}_{2} \mathrm{AgBiBr}_{6}$ films have a long carrier diffusion length greater than $100 \mathrm{~nm} .{ }^{14}$ Naomi S. Ginsberg and co-workers reported that the carrier diffusion length in $\mathrm{Cs}_{2} \mathrm{AgBiBr}_{6}$ crystal can even exceed $1 \mathrm{um}^{63}$ 
Moreover, $\mathrm{Cs}_{2} \mathrm{AgBiBr}_{6}$ possesses relatively low carrier effective masses which are favorable for efficient charge transport and extraction.

More attractively, HDPs usually show excellent moisture, light, and thermal stability. For example, there was no decomposition for $\mathrm{Cs}_{2} \mathrm{AgBiBr}_{6}$ after storing under $55 \%$ humidity for 30 days or irradiating it with a white LED lamp ( 0.75 Sun) under $\mathrm{N}_{2}$ for one month (Figure 2.3a). Meanwhile, the decomposition temperature of $\mathrm{Cs}_{2} \mathrm{AgBiBr}_{6}$ is higher than $500{ }^{\circ} \mathrm{C}$ (Figure 2.3b). ${ }^{64}$ These excellent chemical and thermal stability make $\mathrm{Cs}_{2} \mathrm{AgBiBr}_{6}$ double perovskite a promising candidate for stable photovoltaic applications.
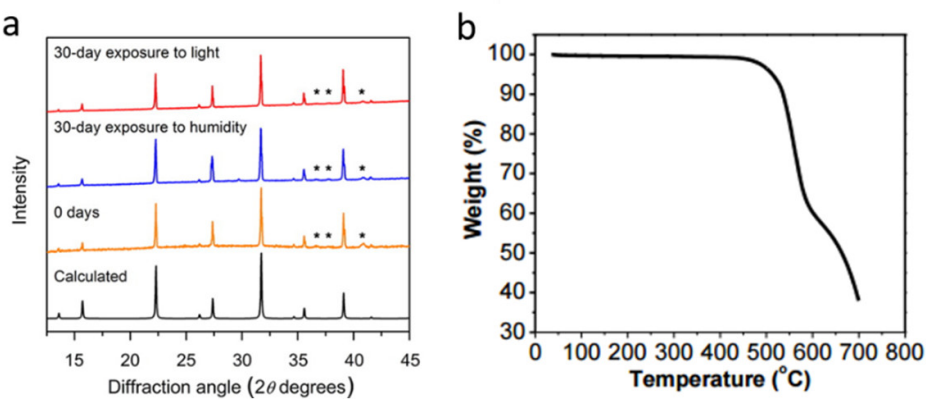

Figure 2.3 (a) PXRD patterns of $\mathrm{Cs}_{2} \mathrm{AgBiBr}_{6}$ after exposure to humidity $(55 \% \mathrm{RH})$ or light $(0.75$ Sun) for 30 days. Asterisks denote signals from the sample holder. ${ }^{53}$ (b) Thermogravimetric analysis (TGA) of $\mathrm{Cs}_{2} \mathrm{AgBiBr}_{6}$ double perovskite. ${ }^{64}$

Another interesting halide double perovskite is $\mathrm{Cs}_{2} \mathrm{AgInCl}_{6}$, which crystallizes in a cubic unit cell with the same space group $\mathrm{Fm} 3 \mathrm{~m}$ as $\mathrm{Cs}_{2} \mathrm{AgBiBr}_{6} . \mathrm{Cs}_{2} \mathrm{AgInCl}_{6}$ has a typical double perovskite structure consisting of alternating $\left[\mathrm{AgCl}_{6}\right]^{5-}$ and $\left[\mathrm{InCl}_{6}\right]^{3-}$ octahedra in all three directions. In 2018, Tang and co-workers grow high-quality $\mathrm{Cs}_{2} \mathrm{AgInCl}_{6}$ single crystals with extremely low trap density, $(8.6 \pm 1.9) \times 10^{8} \mathrm{~cm}^{-3}$, by employed the hydrothermal method. The carrier mobility of the resulted $\mathrm{Cs}_{2} \mathrm{AgInCl}_{6}$ can up to3.31 $\mathrm{cm}^{2} \mathrm{~V}^{-1} \mathrm{~s}^{-1}$. ${ }^{65}$ It is noted that $\mathrm{Cs}_{2} \mathrm{AgInCl}_{6}$ has a direct band gap with both the CBM and VBM located at the $\Gamma$ point, as shown in Figure 2.4a. However, the transitions from VBM to CBM at the $\Gamma$ point are parity forbidden (Figure 2.4a,c), as VBM and CBM have the same even parity, where the CBM mainly derives from the delocalized In $5 \mathrm{~s}$ states and the VBM mainly derives from $\mathrm{Ag} 4 \mathrm{~d}$ and $\mathrm{Cl} 3 \mathrm{p}$ states. ${ }^{66}$ Therefore, $\mathrm{Cs}_{2} \mathrm{Ag}$ $\mathrm{InCl}_{6}$ should have a weak optical absorption coefficient near the band edge. The optical transitions gradually become allowed as the $\mathrm{k}$ point changes from $\Gamma$ to $\mathrm{L}$ point due to the introduce of odd character, which is evident in the calculated dipole transition matrix element (Figure 2.4b). 


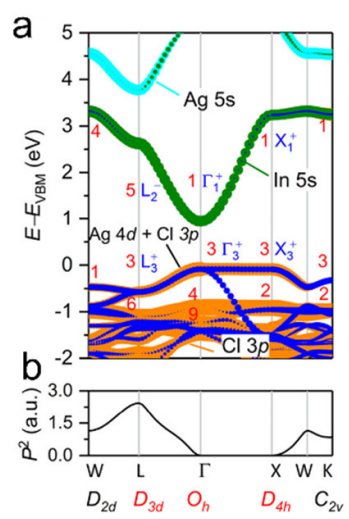

C

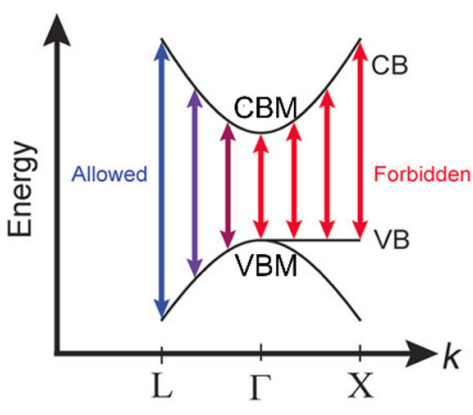

Figure 2.4 PBE calculated (a) band structure and (b) transition matrix elements for $\mathrm{Cs}_{2} \mathrm{AgInCl}_{6}$. The orange color corresponds to $\mathrm{Cl} 3 \mathrm{p}$ states, the green color to In $5 \mathrm{~s}$ states, and the blue/cyan color to $\mathrm{Ag} 4 \mathrm{~d} / 5$ s states ${ }^{66}$ (c) Band diagram depicting allowed and forbidden optical transitions. ${ }^{65}$

The optical properties of $\mathrm{Cs}_{2} \mathrm{AgInCl}_{6}$ have been widely investigated by $\mathrm{UV}$-vis and PL spectra. UV-Vis absorption spectra shows two absorption edges with a sharp absorption near $384 \mathrm{~nm}(3.2 \mathrm{eV})$ and a weak absorption near $595 \mathrm{~nm}(2.1 \mathrm{eV})$ (Figure 2.5a). ${ }^{65}$ The calculated optical bandgap of $\mathrm{Cs}_{2} \mathrm{AgInCl}_{6}$ is in the range of $2.8 \mathrm{eV}-3.3 \mathrm{eV}$. ${ }^{67,68,56}$ The different bandgap values are possibly related to the different forms of the measured samples (powder or crystal). It is noted that $\mathrm{Cs}_{2} \mathrm{AgInCl}_{6}$ shows a broad PL peak centered at around $2.0 \mathrm{eV}$ with a large stock shift compared with its fundamental bandgap (Figure 2.5b). It also shows an extremely low PLQY $(<0.1)$, which is mainly related to its self-trapped excitons (STEs) luminescence. Specifically, STEs in $\mathrm{Cs}_{2} \mathrm{AgInCl}_{6}$ should arise from the strong Johan-Teller distortion of the $\mathrm{AgCl}_{6}$ octahedron in the excited state, indicated by first-principles density-functional-theory calculations (Figure 2.5d). ${ }^{68}$ The energy difference between STE emission and bandgap relates with the exciton binding energy $E_{\mathrm{b}}$, the self-trap energy $E_{\mathrm{st}}$ and the lattice deformation energy $E_{\mathrm{d}}$ (Figure 2.5c). For $\mathrm{Cs}_{2} \mathrm{AgInCl}_{6}$, there is another small PL peak located at $425 \mathrm{~nm}$, possibly from the free-exciton emission. The PL lifetime of $\mathrm{Cs}_{2} \mathrm{AgInCl}_{6}$ at $595 \mathrm{~nm}(566.9 \mathrm{~ns})$ is much longer than that at $425 \mathrm{~nm}(9.8 \mathrm{~ns})$. The parity-forbidden transitions from CBM to VBM, together with STEs, cause the relatively long lifetime at 595nm and low PLQY $(<0.1)$. 
a

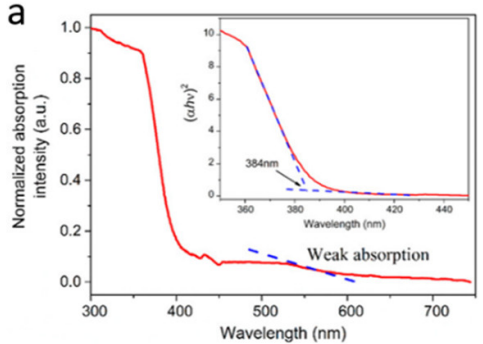

C

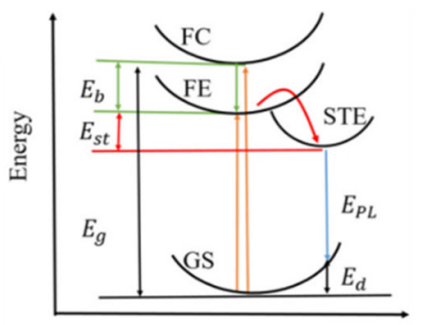

Nuclear Coordinate

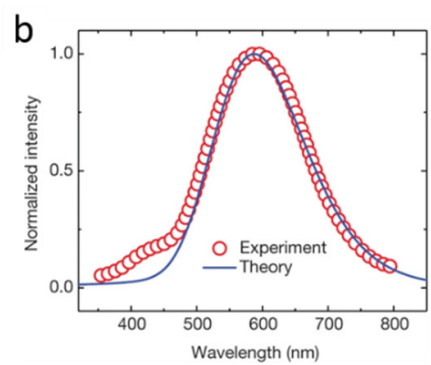

d

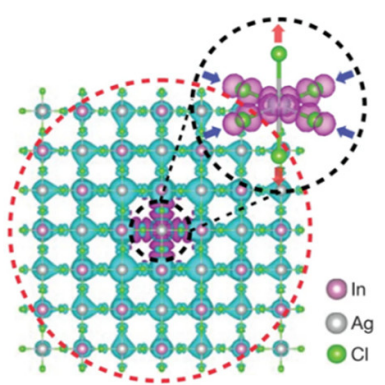

Figure 2.5 (a) Absorption spectrum of $\mathrm{Cs}_{2} \mathrm{AgInCl}_{6}$ single crystals. Weak absorption was observed around $595 \mathrm{~nm}$. Inset: Tauc plot showing the characteristics of a direct band gap of $3.2 \mathrm{eV} \mathrm{(384}$ $\mathrm{nm}){ }^{65}$ (b) Calculated photoluminescence spectrum compared with the experimental result. The calculated curve has been shifted to align its maximum with that of the experimentally measured curve for better comparison. ${ }^{68}$ (c) Schematic of the energy level structure of STE (GS, ground state; FE, free exciton state; FC, free carrier state; STE, self-trapped exciton state; $E_{\mathrm{g}}$, bandgap energy; $E_{\mathrm{b}}$, exciton binding energy; $E_{\mathrm{st}}$, self-trapping energy; $E_{\mathrm{d}}$, lattice deformation energy; $E_{\mathrm{PL}}$, emission energy). ${ }^{69}(\mathrm{~d}) \mathrm{STE}$ in $\mathrm{Cs}_{2} \mathrm{AgInCl}_{6}$. Cs atoms are omitted for clarity. The cyan and magenta isosurfaces represent the electron and hole orbital densities, respectively. The electron state (red dashed circle) is rather extended and the hole state (black dashed circle) is compact, consistent with the small (large) effective mass of the conduction (valence) band. The inset shows the JahnTeller distortion of the $\mathrm{AgCl}_{6}$ octahedron. Here the hole isosurface is obvious, whereas the electron isosurface is invisible owing to its small density. ${ }^{68}$

$\mathrm{Cs}_{2} \mathrm{AgInCl}_{6}$ also shows excellent chemical, light, and thermal stability. There is no decomposition in the PXRD patterns after storing $\mathrm{Cs}_{2} \mathrm{AgInCl}_{6}$ either in the dark at $55 \%$ relative humidity for 300 days or irradiated at $50{ }^{\circ} \mathrm{C}$ with an LED lamp at an intensity of $5.02 \mathrm{~mW} / \mathrm{cm}^{-2}$ for $48 \mathrm{~h}$, as shown in Figure 2.6 a,b. Meanwhile, $\mathrm{Cs}_{2} \mathrm{AgInCl}_{6}$ exhibits high thermal stability without phase transition before the decomposition temperature of around $507^{\circ} \mathrm{C}$. (Figure 2.6c). ${ }^{65}$ 

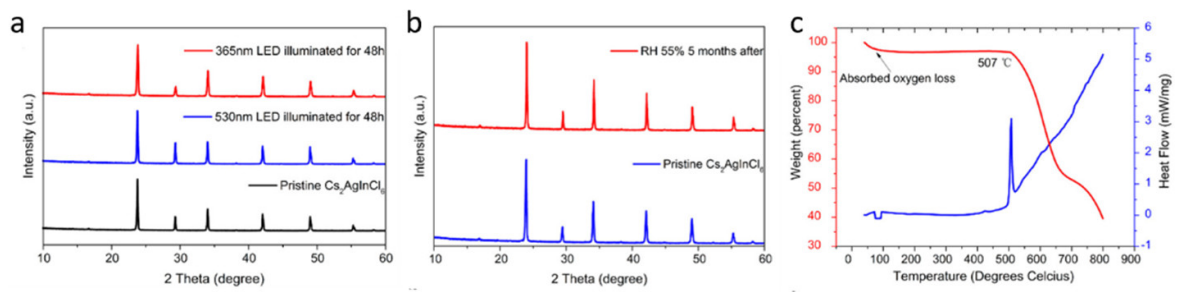

Figure 2.6 (a) PXRD patterns of $\mathrm{Cs}_{2} \mathrm{AgInCl}_{6}$ powder after exposure to humidity $(55 \% \mathrm{RH}){ }^{65}$ (b) PXRD patterns of $\mathrm{Cs}_{2} \mathrm{AgInCl}_{6}$ powder after exposure to light $\left(5.02 \mathrm{~mW} / \mathrm{cm}^{-2}\right){ }^{65}$ (c) Thermogravimetric differential thermal analysis of $\mathrm{Cs}_{2} \mathrm{AgInCl} \mathrm{In}_{6}$ powder. ${ }^{65}$

In addition to the benchmark double perovskites $\mathrm{Cs}_{2} \mathrm{AgBiBr}_{6}$ and $\mathrm{Cs}_{2} \mathrm{AgInCl}_{6}$, researchers are committed to exploring other new promising HDPs for efficient photovoltaic applications. Hemamala I. Karunadasa and co-workers synthesized Tl-based double perovskites $\mathrm{Cs}_{2} \mathrm{AgTlX}_{6}(\mathrm{X}=\mathrm{Br}, \mathrm{Cl})$ for the first time. ${ }^{58}$ Impressively, $\mathrm{Cs}_{2} \mathrm{AgTlBr}_{6}$ shows a direct bandgap with the lowest bandgap $(0.95 \mathrm{eV})$ amongst reported halide perovskites (Figure 2.7a). Unfortunately, there is no $\mathrm{PL}$ in $\mathrm{Cs}_{2} \mathrm{AgTlBr}_{6}$ and $\mathrm{Cs}_{2} \mathrm{AgTiCl}_{6}$ even at $20 \mathrm{~K}$, mainly because of the symmetry-forbidden transition. Recently, Li and coworkers investigated a new class double perovskite $\mathrm{Cs}_{2} \mathrm{AgIn}_{\mathrm{x}} \mathrm{Fe}_{1-\mathrm{x}} \mathrm{Cl}_{6}(0 \leq \mathrm{x} \leq 1)$ with a broadband absorbance in the range of $450-800 \mathrm{~nm}$, as shown in Figure 2.7b. Among these different compositions, $\mathrm{Cs}_{2} \mathrm{AgFeCl}_{6}$ shows a direct bandgap of around $1.55 \mathrm{eV}$, but it displays no PL. ${ }^{60}$ The underlying reasons were explained by lacking of electronic transitions occur to maintain the radiative recombination of electric charges, as the valance electrons originating from the $\mathrm{Cs}_{2} \mathrm{AgFeCl}_{6}$ are more likely to undergo the bound transition state. Additionally, a serious of Na-based double perovskites have been studied by Xia's group. For example, $\mathrm{Cs}_{2} \mathrm{NaBi}_{1-\mathrm{x}} \mathrm{In}_{\mathrm{x}} \mathrm{Cl}_{6}$ exhibit relatively large bandgap, ranging from $3.41 \mathrm{eV}$ to $3.7 \mathrm{eV}$, as shown in Figure 2.7c. ${ }^{70}$ Although a range of different HDPs have been investigated, we believe that there is still a huge room for further exploration of new double perovskites with interesting properties. 

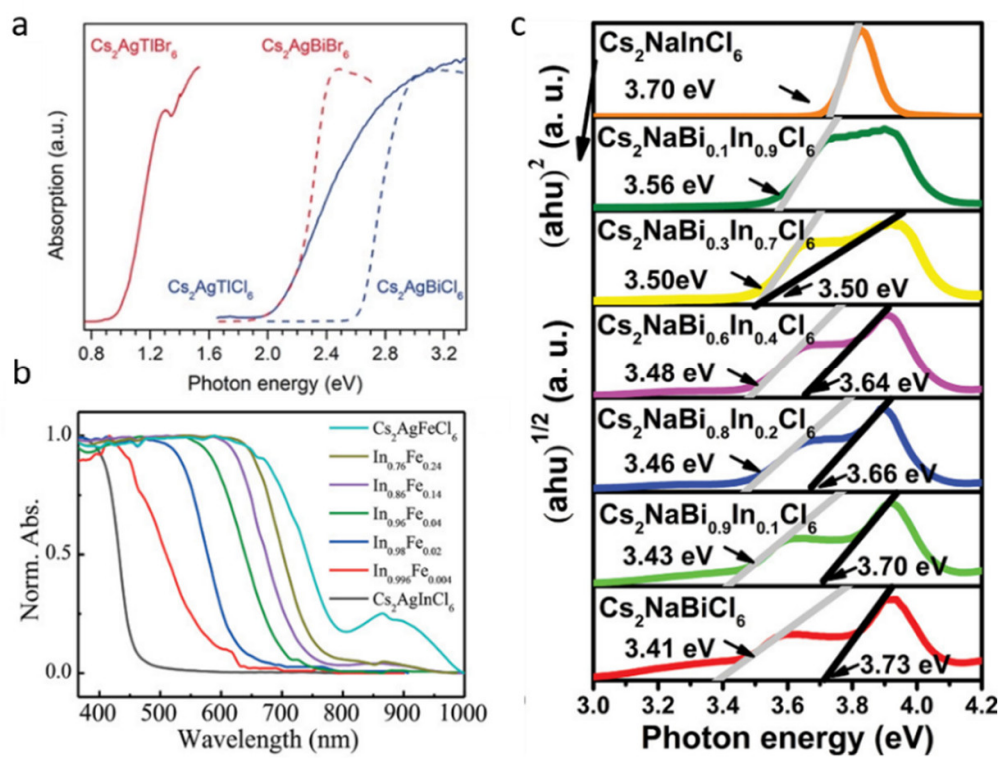

Figure 2.7 (a) Absorption spectra of $\mathrm{Cs}_{2} \mathrm{AgTlBr}_{6}$ and $\mathrm{Cs}_{2} \mathrm{AgTlCl}_{6}$ (solid lines) and those of $\mathrm{Cs}_{2} \mathrm{AgBiCl}_{6}$ and $\mathrm{Cs}_{2} \mathrm{AgBiBr}_{6}$ (dashed lines) ${ }^{58}$ (b) UV-vis absorbance spectra of as-prepared $\mathrm{Cs}_{2} \mathrm{AgFe}_{1-\mathrm{x}} \mathrm{In}_{\mathrm{x}} \mathrm{Cl}_{6}(0 \leq \mathrm{x} \leq 1)$ double perovskite single crystals with different $\mathrm{x}$ values. ${ }^{60}$ (c) Tauc plots for $\mathrm{Cs}_{2} \mathrm{NaBi}_{1-\mathrm{x}} \mathrm{In}_{\mathrm{x}} \mathrm{Cl}_{6}\left(\mathrm{x}=0,0.1,0.2,0.3,0.4,0.7,0.9\right.$, and 1.0). ${ }^{70}$

\subsubsection{Applications of Lead-free Halide Double Perovskites}

Encouraged by the interesting optoelectronic properties of HDPs, these materials are attractive for practical optoelectronic applications, such as solar cells, ${ }^{71}$ laser, ${ }^{72}$ light emitting diode (LED), ${ }^{68}$ photodetector, ${ }^{73} \mathrm{X}$-ray detector and imaging, ${ }^{74}$ photocatalyst, ${ }^{75}$ etc. (Figure 2.8).

The early applications of HDPs are limited to single crystals, as it is difficult to develop double perovskite films using the solution method. For example, Tang and coworkers demonstrated a sensitive (detectivity of $\sim 10^{12}$ Jones), stable and fast ( $3 \mathrm{~dB}$ bandwidth of $1035 \mathrm{~Hz}$ ) UV photodetectors based on the $\mathrm{Cs}_{2} \mathrm{AgInCl}_{6}$ single crystals. ${ }^{65}$ Besides, $\mathrm{Cs}_{2} \mathrm{AgBiBr}_{6}$ has also been used to detect photons and even high-energy radiation, such as X-rays and g-rays. Due to the high average atomic number, adequate $\mu \tau$ product, low ionization energy and high resistivity of $\mathrm{Cs}_{2} \mathrm{AgBiBr}_{6}$ single crystals, the fabricated X-ray detector shows a high sensitivity of $105 \mu \mathrm{C} \mathrm{Gyair}^{-1} \mathrm{~cm}^{-2}$ and a low detection limit of $59.7 \mathrm{nGy}_{\text {air }} \mathrm{s}^{-1}$ under an external bias of $5 \mathrm{~V}^{74}$ 


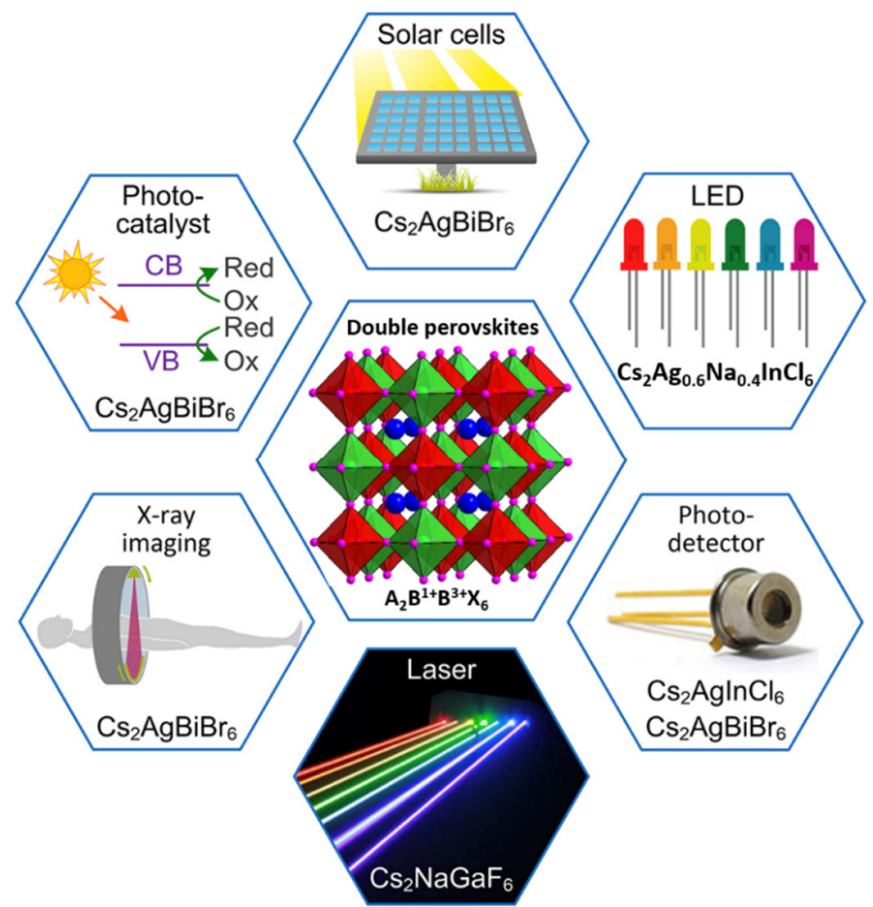

Figure 2.8 Optoelectronic Applications of Halide Double Perovskites. ${ }^{76}$

The breakthrough for double perovskite films was made in 2017 by Bein and coworkers. They resolved the solubility issue of $\mathrm{Cs}_{2} \mathrm{AgBiBr}_{6}$ through choosing dimethyl sulfoxide (DMSO) as solvent and heating the precursor solution at $75^{\circ} \mathrm{C}$. As such, they have been able to deposit $\mathrm{Cs}_{2} \mathrm{AgBiBr}_{6}$ films by the spin-coating method for the first time. ${ }^{71}$ Based on the prepared films, they developed the $\mathrm{Cs}_{2} \mathrm{AgBiBr}_{6}$-based solar cells with traditional mesoporous structure and achieved a PCE of $2.43 \%$. $^{71}$ They also emphasized that the high annealing temperature $\left(250^{\circ} \mathrm{C}\right)$ is important for obtaining pure $\mathrm{Cs}_{2} \mathrm{AgBiBr}_{6}$ double perovskite phase. The successful preparation of the $\mathrm{Cs}_{2} \mathrm{AgBiBr}_{6}$ thin films broke the main barrier of double perovskite materials for photovoltaic solar cell applications. Thereafter, different methods have been applied to fabricate the $\mathrm{Cs}_{2} \mathrm{Ag}$ $\mathrm{BiBr}_{6}$ based solar cells, such as antisolvent dropping technology, ${ }^{77}$ low-pressure-assisted method, ${ }^{78}$ and sequential vapor deposition. ${ }^{79}$ Table 2.1 summarizes the device photovoltaic performance of $\mathrm{Cs}_{2} \mathrm{AgBiBr}_{6}$ based solar cells. Our group fabricated the $\mathrm{Cs}_{2} \mathrm{AgBiBr}_{6}$ solar cells with planar structure for the first time and achieve a PCE of $1.22 \%$ in 2018. ${ }^{14}$ Particularly, we achieved a uniform and high quality $\mathrm{Cs}_{2} \mathrm{AgBiBr}_{6}$ film by using single crystal $\mathrm{Cs}_{2} \mathrm{AgBiBr}_{6}$ precursor solution and one-step spin-coating method. Very recently, some researchers have enhanced the $\mathrm{PCE}$ of $\mathrm{Cs}_{2} \mathrm{AgBiBr}_{6}$ solar cells 
through optimizing the electron transport layer (ETL). For example, Yang and co-workers developed a multifunctional ETL $\left(\mathrm{Ti}_{3} \mathrm{C}_{2} \mathrm{~T}_{\mathrm{x}} @ \mathrm{TiO}_{2}\right)$ to improve the efficiency and stability of $\mathrm{Cs}_{2} \mathrm{AgBiBr}_{6}$ solar cells compared to the device based on $\mathrm{TiO}_{2}{ }^{80}$ Wang and co-workers demonstrated a state-of-the-art PCE of $3.11 \%$ by introducing a carboxychlorophyll derivative (C-Chl)-sensitized mesoporous $\mathrm{TiO}_{2}\left(\mathrm{~m}-\mathrm{TiO}_{2}\right)$ film as an ETL, which could enhance the optical absorption of device, and increase short-circuit current density from 3.22 to $4.09 \mathrm{~mA} \mathrm{~cm}{ }^{-2}{ }^{81}$ In all, $\mathrm{Cs}_{2} \mathrm{AgBiBr}_{6}$ solar cells usually exhibit excellent stability under ambient environment, but the PCE still needs to be improved.

Table 2.1 Device architecture and photovoltaic parameters of double perovskite-based solar cells.

\begin{tabular}{|c|c|c|c|c|c|c|}
\hline Device structure & $\begin{array}{l}\mathrm{Sc} \\
{[\mathrm{mA}} \\
\left.\mathrm{cm}^{-2}\right]\end{array}$ & $\begin{array}{l}\text { Voc } \\
{[\mathrm{V}]}\end{array}$ & $\mathrm{FF}$ & $\begin{array}{l}\text { PCE } \\
{[\%]}\end{array}$ & Methods & Ref. \\
\hline $\begin{array}{l}\mathrm{FTO} / \mathrm{TiO}_{2} / \mathrm{m}-\mathrm{TiO}_{2} / \\
\mathrm{Cs}_{2} \mathrm{AgBiBr}_{6} / \mathrm{Spiro}- \\
\mathrm{OMeTAD} / \mathrm{Au}\end{array}$ & 3.93 & 0.98 & 0.63 & 2.43 & $\begin{array}{l}\text { One-step spin } \\
\text { coating }\end{array}$ & 71 \\
\hline $\begin{array}{l}\mathrm{ITO} / \mathrm{Cu}- \\
\mathrm{NiO} / \mathrm{Cs}_{2} \mathrm{AgBiBr}_{6} / \mathrm{C} 60 / \\
\mathrm{BCP} / \mathrm{Ag}\end{array}$ & 3.19 & 1.01 & 0.69 & 2.23 & $\begin{array}{l}\text { Antisolvent } \\
\text { dropping }\end{array}$ & 77 \\
\hline $\begin{array}{l}\mathrm{ITO} / \mathrm{SnO}_{2} / \mathrm{Cs}_{2} \mathrm{AgBiBr}_{6} / \\
\mathrm{P}_{3} \mathrm{HT} / \mathrm{Au}\end{array}$ & 1.78 & 1.04 & 0.78 & 1.44 & $\begin{array}{l}\text { Low-pres- } \\
\text { sure-assisted }\end{array}$ & 78 \\
\hline $\mathrm{ITO} / \mathrm{SnO}_{2} / \mathrm{Cs}_{2} \mathrm{AgBiBr}_{6} / \mathrm{Au}$ & 1.5 & 0.95 & 0.6 & 0.86 & $\begin{array}{l}\text { Low-pres- } \\
\text { sure-assisted }\end{array}$ & 78 \\
\hline $\begin{array}{l}\mathrm{FTO} / \mathrm{TiO}_{2} / \mathrm{Cs}_{2} \mathrm{AgBiBr}_{6} / \\
\mathrm{P} 3 \mathrm{HT} / \mathrm{Au}\end{array}$ & 1.79 & 1.12 & 0.68 & 1.37 & $\begin{array}{l}\text { Sequential } \\
\text { vapor deposi- } \\
\text { tion }\end{array}$ & 79 \\
\hline $\begin{array}{l}\mathrm{ITO} / \mathrm{TiO}_{2} / \mathrm{Cs}_{2} \mathrm{AgBiBr}_{6} / \\
\text { Spiro-OMeTAD/Au }\end{array}$ & 1.55 & 1.06 & 0.74 & 1.22 & $\begin{array}{l}\text { One-step spin } \\
\text { coating }\end{array}$ & 14 \\
\hline $\begin{array}{l}\mathrm{FTO} / \mathrm{Ti}_{3} \mathrm{C}_{2} \mathrm{~T}_{\mathrm{x}} @ \mathrm{TiO}_{2}(0.2 \\
\text { wt \%o } / \mathrm{Cs}_{2} \mathrm{AgBiBr}_{6} / \text { Spiro- } \\
\text { OMeTAD/MoO} / \mathrm{Ag}\end{array}$ & 4.14 & 0.96 & 0.70 & 2.81 & $\begin{array}{l}\text { One-step spin } \\
\text { coating }\end{array}$ & 80 \\
\hline $\begin{array}{l}\mathrm{FTO} / \mathrm{TiO}_{2} / \quad \mathrm{C}-\mathrm{Chl} \quad \mathrm{m}- \\
\mathrm{TiO}_{2} / \mathrm{Cs}_{2} \mathrm{AgBiBr} / \text { /Spiro- } \\
\mathrm{OMeTAD}_{\mathrm{Agg}}\end{array}$ & 4.09 & 1.04 & 0.73 & 3.11 & $\begin{array}{l}\text { One-step spin } \\
\text { coating }\end{array}$ & 81 \\
\hline
\end{tabular}

The benchmark HDPs for potential light emitting applications is $\mathrm{Cs}_{2} \mathrm{AgInCl}_{6}$ with a direct bandgap. As mentioned above, $\mathrm{Cs}_{2} \mathrm{AgInCl}_{6}$ shows an extremely low PLQY $(<0.1)$ 
due to the parity-forbidden transitions, which is a disadvantage for light emitting applications. Attractively, Tang and co-workers break the parity-forbidden transitions of $\mathrm{Cs}_{2} \mathrm{AgInCl}_{6}$ by $\mathrm{Na}$ alloying. The photoluminescence efficiency of $\mathrm{Na}$-alloyed $\mathrm{Cs}_{2} \mathrm{Ag}$ $\mathrm{InCl}_{6}$ has increased by three orders of magnitude compared to pure $\mathrm{Cs}_{2} \mathrm{AgInCl}_{6}$. Further introducing a trace amount of $\mathrm{Bi}^{3+}$ doping, the PLQY of $\mathrm{Cs}_{2} \mathrm{Ag}_{0.60} \mathrm{Na}_{0.40} \mathrm{InCl}_{6}$ is up to $(86 \pm 5) \%$, which represents the highest reported value for white-emitting phosphors (Figure 2.9a). Meanwhile, the alloyed $\mathrm{Cs}_{2} \mathrm{Ag}_{0.60} \mathrm{Na}_{0.40} \mathrm{InCl}_{6}$ also exhibited outstanding stability, indicating promise for solid-state lighting. Moreover, they also successfully fabricated a pure phase $\mathrm{Cs}_{2} \mathrm{Ag}_{0.60} \mathrm{Na}_{0.40} \mathrm{InCl}_{6}$ film for LED devices through thermally evaporate method (Figure 2.9b,c,d). ${ }^{6}$ This work demonstrated the great potential of HDPs for LED applications, although further optimization is still needed to improve device performance.
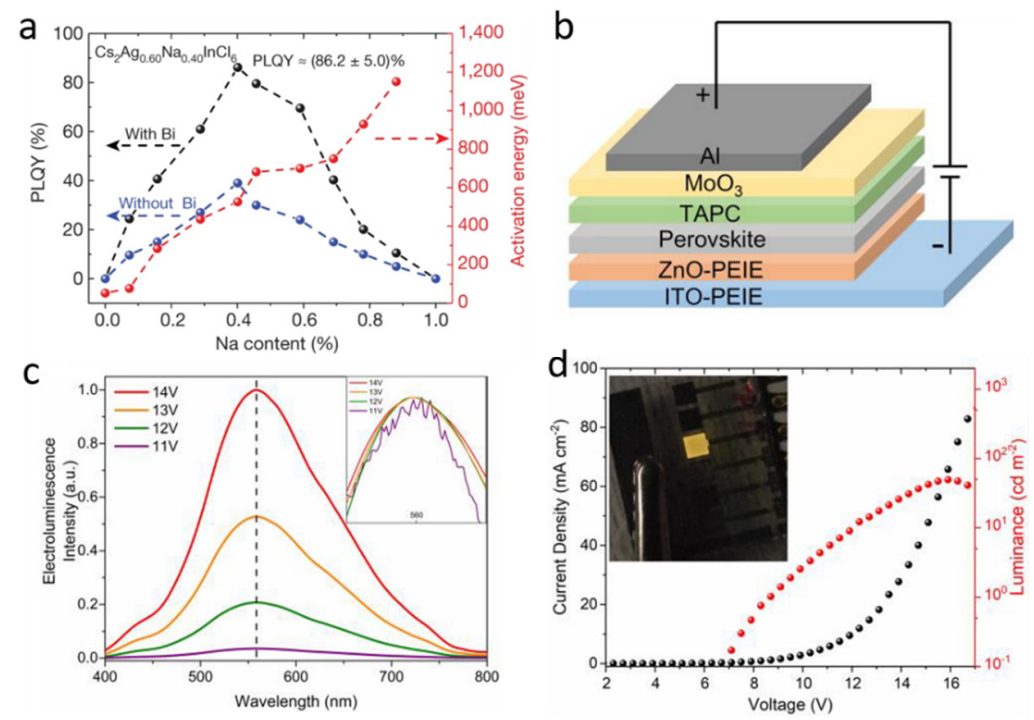

Figure 2.9 (a) Activation energy and PLQY of $\mathrm{Cs}_{2} \mathrm{Ag}_{\mathrm{x}} \mathrm{Na}_{1-\mathrm{x}} \mathrm{InCl}_{6}$ powder versus $\mathrm{Na}$ content. ${ }^{68}$ (b) The electroluminescent device structure, glass/ PEIE modified ITO /PEIE modified ZnO (20 nm) $/ \mathrm{Cs}_{2} \mathrm{Ag}_{0.60} \mathrm{Na}_{0.40} \mathrm{InCl}_{6}$ film $(50 \mathrm{~nm}) / \mathrm{TAPC}(40 \mathrm{~nm}) / \mathrm{MoO}_{3}(8 \mathrm{~nm}) / \mathrm{Al}(100 \mathrm{~nm})$, where PEIE is polyethylenimine, TAPC is 4,4'-Cyclohexylidenebis[N,N-bis(4-methylphenyl) benzenamine]. ${ }^{68}$ (c) Electroluminescence spectra at an applied voltage of $11 \mathrm{~V}, 12 \mathrm{~V}, 13 \mathrm{~V}$ and $14 \mathrm{~V}$, respectively. The inset is the normalized spectra. ${ }^{68}$ (d) Dependence of current density and luminance on the driving voltage. ${ }^{68}$

Apart from $\mathrm{Na}^{+}$alloying, a series of dopants has been used to change the PL emission of $\mathrm{Cs}_{2} \mathrm{AgInCl}_{6}$, such as $\mathrm{Mn}^{2+}, \mathrm{Bi}^{3+}$ and rare earth elements $\left(\mathrm{Yb}^{3+}, \mathrm{Er}^{3+}\right) .{ }^{82-84}$ In the $\mathrm{Mn}$ doped $\mathrm{Cs}_{2} \mathrm{AgInCl}_{6}$ system, the photoexcited host $\left(\mathrm{Cs}_{2} \mathrm{AgInCl}_{6}\right)$ transfers the energy to 
Mn ions, resulting in a red colored emission at around $632 \mathrm{~nm}$. Generally, the photoluminescent mechanism in Mn-doped materials originates from the de-excitation of $\mathrm{Mn} \mathrm{d}$ electrons from the ${ }^{4} \mathrm{~T} 1$ to ${ }^{6} \mathrm{~A} 1$ state. ${ }^{82}$ Recently, Nag and co-workers developed a $\mathrm{Bi}^{3+}$ $\mathrm{Ln}^{3+}\left(\mathrm{Ln}=\mathrm{Er}^{3+}\right.$ and $\left.\mathrm{Yb}^{3+}\right)$ co-doping system to achieve efficient near-infrared PL in $\mathrm{Cs}_{2} \mathrm{AgInCl}_{6}$. Upon excitation, the absorption energy can be efficiently transferred to $\mathrm{Er}^{3+}$ and $\mathrm{Yb}^{3+}$ f electrons, and then de-excite by emitting light at 1540 and $994 \mathrm{~nm}$, respectively. ${ }^{84}$ Impressively, $\mathrm{Bi}^{3+}$ co-doping significantly promoted the near infrared (NIR) dopant emissions by creating a new absorption channel in 350-400 $\mathrm{nm}$ range. This codoping strategy also provide a possibility of using doped double perovskites in infrared detection.

In addition, there are some other optoelectronic applications for halide double perovskites, such as lasers and photocatalysts, as shown in Figure 2.8. For instance, many fluoride double perovskites have been used as a host for $\mathrm{Ce}^{3+}$-based laser materials for a long time. ${ }^{72}$ In 2018, Su and co-workers have demonstrated the photocatalytic application of $\mathrm{Cs}_{2} \mathrm{AgBiBr}_{6}$ nanocrystals for the first time. These $\mathrm{Cs}_{2} \mathrm{AgBiBr}_{6}$ nanocrystals were used to artificial photochemical conversion of the $\mathrm{CO}_{2}$ into sustainable solar fuels $\left(\mathrm{CO}, \mathrm{CH}_{4}\right)$ with an impressive electron consumption of $105 \mu \mathrm{mol} \mathrm{g}^{-1}(6 \mathrm{~h})$, which holds a great potential in further photochemical applications. ${ }^{75}$

\subsection{Challenges}

HDPs provide a wide range of possible combinations and rich substitutional chemistry with attractive optical and electronic features. They are promising to overcome the toxicity and instability issues of $\mathrm{Pb}$ halide perovskites for optoelectronic applications.

Up to now, a range of halide double perovskites have been synthesized, such as $\mathrm{Cs}_{2} \mathrm{AgBiBr}_{6}, \mathrm{Cs}_{2} \mathrm{AgBiCl}_{6}, \mathrm{Cs}_{2} \mathrm{AgSbCl}_{6}, \mathrm{Cs}_{2} \mathrm{AgInCl}_{6}, \mathrm{Cs}_{2} \mathrm{NaInCl}_{6}, \mathrm{Cs}_{2} \mathrm{NaBiCl}_{6}$, $\mathrm{Cs}_{2} \mathrm{NaFeCl}_{6},{ }^{85} \mathrm{Cs}_{2} \mathrm{AgFeCl}_{6}$ and $\mathrm{Cs}_{2} \mathrm{NaVCl}_{6} .{ }^{86}$ However, there are still some challenges for the optoelectronic applications. For example, the Fe-based double perovskite $\mathrm{Cs}_{2} \mathrm{Ag}$ $\mathrm{FeCl}_{6}$ with a relatively narrow direct band gap of about $1.55 \mathrm{eV}$ shows no PL emission. Similarly, no PL signal can be observed in $\mathrm{Cs}_{2} \mathrm{AgTlX}_{6}(\mathrm{X}=\mathrm{Br}, \mathrm{Cl})$ even at extremely low temperature $(20 \mathrm{k})$. The non-luminescent behavior of these HDPs limit their optoelectronic applications. In addition, the high toxicity of Tl-based double perovskites must be considered for any applications. Na-based double perovskites show relatively large band gaps with the value of $3.41 \mathrm{eV}$ and $3.70 \mathrm{eV}$ for $\mathrm{Cs}_{2} \mathrm{NaBiCl}_{6}$ and $\mathrm{Cs}_{2} \mathrm{NaInCl}_{6}$, which are not ideal for photovoltaic applications either. ${ }^{70}$

Currently, the most promising HDPs for photoelectronic applications are two benchmark double perovskites $\mathrm{Cs}_{2} \mathrm{AgBiBr}_{6}$ and $\mathrm{Cs}_{2} \mathrm{AgInCl}_{6}$. However, the bandgap of both 
$\mathrm{Cs}_{2} \mathrm{AgBiBr}_{6}(>1.95 \mathrm{eV})$ and $\mathrm{Cs}_{2} \mathrm{AgInCl}_{6}(>2.8 \mathrm{eV})$ are too large for single junction photovoltaic applications. The large bandgap results in low absorption in the visiblelight region, limiting their photovoltaic performance. To date, the highest reported PCE of $\mathrm{Cs}_{2} \mathrm{AgBiBr}_{6}$ double perovskite solar cells is only $3.11 \%$. For $\mathrm{Cs}_{2} \mathrm{AgInCl}_{6}$ with a direct bandgap, it suffers from an unfavorable parity-forbidden transitions from CBM to VBM. Meanwhile, it is still challenging to fabricate $\mathrm{Cs}_{2} \mathrm{AgInCl}_{6}$ films by the solution method due to the low solubility of $\mathrm{CsCl}$ and $\mathrm{AgCl}$.

In short, apart from the benchmark double perovskites $\mathrm{Cs}_{2} \mathrm{AgInCl}_{6}$ and $\mathrm{Cs}_{2} \mathrm{AgBiBr}_{6}$, more efforts are required before new promising double perovskites for optoelectronic applications can be identified. Meanwhile, the benchmark double perovskites $\mathrm{Cs}_{2} \mathrm{Ag}$ $\mathrm{BiBr}_{6}$ and $\mathrm{Cs}_{2} \mathrm{AgInCl}_{6}$ either have a large indirect bandgap or large direct bandgap with parity-forbidden transitions, which greatly limit their optoelectronic applications. Therefore, more efforts should be taken in the future to modify the band structure of benchmark double perovskites or/and to further explore other new promising double perovskite candidates for efficient photovoltaic applications. 
Chapter 2 Lead-free Halide Perovskites 


\section{Chapter 3 Bandgap Engineering of Halide Double}

\section{Perovskites}

As discussed in Chapter 2, the reported HDPs usually show relatively large band gaps and indirect bandgap nature or direct bandgap with parity-forbidden transitions and/or no PL emission, hindering their further application in optoelectronic field. Therefore, finding effective strategies to overcome these issues of HDPs is highly desirable.

In general, changing the halide is a simple yet efficient method to tune the bandgaps of perovskites because their VBM is mainly derived from the states of halogen orbitals. The I-based perovskites usually show the lowest bandgap compared to the corresponding Br-based and Cl-based compounds. Up to now, the only reported I-based double perovskite is $\mathrm{Cs}_{2} \mathrm{AgBiI}_{6}$ nanocrystals, which were synthesized by Gamelin and coworkers through the anion exchange method by treatment with trimethylsilyl iodide (TMSI) (Figure 3.1a) ${ }^{87}$ The conversion progress was identified by optical characterization and $\mathrm{XRD}$ data, as shown in Figure 3.1b-d. However, these $\mathrm{Cs}_{2} \mathrm{AgBiI}_{6}$ nanocrystals are easily decomposed into $\mathrm{Cs}_{3} \mathrm{Bi}_{2} \mathrm{I}_{9}$ nanocrystals after being exposed to air for several days. It is noted that there is still no report about $\mathrm{Cs}_{2} \mathrm{AgBiI}_{6}$ in the bulk form (crystals and films), instead, only the $\mathrm{Cs}_{3} \mathrm{Bi}_{2} \mathrm{I}_{9}$ byproduct is formed. For Br-based HDPs, only several stable compounds have been synthesized so far, such as $\mathrm{Cs}_{2} \mathrm{AgBiBr}_{6},{ }^{53}\left(\mathrm{CH}_{3} \mathrm{NH}_{3}\right)_{2} \mathrm{AgBiBr}_{6},{ }^{88}$ and $\mathrm{Cs}_{2} \mathrm{AgTlBr}_{6} .{ }^{57,58} \mathrm{Up}$ to now, most of the reported stable HDPs are Cl-based compounds with a large bandgap. 


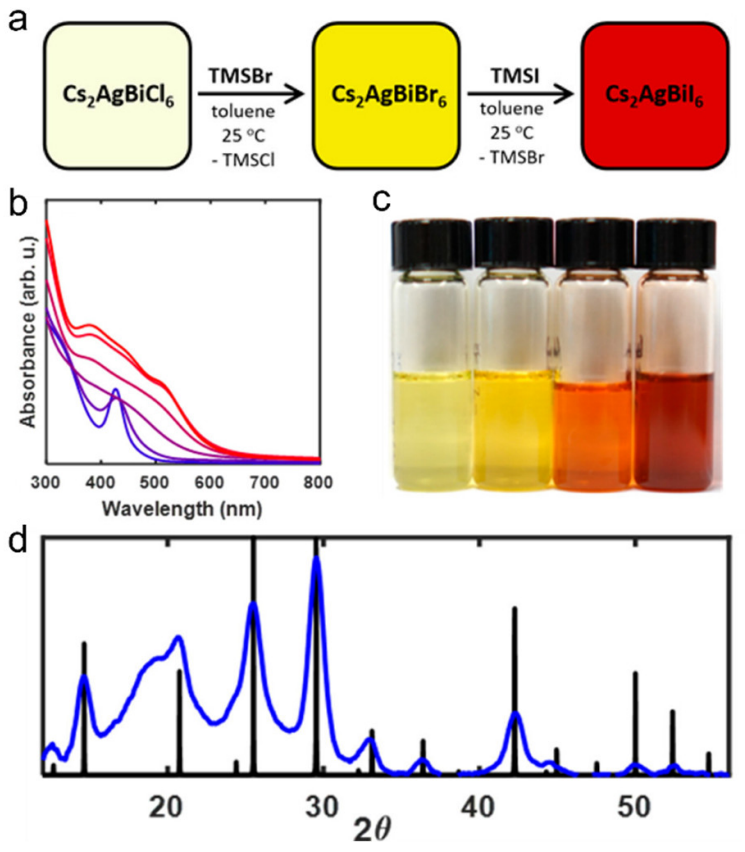

Figure 3.1 (a) Schematic diagram of synthesis of $\mathrm{Cs}_{2} \mathrm{AgBiI}_{6}$ Nanocrystals. ${ }^{87}$ (b) Absorption spectra illustrating the conversion of $\mathrm{Cs}_{2} \mathrm{AgBiBr}_{6}$ nanocrystals to $\mathrm{Cs}_{2} \mathrm{AgBiI}_{6}$ nanocrystals by treatment with increasing amounts of TMSI (reaction progresses from blue to red). ${ }^{87}$ (c) Photograph of dilute toluene solutions of (Lift to Right) $\mathrm{Cs}_{2} \mathrm{AgBiBr}_{6}, \mathrm{Cs}_{2} \mathrm{AgBiBr}_{5.2} \mathrm{I}_{0.8}, \mathrm{Cs}_{2} \mathrm{AgBiBr}_{1.6} \mathrm{I}_{4.4}$, and $\mathrm{Cs}_{2} \mathrm{Ag}$ BiI $_{6}$ nanocrystals. ${ }^{87}$ (d) Powder XRD pattern of $9.9 \mathrm{~nm} \mathrm{Cs} 2 \mathrm{AgBiI}_{6}$ nanocrystals, compared to a calculated pattern. ${ }^{87}$

To understand the underlying reason for poor stability of most I-based or Br-based HDPs, two important parameters, Goldschmidt tolerance factor $t$ and the octahedral factor $u$, are important to predict their crystallographic stability. Since the tolerance factor $t$ of almost all HDPs combined with frequently used cations $\left(\mathrm{Cs}^{+}, \mathrm{Ag}^{+}, \mathrm{Na}^{+}, \mathrm{Cu}^{+}, \mathrm{Sb}^{3+}\right.$, $\left.\mathrm{Bi}^{3+}, \mathrm{In}^{3+}, \mathrm{Fe}^{3+}, \mathrm{Tl}^{3+}\right)$ and anions $\left(\mathrm{Cl}^{-}, \mathrm{Br}^{-}, \mathrm{I}^{-}\right)$are within the range of requirement for stable perovskites $(0.81<t<1.11)$, the octahedral factor $\mu$ provides more insights for the formation of a stable $\mathrm{BX}_{6}$ octahedra, as shown in Figure 3.2. Obviously, a lot of Ibased and Br-based octahedrons show a small octahedral factor $\mu$ outside the stable region $(\mu<0.41)$, which would explain the instability of the corresponding HDPs. There are some special cases for stable HDPs with a small value of $\mu$. For example, stable $\mathrm{Cs}_{2} \mathrm{NaFeCl}_{6}$ and $\mathrm{Cs}_{2} \mathrm{AgFeCl}_{6}$ double perovskites with $\mu$ value of only 0.36 for $\left[\mathrm{FeCl}_{6}\right]^{3-}$. Therefore, Goldschmidt tolerance factor $t$ and the octahedral factor $u$ should not the whole story. Some compounds (for example $\mathrm{Cs}_{2} \mathrm{CuBiCl}_{6}, \mathrm{Cs}_{2} \mathrm{AgBiI} 6$ (bulk form), 
$\mathrm{Cs}_{2} \mathrm{NaBiI}_{6}$ ) with both appropriate Goldschmidt tolerance factor $t$ and the octahedral factor $\mu$ cannot be synthesized experimentally. Along this line, Mitzi and co-workers found that $\mathrm{Cu}^{1+}$-based halide compounds are more energetically favorable within 4-fold coordination, rather than 6 -fold coordination for $\left[\mathrm{CuX}_{6}\right]^{5-}$ octahedra, which rationalizes why $\mathrm{Cs}_{2} \mathrm{CuBiCl}_{6}$ cannot be formed. In addition, the thermodynamic stability of $\mathrm{Cs}_{2} \mathrm{AgBiI}_{6}$ was systematically studied using DFT by constructing its compositional phase diagram. ${ }^{89}$ Results indicate that the $\mathrm{Cs}_{3} \mathrm{Bi}_{2} \mathrm{I}_{9}$ byproduct is much stable than $\mathrm{Cs}_{2} \mathrm{AgBiI}_{6}$, which is consistent with the unsuccessful synthesis of $\mathrm{Cs}_{2} \mathrm{AgBiI}_{6}$ crystals or films. Similarly, $\mathrm{Cs}_{2} \mathrm{NaBiI}_{6}$ also tends to form the $\mathrm{Cs}_{3} \mathrm{Bi}_{2} \mathrm{I}_{9}$ byproduct. In all, the small octahedral factor $\mu(\mu<0.41)$, unfavorable B-site coordination number, and thermodynamic instability could be responsible for the instability of most I-based or Br-based HDPs.

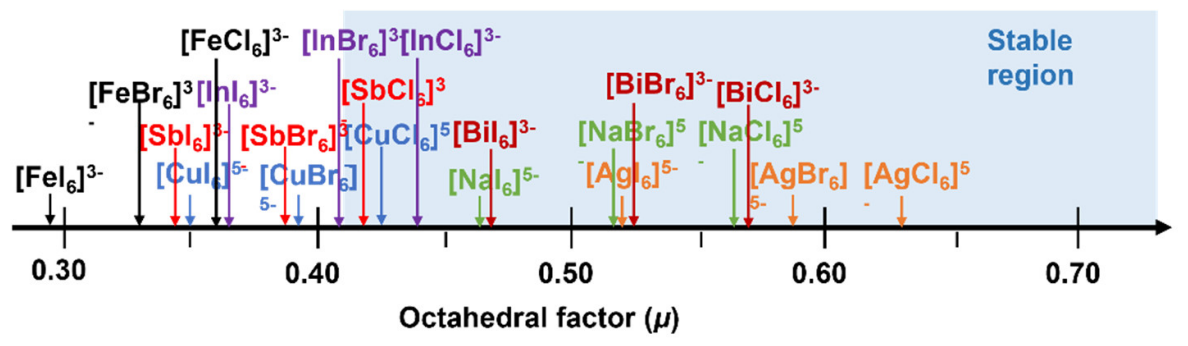

Figure 3.2 The octahedral factor $\mu$ of various octahedrons.

Halide mixing is another feasible approach to increase the octahedral factor $\mu$ to form stable alloyed HDPs with a reduced bandgap. However, this well-established strategy for halide lead-based perovskites is not always efficient for narrowing the bandgap of HDPs. Take $\mathrm{Cs}_{2} \mathrm{AgBiX}_{6}\left(\mathrm{X}=\mathrm{Cl}^{-}, \mathrm{Br}^{-}\right.$and $\left.\mathrm{I}^{-}\right)$as an example; the $\mathrm{Cl}^{-}$can be alloyed into $\mathrm{Cs}_{2} \mathrm{AgBiBr}_{6}$ in any ratio with increasing the bandgap of the host material, while only a low level $\left(<3 \mathrm{~mol} \% \mathrm{I}^{-}\right)$of $\mathrm{I}^{-}$can be doped into the $\mathrm{Cs}_{2} \mathrm{AgBiBr}_{6}$ and $\mathrm{Cs}_{2} \mathrm{AgBiCl}_{6}$ host lattice. Further Increasing $\mathrm{I}^{-}$will lead to a phase segregation of silver-rich and bismuthrich non-perovskite compounds (Figure 3.3) ${ }^{90}$ Therefore, It is highly desirable to find other effective strategies to adjust the bandgap of HDPs.

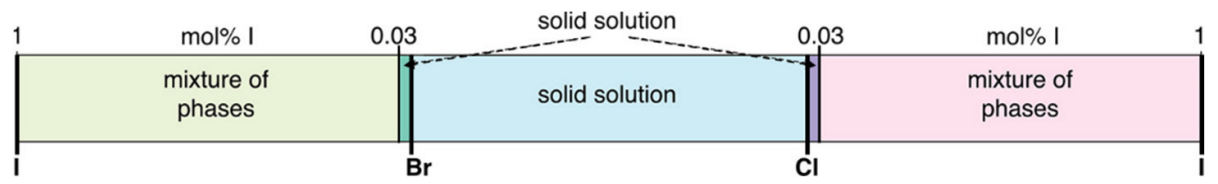

Figure 3.3 Schematic representation of the $\mathrm{Cs}_{2} \mathrm{AgBiX}_{6}(\mathrm{X}=\mathrm{Cl} / \mathrm{Br}, \mathrm{Br} / \mathrm{I}$ and $\mathrm{Cl} / \mathrm{I})$ miscibility. ${ }^{90}$

\subsection{Metal Doping/Alloying}


Doping/alloying is a common method to tune the bandgap and/or change the direct/indirect nature of bandgap of semiconductors. For HDPs, two different B-site metal ions provide more degrees of freedom in selecting the suitable doping/alloying ions for HDPs. In general, it includes isovalent (monovalent and trivalent) and heterovalent (bivalent and tetravalent) metal doping/alloying.

\subsubsection{Monovalent Metal Doping/Alloying}

The first successful example was a dilute $\mathrm{Tl}^{+}$doped $\mathrm{HDPs} \mathrm{Cs}_{2} \mathrm{AgBiBr}_{6}$ with a $0.1 \mathrm{eV}$ bandgap reduction, developed by Karunadasa and coworkers in 2017. Interestingly, calculation results indicated that $\mathrm{Ti}^{+}$doping could convert the indirect bandgap to a direct bandgap. This was explained by hybridization of $\mathrm{Tl} \mathrm{p}$ states with $\mathrm{Br} \mathrm{p}$ and $\mathrm{Bi} \mathrm{p}$ orbitals with decreasing the energy of the $\mathrm{CBM}$ at $\Gamma$ and creating a direct bandgap (Figure 3.4a). ${ }^{91}$ It is noted that $\mathrm{Tl}$ is about ten times more toxic than $\mathrm{Pb}$, which should be considered with respect to any practical application of Tl-doped double perovskites. Later, we developed a nontoxic and more efficient dopant $\mathrm{Cu}^{+}$, which can broaden the absorption profiles of $\mathrm{Cs}_{2} \mathrm{AgBiBr}_{6}$ from $\sim 610$ to $\sim 860 \mathrm{~nm}$ (Figure 3.4b).${ }^{92} \mathrm{We}$ also found that the strong near-infrared range (NIR) absorption of $\mathrm{Cu}$-doped $\mathrm{Cs}_{2} \mathrm{AgBiBr}_{6}$ is related to the sub-bandgap states (defect states) in the bandgap. More interestingly, these subbandgap states can generate considerable band carriers through NIR excitation (Figure 3.4c), implying a great potential application of $\mathrm{Cu}$-doped $\mathrm{Cs}_{2} \mathrm{AgBiBr}_{6}$ in NIR photodetector. Recently, a series of $\mathrm{Ag}^{+}$doped/alloyed $\mathrm{Cs}_{2} \mathrm{NaFeCl}_{6}$ perovskite single crystals have been synthesized by partial/complete substitution of monovalent $\mathrm{Na}^{+}$with $\mathrm{Ag}^{+} \cdot{ }^{93}$ As shown in Figure 3.4d, the absorption edge of $\mathrm{Cs}_{2} \mathrm{NaFeCl}_{6}$ was significantly broadened from $600 \mathrm{~nm}$ to the near-infrared range (800nm) after Ag-doping/alloying. Meanwhile, calculations show that the incorporation of $\mathrm{Ag}^{+}$could increase the electron mobility and carrier diffusion length. 

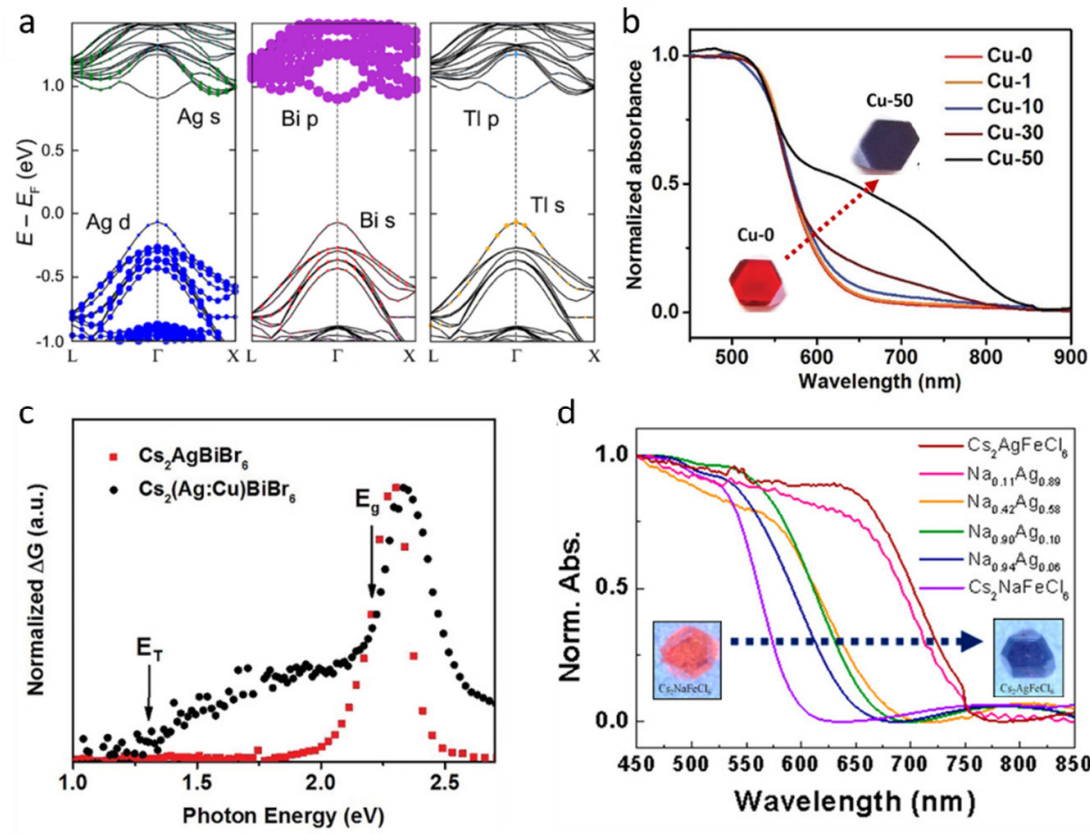

Figure 3.4 (a) Band structures of $\mathrm{Cs}_{2}\left(\mathrm{Ag}_{1-\mathrm{a}} \mathrm{Bi}_{1-\mathrm{b}}\right) \mathrm{Tl}_{\mathrm{x}} \mathrm{Br}_{6}(\mathrm{x}=0.06)$ for substitution of $\mathrm{Tl}^{+}$for $\mathrm{Ag}^{+}$. Metal orbital characters of the bands are shown in color. ${ }^{91}$ (b) Normalized UV-vis absorption of pristine $\mathrm{Cs}_{2} \mathrm{AgBiBr}_{6}(\mathrm{Cu}-0)$ and $\mathrm{Cu}$-doped $\mathrm{Cs}_{2} \mathrm{AgBiBr}_{6}(\mathrm{Cu}-1, \mathrm{Cu}-10, \mathrm{Cu}-30, \mathrm{Cu}-50)$ double perovskites. The inset shows the optical images of $\mathrm{Cu}-0$ and $\mathrm{Cu}$-doped $\mathrm{Cu}-50 .{ }^{92}$ (c) The photoconductance spectra of the $\mathrm{Cs}_{2} \mathrm{AgBiBr}_{6}(\mathrm{Cu}-0)$ and $\mathrm{Cs}_{2}(\mathrm{Ag}: \mathrm{Cu}) \mathrm{BiBr}_{6}(\mathrm{Cu}-50)$ single crystals at room temperature. ${ }^{92}(\mathrm{~d}) \mathrm{UV}$-vis spectra of the $\mathrm{Cs}_{2} \mathrm{Ag}_{\mathrm{x}} \mathrm{Na}_{1-\mathrm{x}} \mathrm{FeCl}_{6}(\mathrm{x}=0,0.06,0.10,0.58,0.89,1)$ single crystals. The inset shows the optical images of $\mathrm{Cs}_{2} \mathrm{NaFeCl}_{6}$ and $\mathrm{Cs}_{2} \mathrm{AgFeCl}_{6}{ }^{93}$

In addition to bandgap narrowing, another possible merit of metal doping/alloying is to bring attractive emission properties. A typical example is $\mathrm{Na}^{+}$doped $\mathrm{Cs}_{2} \mathrm{AgInCl}_{6}$ with a direct bandgap. It is worth mentioning that pure $\mathrm{Cs}_{2} \mathrm{AgInCl}_{6}$ suffers from a low PLQY $(<1 \%)$ due to the parity forbidden transition from the CBM to VBM. Fortunately, Tang and coworkers demonstrated that the monovalent $\mathrm{Na}^{+}$doping/alloying can break the parity forbidden transition in $\mathrm{Cs}_{2} \mathrm{AgInCl}_{6}$ by manipulating the symmetry of electron wavefunction at the Ag site (Figure 3.5a) ${ }^{68}$ Meanwhile, incorporated $\left[\mathrm{NaCl}_{6}\right]^{5-}$ octahedra serve as barriers to confine the spatial distribution of the STEs (Figure 3.5b), thus enhancing the electron and hole orbital overlap and increasing the transition dipole moment. As a result, the PL intensity of white emission was enhanced by three orders of magnitude after $\mathrm{Na}$ doping, as shown in Figure 3.5c. 

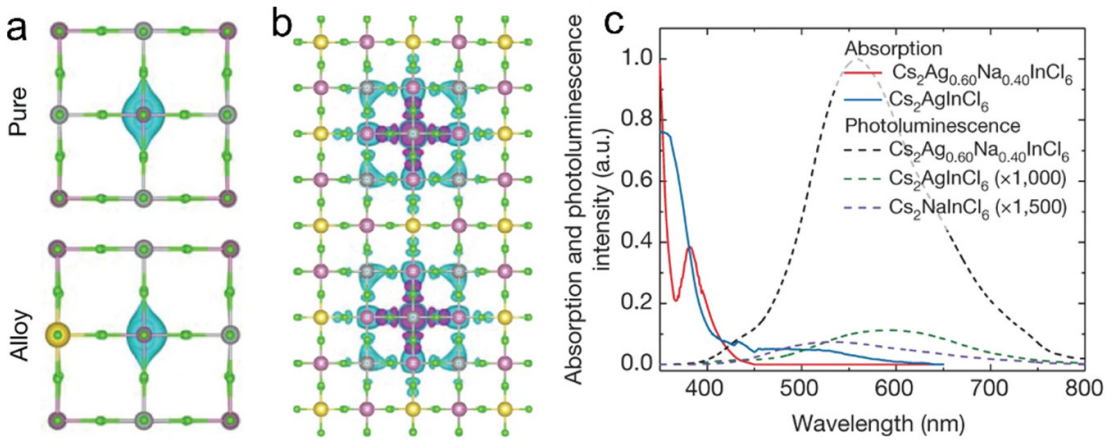

Figure 3.5 (a) Parity change of the electron wavefunction (isosurface at the Ag site) of the STE before and after Na incorporation. ${ }^{68}$ (b) Configuration showing the strengthened STE confinement by the surrounding $\left[\mathrm{NaCl}_{6}\right]^{5-}$ octahedra. The STEs are confined within two lattice parameters surrounded by the $\left[\mathrm{NaCl}_{6}\right]^{5-}$ octahedra. In (a) and (b), the cyan and magenta isosurfaces denote electrons and holes, respectively. ${ }^{68}$ (c) Optical absorption (solid lines) and photoluminescence (dashed lines) spectra of pure $\mathrm{Cs}_{2} \mathrm{AgInCl}_{6}$ and $\mathrm{Cs}_{2} \mathrm{Ag}_{0.60} \mathrm{Na}_{0.40} \mathrm{InCl}_{6}{ }^{68}$

\subsubsection{Trivalent Metal Doping/Alloying}

Compared with monovalent doping/alloying, trivalent metal doping/alloying is more widely used in HDPs since more than 34 elements can occupy the $\mathrm{B}^{3+}$ site in HDPs. An example is that partial substitution of $\mathrm{Bi}^{3+}$ with $\mathrm{Tl}^{3+}$ can reduce the bandgap of $\mathrm{Cs}_{2} \mathrm{Ag}$ $\mathrm{BiBr}_{6}$ by $0.8 \mathrm{eV}$, while the band gap remained indirect (Figure 3.6a). ${ }^{91}$ Mitzi and coworkers employed nontoxic $\mathrm{Sb}^{3+}$ and $\mathrm{In}^{3+}$ to tune the bandgap of $\mathrm{Cs}_{2} \mathrm{AgBiBr}_{6} .{ }^{94} \mathrm{As}$ shown in Figure 3.6 b,c, up to $75 \% \mathrm{In}^{3+}$ can be alloyed in the $\mathrm{Cs}_{2} \mathrm{AgBiBr}_{6}$ lattice with increased bandgap to $2.27 \mathrm{eV}$, and up to $37.5 \% \mathrm{Sb}^{3+}$ can be alloyed in the lattice with decreased the bandgap to $1.86 \mathrm{eV}$. The different directions (decrease or increase) of bandgap changes were explained by the different band structures caused by different atomic configurations of $\mathrm{Sb}^{3+}$ and $\mathrm{In}^{3+}$. Interestingly, $\mathrm{Sb}^{3+}$ was also employed to narrow the bandgap of $\mathrm{Cs}_{2} \mathrm{AgBiBr}_{6}$ thin films with an enhanced PCE compared with that of unalloyed $\mathrm{Cs}_{2} \mathrm{AgBiBr}_{6}$ solar cells. ${ }^{95}$

Recently, transition metal $\mathrm{Fe}^{3+}$ is also attractive for doped/alloyed HDPs. For instance, our group doped magnetic element $\mathrm{Fe}^{3+}$ into optoelectronic double perovskite $\mathrm{Cs}_{2} \mathrm{AgBiBr}_{6}$ with the formation of halide perovskite alloys $\mathrm{Cs}_{2} \mathrm{Ag}(\mathrm{Bi}: \mathrm{Fe}) \mathrm{Br}_{6}($ Figure 3.6 d) ${ }^{96}$ Afterwards, we have successfully alloyed $\mathrm{Fe}^{3+}$ into the benchmark $\mathrm{Cs}_{2} \mathrm{AgInCl}_{6}$, tuning the bandgap of $\mathrm{Cs}_{2} \mathrm{AgIn}_{1-\mathrm{x}} \mathrm{FexCl}_{6}(\mathrm{x}=0-1)$ from $2.8 \mathrm{eV}$ to $1.6 \mathrm{eV}$ (Figure 3.6 e,f).${ }^{67} \mathrm{We}$ further reveal the atomic-level structure of $\mathrm{Cs}_{2} \mathrm{AgIn}_{1-\mathrm{x}} \mathrm{Fe}_{\mathrm{x}} \mathrm{Cl}_{6}$ alloys using solid state NMR measurements. Our results indicate that $\mathrm{Fe}^{3+}$ substitutes $\mathrm{In}^{3+}$ in the lattice with the formation of $\left[\mathrm{FeCl}_{6}\right]^{3-} \cdot\left[\mathrm{AgCl}_{6}\right]^{5-}$ domains, which grow larger gradually as the 
$\mathrm{Fe}^{3+}$ concentration increases. These domains could be further connected to form microscopically segregated $\mathrm{Fe}^{3+}$-rich phases in the double perovskite alloys. The ferromagnetic or antiferromagnetic properties $\mathrm{Fe}^{3+}$ potentially bring the application of $\mathrm{Fe}^{3+}$ based HDPs for spintronics.
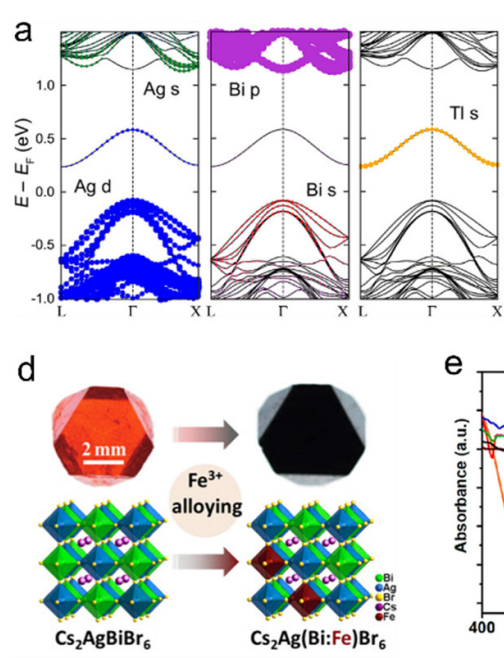
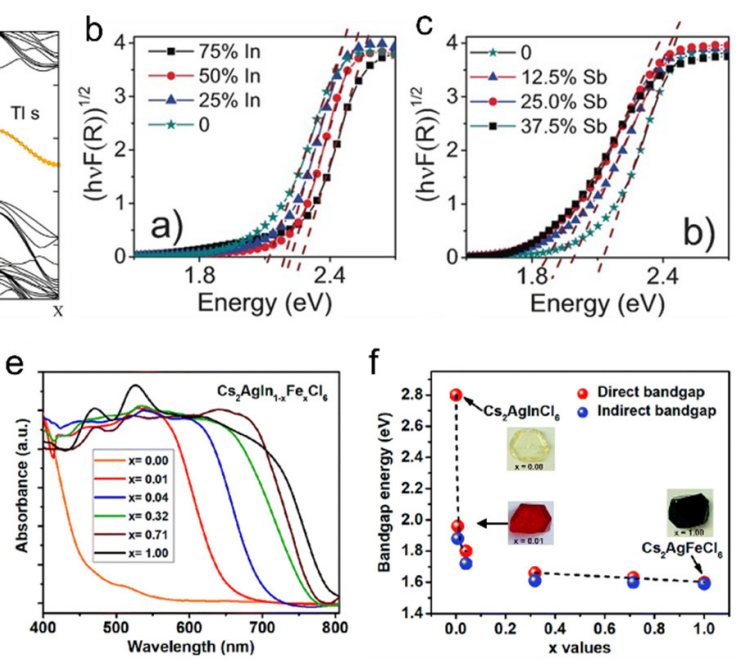

Figure 3.6 (a) Band structures of $\mathrm{Cs}_{2}\left(\mathrm{Ag}_{1-\mathrm{a}} \mathrm{Bi}_{1-\mathrm{b}}\right) \mathrm{Tl}_{\mathrm{x}} \mathrm{Br}_{6}(\mathrm{x}=0.06)$ for substitution of $\mathrm{Tl}^{3+}$ for $\mathrm{Bi}^{3+} \cdot{ }^{91}$ Metal orbital characters of the bands are shown in color. Indirect Tauc plots of (b) $\mathrm{Cs}_{2} \mathrm{AgBi}_{(1-\mathrm{x})} \mathrm{In}_{\mathrm{x}} \mathrm{Br}_{6}$ and (c) $\mathrm{Cs}_{2} \mathrm{AgBi}_{(1-\mathrm{x})} \mathrm{Sb}_{\times} \mathrm{Br}_{6} .{ }^{94}$ (d) Photographs and crystal structures of double perovskites $\mathrm{Cs}_{2} \mathrm{AgBiBr}_{6}$ and $\mathrm{Fe}$-doped $\mathrm{Cs}_{2} \mathrm{AgBiBr}_{6}{ }^{96}$ (e) Normalized UV-vis absorption spectra of $\mathrm{Cs}_{2} \mathrm{AgIn}_{1-\mathrm{x}} \mathrm{Fe}_{\mathrm{x}} \mathrm{Cl}_{6}$ ( $\mathrm{x}=0.00,0.01,0.04,0.32,0.71$ and 1.00) crystals. $^{67}$ (f) Bandgaps of $\mathrm{Cs}_{2} \mathrm{AgIn}_{1-\mathrm{x}} \mathrm{Fe}_{\mathrm{x}} \mathrm{Cl}_{6}$ extracted by linear fits to both direct bandgap and indirect bandgap Tauc plots. Inset: Photographs of $\mathrm{Cs}_{2} \mathrm{AgInCl}_{6}, \mathrm{Cs}_{2} \mathrm{AgIn}_{0.99} \mathrm{Fe}_{0.01} \mathrm{Cl}_{6}$ and $\mathrm{Cs}_{2} \mathrm{AgFeCl}_{6}$ crystals. ${ }^{67}$

Along with the bandgap changes, the direct and indirect nature of the band gap in HDPs could also be changed after trivalent metal doping. In 2017, McQueen and coworkers presented an alloying strategy for tuning the convergence of direct and indirect bandgaps based on chemical adjustment of the s- and p-orbital character of the CBM. ${ }^{59}$ As shown in Figure 3.7a, with increasing percentage of $\mathrm{Sb}^{3+}$ in $\mathrm{Cs}_{2} \mathrm{AgSb}_{\mathrm{x}} \mathrm{In}_{(1-\mathrm{x})} \mathrm{Cl}_{6}$ solid solutions, the contribution of Sb-5 $\mathrm{s}^{2}$ state to the valence bands increases and that of In$5 \mathrm{~s}^{0}$ state to the conduction bands decreases. Then, the direct to indirect band gap transition occurred at $\mathrm{x}=0.4$. Recently, a series of $\mathrm{Bi}^{3+}$ alloyed $\mathrm{Cs}_{2} \mathrm{Bi}_{1-\mathrm{x}} \mathrm{In}_{\mathrm{x}} \mathrm{AgCl}_{6} \mathrm{HDPs}$ have been proposed, and these alloys span the indirect to direct bandgap modification (Figure 3.7b). ${ }^{97}$ DFT calculations indicated that $\mathrm{CBM}$ is moved from the $\mathrm{L}$ symmetry point to near the $\Gamma$ point after $75 \% \mathrm{In}^{3+}$ alloying, composing a direct $\Gamma-\Gamma$ band gap, as shown in 
Figure 3.7c. Additionally, these alloys are capable of broadband white light PL emission upon ultraviolet excitation, and the maximum PLQY reached $34 \pm 4 \%$ for $\mathrm{Cs}_{2} \mathrm{Bi}_{0.085} \mathrm{In}_{0.915} \mathrm{AgCl}_{6}$, which is promising for solid-state white-light emitting applications.
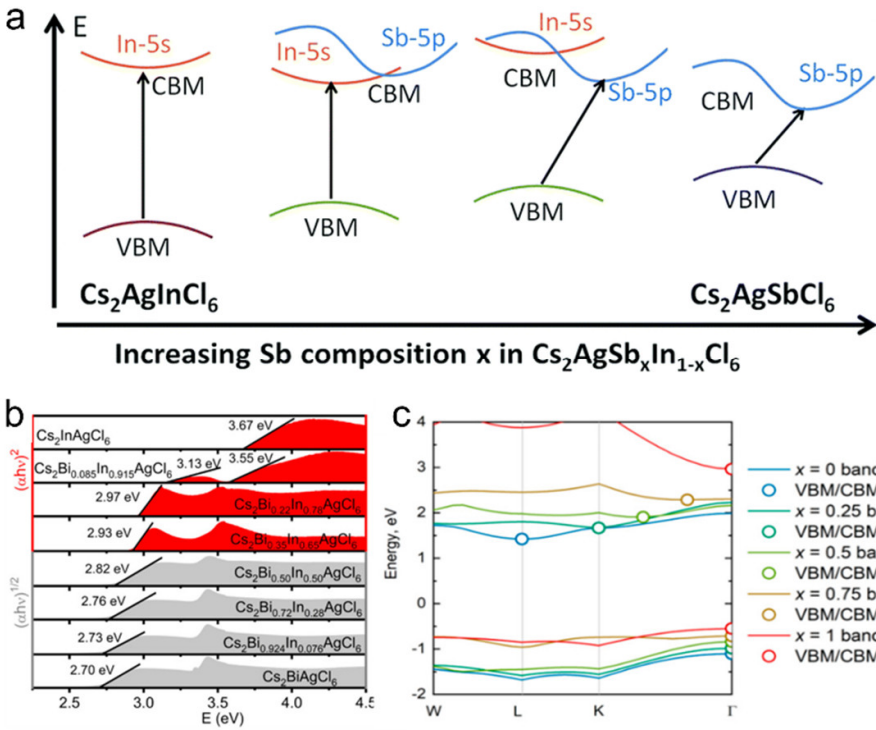

$\mathrm{Cs}_{2} \mathrm{AgSbCl}_{6}$

Increasing Sb composition $\mathrm{x}$ in $\mathrm{Cs}_{2} \mathrm{AgSb}_{x} \mathrm{In}_{1-\mathrm{x}} \mathrm{Cl}_{6}$

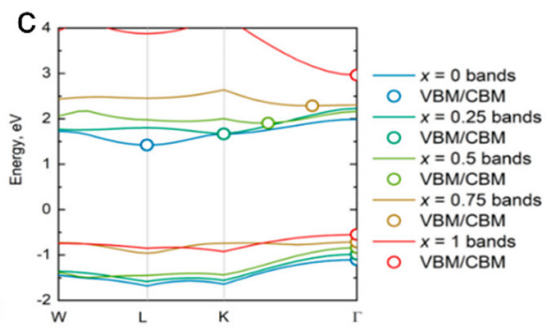

Figure 3.7 (a) The schematic representation of the proposed band diagram of $\mathrm{Cs}_{2} \mathrm{AgSb}_{\mathrm{x}} \mathrm{In}_{1-\mathrm{x}} \mathrm{Cl}_{6} .{ }^{59}$ (b) Tauc plots showing indirect $(\mathrm{x} \leq 0.5$, gray) and direct $(\mathrm{x}>0.50$, red) band gaps (b) for $\mathrm{Cs}_{2} \mathrm{Bi}_{1-\mathrm{x}} \mathrm{In}_{\mathrm{x}} \mathrm{AgCl}_{6}(0 \leq \mathrm{x} \leq 1) .{ }^{97}$ (c) Indirect to direct band gap transition of $\mathrm{Cs}_{2} \mathrm{Bi}_{1-\mathrm{x}} \mathrm{In}_{\mathrm{x}} \mathrm{AgCl}_{6}$ by using the calculated electronic band structure. ${ }^{97}$

Rare-earth ions with trivalent can also be introduce into HDPs as an isovalent fashion. For example, lanthanide ions $\left(\mathrm{Yb}^{3+}\right.$ and $\left.\mathrm{Er}^{3+}\right)$ have been introduced to replace $\mathrm{In}^{3+}$ in $\mathrm{Cs}_{2} \mathrm{AgInCl}_{6}$ nanocrystals, and the characteristic $\mathrm{f}-\mathrm{f}$ transition emission of $\mathrm{Yb}^{3+}$ at $996 \mathrm{~nm}$ and $\mathrm{Er}^{3+}$ dopants at $1537 \mathrm{~nm}$ have been observed. ${ }^{98}$ Recently, Nag and co-workers further codoped $\mathrm{Bi}^{3+}$ in $\mathrm{Yb}^{3+} / \mathrm{Er}^{3+}$ doped $\mathrm{Cs}_{2} \mathrm{AgInCl}_{6}$ to significantly enhance the intensity of near-infrared emission. ${ }^{99}$ This is possibly due to Bi-codoping can decrease the excitation energy that leads to the absorption of lower-energy photons. The excitation energy is then transferred to $\mathrm{Er}^{3+}$ and $\mathrm{Yb}^{3+}$ f electrons, which de-excite by emitting light at 1540 and $994 \mathrm{~nm}$, respectively (Figure 3.8a-c). This codoping strategy may open a new chapter in the application of halide double perovskites in infrared detection and human sensing. 

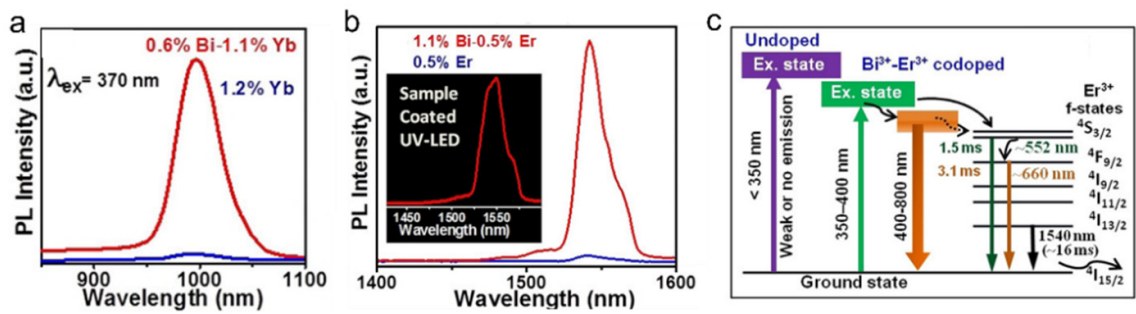

Figure 3.8 $\mathrm{PL}$ spectra of powder samples $\left(\mathrm{Yb}^{3+}\right.$-doped or $\mathrm{Bi}^{3+}-\mathrm{Yb}^{3+}$ codoped $\mathrm{Cs}_{2} \mathrm{AgInCl}_{6}$ (a) and $\mathrm{Er}^{3+}$-doped or $\mathrm{Bi}^{3+}-\mathrm{Er}^{3+}$ codoped $\left.\mathrm{Cs}_{2} \mathrm{AgInCl}_{6}(\mathrm{~b})\right)$ mixed with $\mathrm{BaSO}_{4}$ for quantitative comparisons of intensity. ${ }^{99}$ Excitation at $370 \mathrm{~nm}$. Inset figure in (b): NIR emission from $\mathrm{Bi}^{3+}-\mathrm{Er}^{3+}$ codoped $\mathrm{Cs}_{2} \mathrm{AgInCl}_{6}$ coated on a commercial UV LED. (c) Comparing optical absorption and emission processes in $\mathrm{Bi}^{3+}-\mathrm{Er}^{3+}$ codoped $\mathrm{Cs}_{2} \mathrm{AgInCl}_{6}$ with that of the undoped sample. Very weak or no emission is observed for undoped $\mathrm{Cs}_{2} \mathrm{AgInCl}_{6}{ }^{99}$

\subsubsection{Heterovalent Metal Doping/Alloying}

Apart from isovalent (mono--, trivalent--) doping, heterovalent doping (bivalent) has also been investigated to enhance the absorption and emission properties of HDPs. For example, Karunadasa and co-workers demonstrated that $\mathrm{Sn}^{2+} / \mathrm{Sn}^{4+}$ doping in $\mathrm{Cs}_{2} \mathrm{Ag}$ $\mathrm{BiBr}_{6}$ resulted in a band gap reduction of up to $0.5 \mathrm{eV}$ (Figure 3.9a). ${ }^{100}$ The reduced bandgap relates to the introduction of Sn impurity bands below the CBM of the host material, as indicated by DFT calculations. $\mathrm{Sn}^{2+}$ replaces the position of $\mathrm{Ag}^{+}$while $\mathrm{Sn}^{4+}$ replaces the position of $\mathrm{Bi}^{3+}$, collectively generating $\mathrm{Ag}^{+}$vacancies to maintain charge neutrality, as shown in Figure 3.9b. Another example is $\mathrm{Cu}^{2+}$ doped $\mathrm{Cs}_{2} \mathrm{AgSbCl}_{6}$ with reduced band gap from approximately $2.6 \mathrm{eV}$ to approximately $1 \mathrm{eV}$ (Figure 3.9c). ${ }^{101}$.
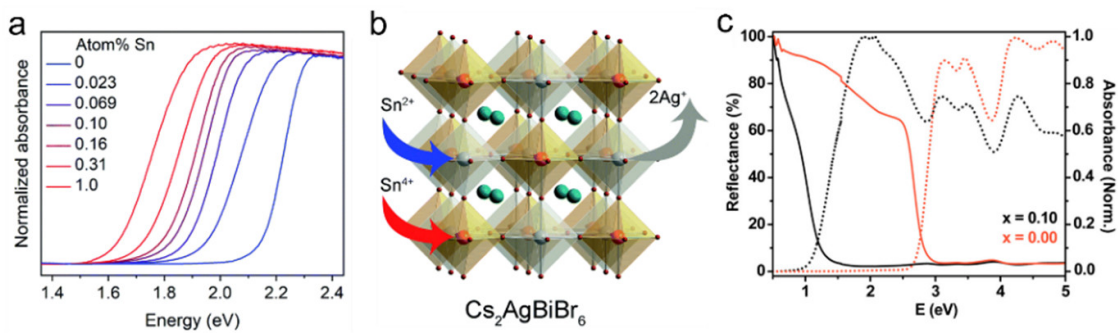

Figure 3.9 (a) UV-vis absorbance spectra of crystals of $\mathrm{Cs}_{2} \mathrm{AgBiBr}_{6}$ and $\mathrm{Sn}$-alloyed $\mathrm{Cs}_{2} \mathrm{AgBiBr}_{6}$ converted from diffuse reflectance spectra using the Kubelka-Munk transformation. ${ }^{100}$ (b) The crystal structure of $\mathrm{Cs}_{2} \mathrm{AgBiBr}_{6}$ and an illustration of the substitution mechanism of $\mathrm{Sn}$ in crystals to yield $\mathrm{Sn}$-alloyed $\mathrm{Cs}_{2} \mathrm{AgBiBr}_{6}$. Orange, gray, turquoise, and brown spheres represent $\mathrm{Bi}, \mathrm{Ag}, \mathrm{Cs}$, and $\mathrm{Br}$ atoms, respectively. ${ }^{100}$ (c) UV-vis diffuse reflectance (solid lines) and normalized absorption (dotted lines) spectra for $\mathrm{Cs}_{2} \mathrm{SbAgCl}_{6}$ parent $(\mathrm{x}=0.00)$ and the maximum $\mathrm{Cu}^{2+}$-doped $(\mathrm{x}=$ $0.10)$ materials. ${ }^{101}$ 
The $\mathrm{Mn}^{2+}$ doping/alloying strategy provide an efficient method to synthesize orangered emitting phosphors based on the ${ }^{4} \mathrm{~T}_{1-}{ }^{6} \mathrm{~A}_{1}$ transition of octahedral $\mathrm{Mn}^{2+}$, which is largely insensitive to structure of the host material. In 2018, Nag and co-workers first reported the $\mathrm{Mn}^{2+}$ doping/alloying in $\mathrm{Cs}_{2} \mathrm{AgInCl}_{6}$, which yields a red color emission (Figure 3.10a) ${ }^{82}$ Later, $\mathrm{Mn}^{2+}$ was also doped into $\mathrm{Cs}_{2} \mathrm{NaBiCl}_{6}$, leading a bright orangered emission centered at 590nm. ${ }^{102}$ Meanwhile, a new family of $\mathrm{Mn}^{2+}$-doped $\mathrm{Cs}_{2} \mathrm{NaBi}_{1}$ ${ }_{\mathrm{x}} \mathrm{In}_{\mathrm{x}} \mathrm{Cl}_{6}$ crystals have been synthesized with a strong orange-red emission in the range of 577 to $585 \mathrm{~nm} .{ }^{70}$ As shown in Figure 3.10b all PLE spectra are corresponding to the transitions of $\mathrm{Mn}^{2+}$ from ground states of ${ }^{6} \mathrm{~A}_{1}\left({ }^{6} \mathrm{~S}\right)$ to excited states of ${ }^{4} \mathrm{~T}_{1}\left({ }^{4} \mathrm{P}\right),{ }^{4} \mathrm{~T}_{2}\left({ }^{4} \mathrm{D}\right)$, and ${ }^{4} \mathrm{~T}_{2}\left({ }^{4} \mathrm{G}\right)$, respectively. Meanwhile, the PL emission intensities gradually increased with the increase of $\mathrm{In}^{3+}$ concentration and reached the maximum in the $\mathrm{Cs}_{2} \mathrm{NaBi}_{0.8} \mathrm{In}_{0.2} \mathrm{Cl}_{6}$.
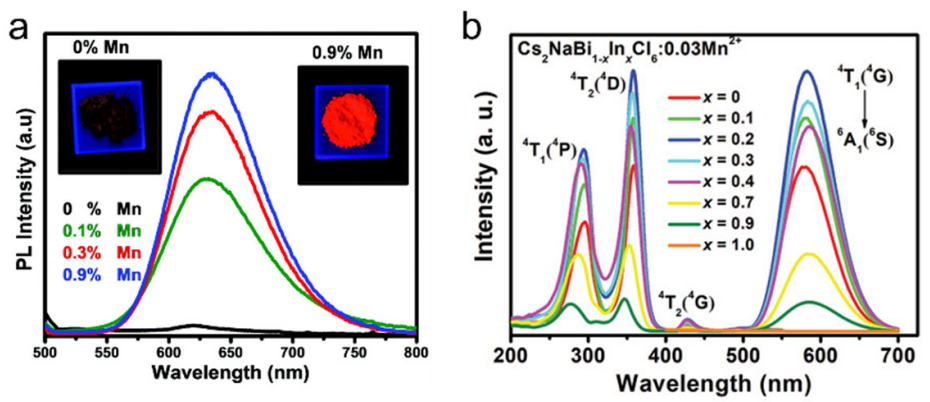

Figure 3.10 (a) PL spectra of Mn-doped $\mathrm{Cs}_{2} \mathrm{AgInCl}_{6}$ with different Mn contents, after excitation with $340 \mathrm{~nm}$ light. Insets show the photographs of luminescence from the powder samples under UV light. ${ }^{82}$ (b) PLE and PL spectra of $\mathrm{Cs}_{2} \mathrm{NaBi}_{1-\mathrm{x}} \mathrm{In}_{\mathrm{x}} \mathrm{Cl}_{6}: 0.03 \mathrm{Mn}^{2+} .{ }^{70}$

In conclusion, metal doping is a simple yet efficient strategy to modify the band structure of host HDPs, which can turn the bandgap values and/or change the indirect and direct bandgap nature. Meanwhile, the emission properties could also be changed after metal doping due to the breaking the parity-forbidden transition between bandgap or emission from dopant ions ( ovalent and trivalent) and heterovalent (bivalent and Tetravalent) metal ions can be doped/alloyed into double perovskites, the considerable compositional diversity of double perovskites has been further expanded. This metal doping/alloying strategy provides more freedom and opportunity to search suitable compounds for high efficiency optoelectronic and/or multifunctional devices.

\subsection{Crystallization Control}


The optical and electronic properties of HDPs are highly correlated with the crystallization processes. The hydrothermal method is widely used to synthesize high-quality HDPs. In this approach, the crystallization process can be easily controlled by tuning the concentration of the precursor solution. For instance, the $\mathrm{Cs}_{2} \mathrm{AgInCl}_{6}$ single crystals grown from $0.076 \mathrm{M}$ solution show higher transparency, lower trap density and higher carrier mobility than those grown from $0.05 \mathrm{M}$ solution. ${ }^{65}$ With increasing volumes of solvent $(\mathrm{HCl})$ from $0.5 \mathrm{~mL}$ to $1.5 \mathrm{~mL}$, the color of obtained $\mathrm{Cs}_{2} \mathrm{AgSbCl}$ powders can be continuously changed from yellow to near black (Figure 3.11a), ${ }^{103}$ related to the different magnitude of reflectance for visible light (the dark sample absorbs more visible light) (Figure 3.11b) and the optical bandgap changing from $2.61 \mathrm{eV}$ to $2.24 \mathrm{eV}$ (Figure 3.11c). The underlying reason for the bandgap changes is possibly the formation of antisite defect, established using DFT calculations. The calculated bandgap with Ag-Sb anti-site structures shows a decreased bandgap compared with that of Ag-Sb balanced structure, which is consistent with the bandgap narrowing in these powders, indicating that the darker samples possibly form more Ag-Sb defects (Ag-Sb disorder) during the crystallization process.
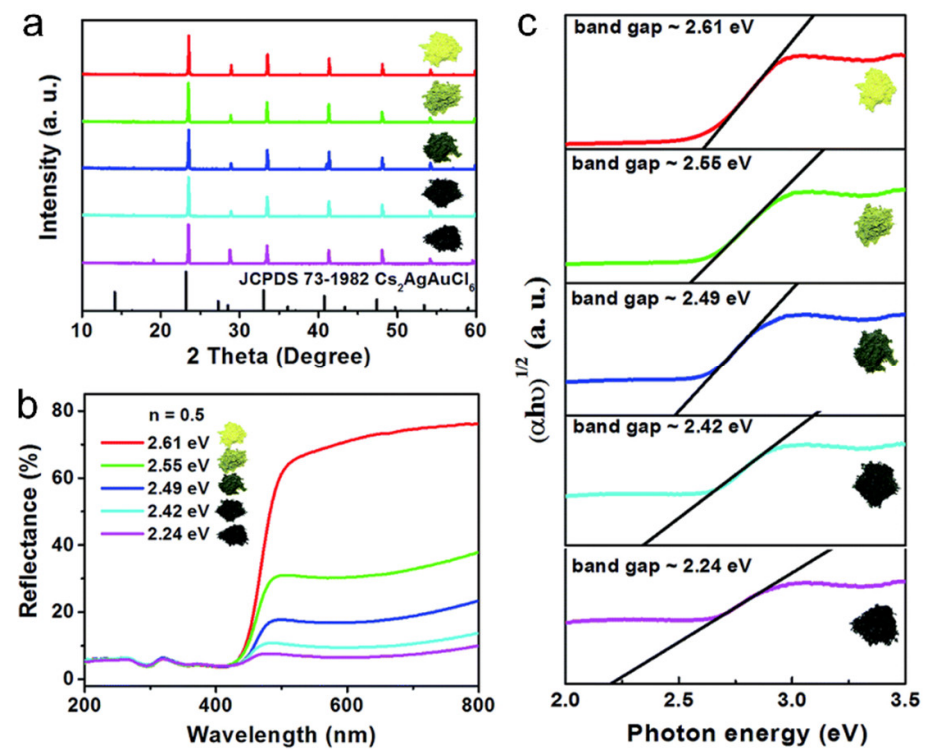

Figure 3.11 Powder XRD patterns (a), UV-vis diffuse reflectance spectra (b), and Tauc plots (c) of different as-prepared $\mathrm{Cs}_{2} \mathrm{AgSbCl}_{6}$ obtained by using different amounts of $\mathrm{HCl}(0.5,0.75,1.0$, 1.25 and $1.5 \mathrm{~mL}$ ) with variable visible light absorbance. ${ }^{103}$

Besides the concentration, additive-assisted crystallization strategy was adopted to synthesize double perovskites with different bandgaps. For example, the absorption 
band of $\mathrm{Cs}_{2} \mathrm{AgBiBr}_{6}$ single crystals from the phenylethylamine bromide (PEABr) additive precursor (PEA-Cs2 $\mathrm{AgBiBr}_{6}$ ) exhibits a slight blueshift compared with the pristine $\mathrm{Cs}_{2} \mathrm{AgBiBr}_{6}$ (Figure 3.12a). ${ }^{104}$ This blueshift can be explained by the enlarged bandgap of the PEA-Cs2 $\mathrm{AgBiBr}_{6}$ crystals caused by the increased degree of Ag-Bi order, possibly due to that the selective coordination of the functionalized phenyl and ammonium ions in $\mathrm{PEA}^{+}$enables the formation of alternatively ordered arrangement of $\mathrm{Ag}^{+}$and $\mathrm{Bi}^{3+}$ ions, as shown in Figure 3.12b. Moreover, the PEA-Cs $2 \mathrm{AgBiBr}_{6}$ crystals show reduced defect density and enhanced carrier mobility, which consequently promotes its application in an X-ray detector.
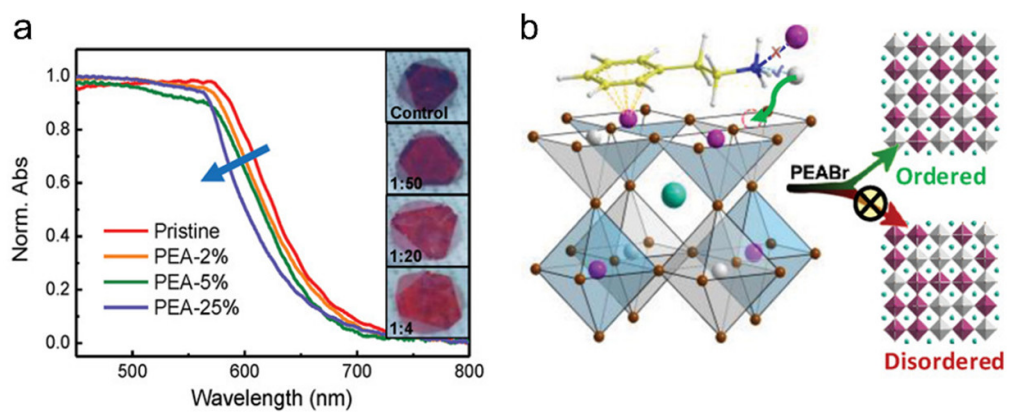

Figure 3.12 (a) UV-vis absorption spectra of pristine $\mathrm{Cs}_{2} \mathrm{AgBiBr} 6$ and $\mathrm{PEA}-\mathrm{Cs}_{2} \mathrm{AgBiBr} 6$ single crystals with different PEABr concentration. ${ }^{104}$ (b) Schematic view of the PEA-induced ordered arrangement of $\mathrm{Ag}^{+}$and $\mathrm{Bi}^{3+}$ ions in $\mathrm{Cs}_{2} \mathrm{AgBiBr}_{6}$ single crystals. ${ }^{104}$

Slow evaporation of precursor solution is another well-known technique to grow perovskite single crystals. In this approach, we found that the evaporation temperature has a significant effect on the optical bandgaps of $\mathrm{Cs}_{2} \mathrm{AgBiBr}_{6}$ single crystals. As shown in Figure 3.13a,b, the $\mathrm{Cs}_{2} \mathrm{AgBiBr} 6$ single crystals synthesized from high evaporation temperature $\left(150{ }^{\circ} \mathrm{C}\right.$, DP-150) exhibit darker color than those synthesized from low evaporation temperature $\left(60^{\circ} \mathrm{C}, \mathrm{DP}-60\right)$, implying a wider absorption range. ${ }^{105} \mathrm{The}$ absorption broadening is further confirmed by UV-vis absorbance spectra, in which the absorption edge of DP-150 crystals shows an obvious red-shift of approximately $90 \mathrm{~nm}$ compared with the DP-60 crystal (Figure 3.13c). More importantly, the PL spectrum of DP-150 exhibits an obvious red shift compared with that of DP-60 (Figure 3.13d), which is consistent with the red shift in absorption spectra, indicating that the absorption edge shift results from the band gap narrowing effect. It is worth noting that the bandgap of DP-150 crystal calculated from the Tauc plots is approximately $1.72 \mathrm{eV}$, which is the lowest value among all the reports for $\mathrm{Cs}_{2} \mathrm{AgBiBr}_{6}$ at ambient conditions. 
a

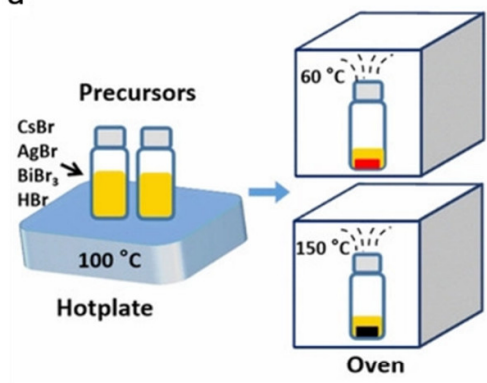

C

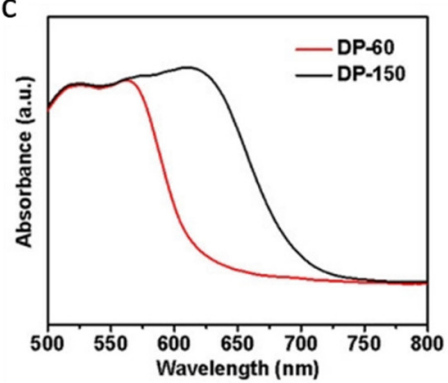

b

DP-60 DP-150

d
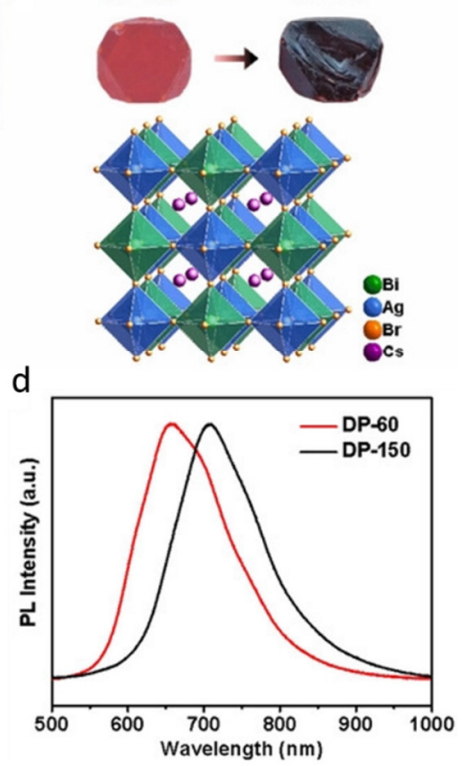

Figure 3.13 (a) Procedure for the crystal growth of DP-60 and DP-150. ${ }^{105}$ (b) Optical images and the crystal structure of the DP-60 and DP-150 single crystals. ${ }^{105}$ Normalized UV/Vis absorption spectra (c) and PL spectra (d) of DP-60 and DP-150 single crystals. ${ }^{105}$

A possible explanation of the observed band gap narrowing is an increased level of $\mathrm{Ag}-\mathrm{Bi}$ disorder in DP-150 as compared to DP-60. As shown in Figure 3.14, our functional theory (DFT) calculations indicate that a low-level disorder would introduce an acceptor-like defect state of $\mathrm{Bi}-\mathrm{p} / \mathrm{Br}-\mathrm{p}$ character into the band gap. As the degree of disorder further increases, this defect state moves deeper into the gap and another, progressively broader set of defect states are formed below the conduction band edge. ${ }^{105}$ 


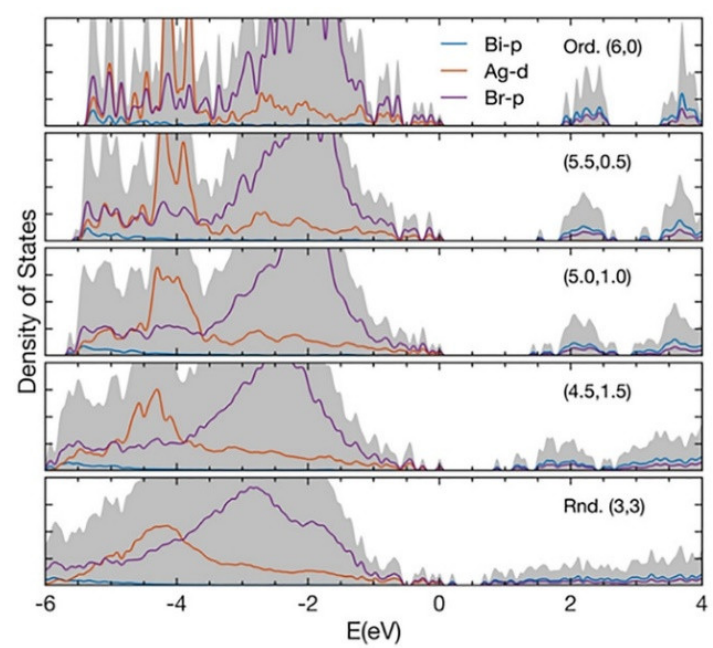

Figure 3.14 Calculated total and partial electronic density of states for a set of $\mathrm{Cs}_{2} \mathrm{AgBiBr}_{6}$ structures with varying degrees of $\mathrm{Ag}-\mathrm{Bi}$ disorder. The energy, $E$, is set to zero at the highest occupied state for each separate structure. ${ }^{105}$

In all, the optical bandgap of HDPs can be modified by the crystallization control method, which can be affected by precursor concentration, additives, and different evaporation temperatures. The main reason is possibly related to different degrees of B-site disorder in the crystal under different crystallization processes. Additionally, several first-principle studies indicated that increasing B-site disorder has a large impact on the band structure and decreases the band gap. ${ }^{106,107}$ These investigations indicate that controlling the degree of B-site disorder by adjusting the crystallization process could be an effective way for band structure engineering of the HDPs for various applications.

\subsection{Structure Engineering}

The optical and electronic properties of HDPs are also related to the lattice structure, which can be tuned by physical treatment, such as high pressure or high temperature treatment. Among them, high pressure treatment usually introduces lattice contraction, while high temperature treatment always produces lattice expansion. Interestingly, the opposite structural behavior during the different physical treatment can cause similar bandgap changes with different mechanisms.

\subsubsection{High-Pressure Treatment}

High-pressure technology is a widespread and controllable method to continuously modify the lattice structure and electronic configuration of materials. In 2017, Zou and co-workers investigated the structure-bandgap relationship in $\mathrm{HDP} \mathrm{Cs}_{2} \mathrm{AgBiBr}_{6}$ under 
high pressure for the first time. ${ }^{108}$ As shown in Figure 3.15a, in the low-pressure region $(<3 \mathrm{GPa})$, the bandgap of $\mathrm{Cs}_{2} \mathrm{AgBiBr}_{6}$ showed a slight narrowing, ascribed to the shrinkage of $\mathrm{Bi}-\mathrm{Br}-\mathrm{Ag}$ bonds and the homogenous octahedral contraction (which promote the overlap of elemental orbitals). With increasing pressure from $3.0 \mathrm{GPa}$ to $4.0 \mathrm{GPa}$, the cubic phase of $\mathrm{Cs}_{2} \mathrm{AgBiBr}_{6}$ gradually transit into a tetragonal phase, confirmed by the angle-dispersive synchrotron X-ray diffraction (ADXRD) results (Figure 3.15b). In tetragonal $\mathrm{Cs}_{2} \mathrm{AgBiBr}_{6}$, the octahedral distortion and tilt result in less coupling between $\mathrm{Bi} 6 \mathrm{p} / \mathrm{Ag} 4 \mathrm{~d}$ and $\mathrm{Br} 4 \mathrm{p}$ orbitals, corresponding to the bandgap widening between 4.0 $\mathrm{Gpa}$ and $6.5 \mathrm{Gpa}$. Impressively, the bandgap of $\mathrm{Cs}_{2} \mathrm{AgBiBr}_{6}$ decreased from $2.3 \mathrm{eV}$ to $1.7 \mathrm{eV}$ as the pressure further increased from $6.5 \mathrm{GPa}$ to $15 \mathrm{Gpa}$. This phenomenon could be explained by the subsequent structural amorphization of tetragonal $\mathrm{Cs}_{2} \mathrm{AgBiBr}_{6}$ at high pressure (Figure 3.15b). Equally important, the narrowed bandgap can be partially retained after releasing pressure, owing to the presence of residual amorphous phase in recovered $\mathrm{Cs}_{2} \mathrm{AgBiBr}_{6}$. Besides, the authors also applied high-pressure treatment to $\mathrm{Cs}_{2} \mathrm{AgBiBr}_{6}$ nanocrystals, which exhibited a similar phase transition from cubic to tetragonal compared to its bulk material, though at a relatively low pressure $(2.3$ Gpa). ${ }^{109}$ Meanwhile, its bandgap narrowed first and then widened as the pressure increased. It is noted that the bandgap of recovered $\mathrm{Cs}_{2} \mathrm{AgBiBr}_{6}$ nanocrystals was slightly wider compared with that of the initial one under ambient conditions, which could be associated with the significant size inhomogeneity of the decompressed samples.
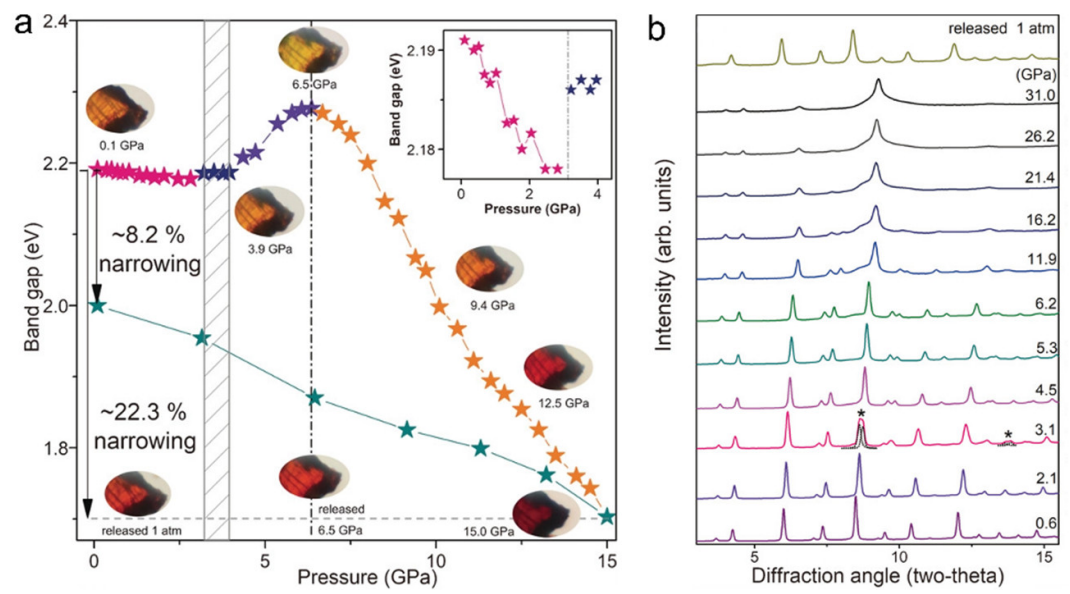

Figure 3.15 (a) Band gap evolution of the $\mathrm{Cs}_{2} \mathrm{AgBiBr}_{6}$ crystal at high pressure, and the representative optical micrographs showing piezochromic transitions. ${ }^{108}$ (b) Representative ADXRD patterns of $\mathrm{Cs}_{2} \mathrm{AgBiBr}_{6}$ perovskite at selected pressures. ${ }^{108}$ 
The emission features of HDPs could also be affected by high-pressure treatment. For example, the $\mathrm{PL}$ emission of the $\mathrm{Cs}_{2} \mathrm{AgBiBr}_{6}$ thin films broadened significantly at a pressure above $4.6 \mathrm{Gpa}$ (Figure 3.16a). ${ }^{110}$ The phase transition from cubic to tetragonal and the increased octahedral tilting are responsible for this bandwidth broadening of PL emission. More importantly, such intriguing broad emission ranging from 520 to 1000 $\mathrm{nm}$ was retainable after the pressure was fully released due to the incomplete recrystallization. The pressure-dependent emission was also observed in $\mathrm{Cs}_{2} \mathrm{AgBiCl}_{6}{ }^{111}$ As shown in Figure 3.16b, $\mathrm{Cs}_{2} \mathrm{AgBiCl}_{6}$ exhibited an abnormal blue shift of the emission peak with high pressure because lattice compression in the cubic phase decreased lattice relaxation energy. The pressure-dependent emission spectra further indicated that lattice compression could effectively alter the electron-phonon coupling strength in HDPs, as the emission of $\mathrm{Cs}_{2} \mathrm{AgBiCl}_{6}$ is ascribed to electron-phonon coupling induced self-trapping excitons.
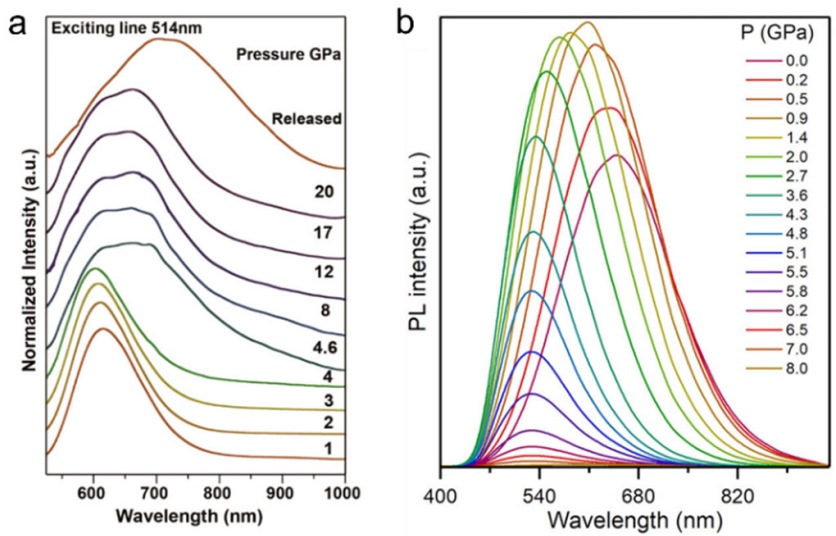

Figure 3.16 (a) Normalized PL spectra of $\mathrm{Cs}_{2} \mathrm{AgBiBr}_{6}$ films under pressure. ${ }^{110}$ (b) PL spectra of $\mathrm{Cs}_{2} \mathrm{AgBiCl}_{6}$ as a function of pressure during compression. ${ }^{11}$

\subsubsection{High-Temperature Treatment}

Temperature is another well-known parameter that could cause lattice thermal expansion and modify carrier-phonon interactions, thus changing the optical properties of materials. Our group investigated the thermal-induced structural and optical change in HDP $\mathrm{Cs}_{2} \mathrm{AgBiBr}_{6}$ for the first time in $2019 .{ }^{64}$ As shown in Figure 3.17a, the color of single crystals changed gradually from red to black with temperature increased from room temperature (RT) to $250{ }^{\circ} \mathrm{C}$ and returned to its original color after cooling. This reversible color transition is further confirmed by temperature-dependent UV-vis absorption spectra, where the absorption edge showed a red shift as the temperature increased and returned after cooling (Figure 3.17b). Since the color change process is fully reversible, 
we also call this interesting phenomenon thermochromism. We further performed $\mathrm{Ab}$ Initio Molecular Dynamics (AIMD) simulations that can provide atomic-scale description of temperature-dependent material structural properties to reveal the mechanism underlying the thermochromism. Figure 3.17c shows the fluctuation of the bond lengths of $\mathrm{Ag}-\mathrm{Br}$ and $\mathrm{Bi}-\mathrm{Br}$ and the averaged bond length at 25 and $200{ }^{\circ} \mathrm{C}$ from the AIMD simulations. Based on the substantial fluctuations of the metal-halide bond lengths, we observed substantial broadening of the bands at both $27^{\circ} \mathrm{C}$ and $227^{\circ} \mathrm{C}$, with the broadening more pronounced at $227^{\circ} \mathrm{C}$ (Figure 3.17d,e). Such broadening of the bands at momentum points contributing to dipole-allowed transitions could have remarkable effect on optical properties. It is also noted that the spin-orbit coupling effect plays an essential role for the conduction band edge broadening. These results indicated that the anharmonic fluctuations of the $\mathrm{Ag}-\mathrm{Br}$ and $\mathrm{Bi}-\mathrm{Br}$ bonds and strong spin-orbit coupling are mainly responsible for thermochromism in $\mathrm{Cs}_{2} \mathrm{AgBiBr}_{6}{ }^{64}$

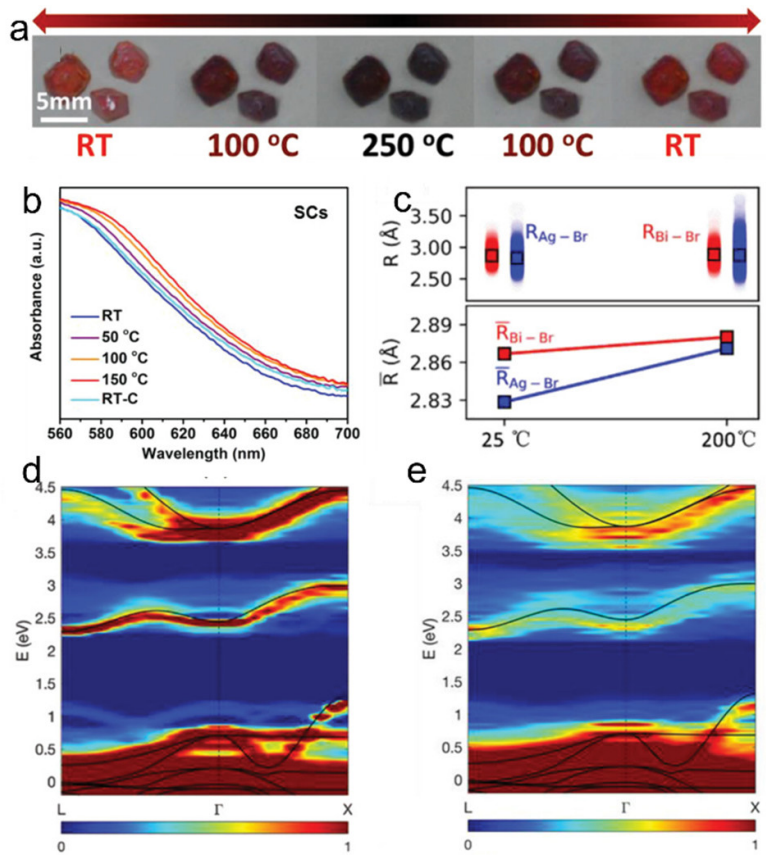

Figure 3.17 (a) Optical images of Single crystals at different temperatures for one heating-cooling cycle. ${ }^{64}$ (b) UV-vis absorption spectra of single crystals at room temperature, $50{ }^{\circ} \mathrm{C}, 100{ }^{\circ} \mathrm{C}$, $150{ }^{\circ} \mathrm{C}$ (RT-C, cooling to room temperature).$^{64}$ (c) Fluctuation of the bond lengths of $\mathrm{Ag}-\mathrm{Br}$ and $\mathrm{Bi}-\mathrm{Br}$ (top panel), and the averaged bond length (bottom panel) at 25 and $200{ }^{\circ} \mathrm{C} .{ }^{64}(\mathrm{~d}, \mathrm{e})$ Unfolded effective band structures including spin-orbit coupling (SOC) at 27 and $227^{\circ} \mathrm{C}$, respectively. The band structure at zero temperature is shown in black line. The color scale represents the weights of the unfolded bands, normalized to the interval $[0,1] .{ }^{64}$ 
Besides, we further discovered another double perovskite $\mathrm{Cs}_{2} \mathrm{NaFeCl}_{6}$ with fully reversible thermochromism, showing a lower thermochromic operating temperature and wider color contrast compared with $\mathrm{Cs}_{2} \mathrm{AgBiBr}_{6}$. As shown in Figure 3.18a, the crystal color change gradually from light yellow to black in the range of 10-423 K. To quantify the color changes during temperature changes, we perform the UV-vis transmittance and diffuse reflectance measurements on $\mathrm{Cs}_{2} \mathrm{NaFeCl}_{6}$ crystal at different temperatures and convert them to pseudo absorbance spectra (Figure 3.18b,c). In the low temperature range of $6.8 \mathrm{~K}$ to $300 \mathrm{~K}$, the absorption edge gradually shifts from $\sim 500 \mathrm{~nm}$ to $\sim 570 \mathrm{~nm}$ (Figure 3.18b). As the temperature further increases from $\mathrm{RT}(\sim 300 \mathrm{~K})$ to $473 \mathrm{~K}$, the absorption edge gradually redshifts to $\sim 670 \mathrm{~nm}$ (Figure 3.18c), corresponding well with the observed crystal color changes. By extrapolating the linear region of the absorption edge to the energy-axis intercept, we determine the optical bandgaps of the $\mathrm{Cs}_{2} \mathrm{NaFeCl}_{6}$ crystals at different temperatures. At low temperatures $(\sim 6.8 \mathrm{~K}$ to $80 \mathrm{~K})$ we find the characteristic weakly temperature dependent behaviour of the optical bandgap, which is followed by a rather steep decrease with temperature (Figure 3.18d). We find a discrepancy between the optical bandgap at $300 \mathrm{~K}$ calculated from transmittance and reflectance results, which could be related to the unfavorable background in the reflectance spectra that has not been successfully removed experimentally. Our measurements of the optical bandgap compares very well to first-principles calculations of the temperature dependence of the electronic bandgap as shown in Figure 3.18d. Which indicates that the thermochromism of $\mathrm{Cs}_{2} \mathrm{NaFeCl}_{6}$ can be described as purely an effect of strong electronphonon coupling.

Moreover, temperature-dependent crystal structure results show that only the $\mathrm{Na}-\mathrm{Cl}$ bond length changes significantly during the heating/cooling process, while the $\mathrm{Fe}-\mathrm{Cl}$ bond length changes are negligible. This behaviour is reproduced in our DFT calculations (Figure 3.19a). Interestingly, focusing on this bond-behaviour yields insight into the nature of the strong-electron phonon coupling in this system. In Figure 3.19b we plot the bandgap of $\mathrm{Cs}_{2} \mathrm{NaFeCl}_{6}$ as a function of volume for two separate cases. In the first, full atomic relaxation is performed at each volume, while in the second, the fractional coordinates are kept fixed at their relaxed value at the RT volume. We see that in the first case, the bandgap remains virtually constant, while in the second case, there is a clear change. On the one hand, this shows that thermal expansion has a very weak explicit effect on the temperature induced bandgap change. On the other hand, it indicates that the bandgap depends on the length of the $\mathrm{Fe}-\mathrm{Cl}$ bond, and accordingly, to vibrations of the $\mathrm{Cl}$ atoms parallel to this bond. 


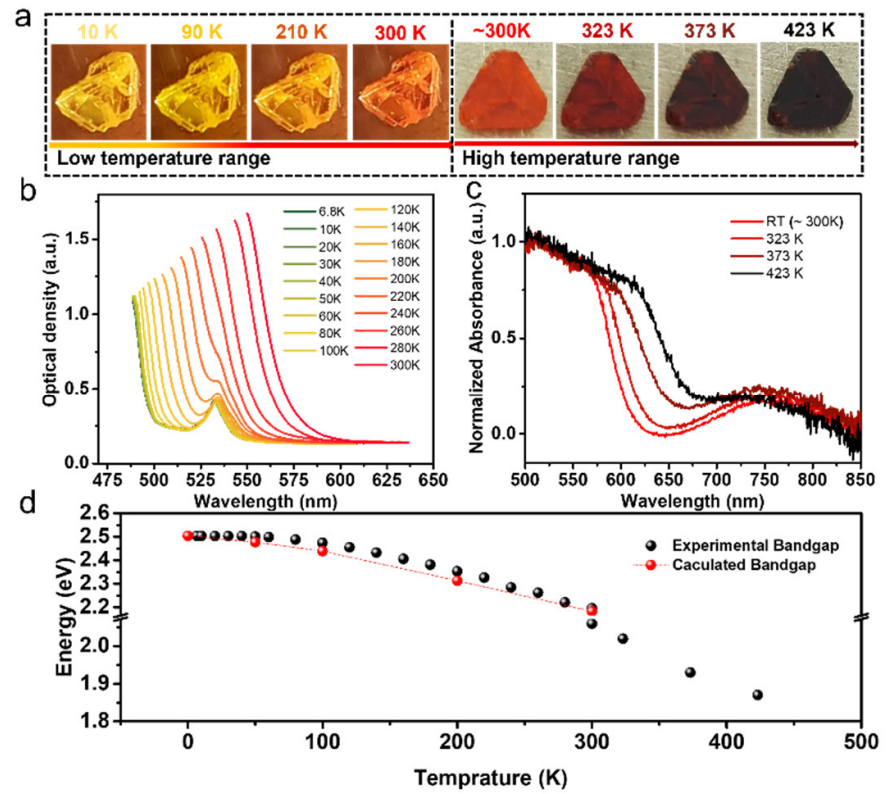

Figure 3.18 (a) Optical images of $\mathrm{Cs}_{2} \mathrm{NaFeCl}_{6}$ single crystal at different temperatures. UV-vis absorption spectra of $\mathrm{Cs}_{2} \mathrm{NaFeCl}_{6}$ single crystal at low temperature range (b) and high temperature range (c) (RT: room temperature). (d) Plots of the optical bandgap of $\mathrm{Cs}_{2} \mathrm{NaFeCl}_{6}$ as a function of temperatures. The calculated bandgaps have been shifted to match the experimental values at the lowest temperature.

We confirm this by examining the dependence on the bandgap on the optical $\mathrm{A}_{1 \mathrm{~g}}$ phonon mode at the $\Gamma$-point. The eigenvectors of this mode corresponds precisely to the motion of the $\mathrm{Cl}$ ion along the $\mathrm{Na}-\mathrm{Cl}-\mathrm{Fe}$ bonds, with positive/negative displacement amplitudes corresponding to elongation and shortening of the $\mathrm{Fe}-\mathrm{Cl}$ bond, respectively. We find that the bandgap depends strongly, and in a highly unusual, non-parabolic, way, on this phonon mode, as shown in Figure 3.19c. Indeed, for positive amplitudes (bond elongation) the bandgap decreases rapidly. Upon close examination this decrease of the bandgap is found to be due to a shift down of the conduction band minimum (CBM). The electronic DOS (in the DLM magnetic state, see computational details) of $\mathrm{Cs}_{2} \mathrm{NaFeCl}_{6}$ is shown in Figure 3.19d, where we can see that the states that make up the $\mathrm{CBM}$ are highly localized Fe- $\mathrm{t}_{2 \mathrm{~g}}$ states, while the main valence band is primarily of $\mathrm{Cl}$ p character. Thus, the strong electron phonon coupling in $\mathrm{Cs}_{2} \mathrm{NaFeCl}_{6}$ can, at least to some degree, be understood in terms of a sensitive dependence of the localized Fe-d states on vibrations that alter the length of the $\mathrm{Fe}-\mathrm{Cl}$ bond. Our results provide a new understanding on thermochromism in HDPs. 

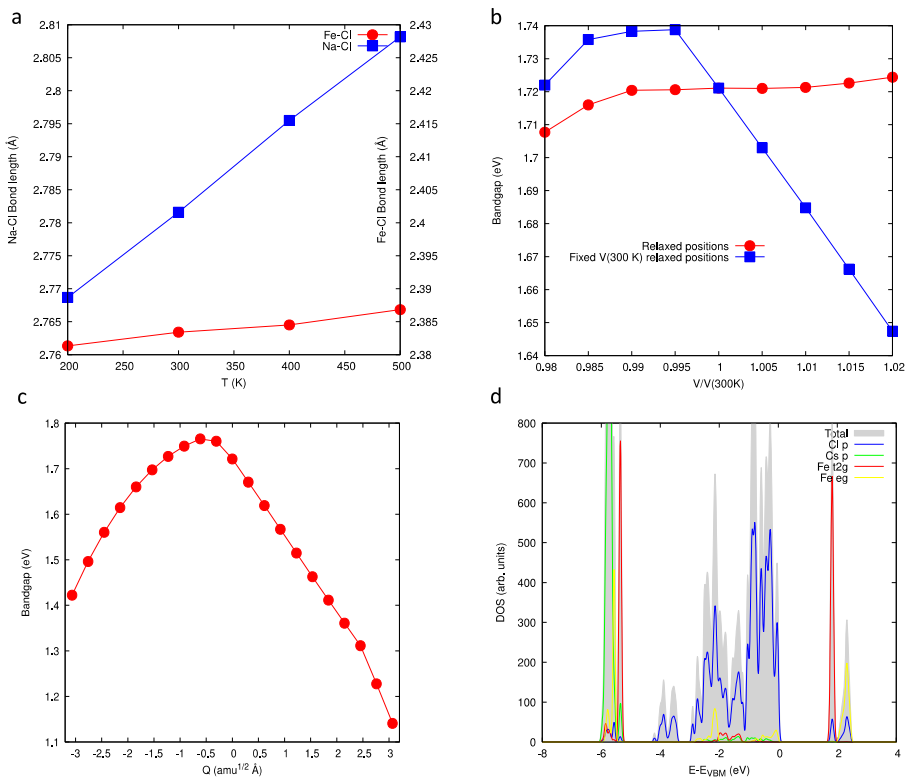

Figure 3.19 (a) $\mathrm{Fe}-\mathrm{Cl}$ and $\mathrm{Na}-\mathrm{Cl}$ bond lengths extracted from AIMD simulations. (b) Bandgap as a function of volume, for fully relaxed atomic positions (red circles) and for atomic positions fixed at the relaxed ones at the volume corresponding to RT. (c) Bandgap as a function of normal mode coordinates of the $\mathrm{A}_{1 \mathrm{~g}} \Gamma$-point phonon mode. The displacement of this mode corresponds to motion of the $\mathrm{Cl}$ atoms along the Na-Cl-Fe bonds. (d) Electronic DOS in the DLM state. All calculations with PBEsol+U $(3 \mathrm{eV})$.

In conclusion, through high-pressure or high-temperature physical treatment, the optical and/or electronic properties of HDPs can be altered without changing chemical composition. These changes during high-pressure treatment are associated with the octahedral contraction and distortion, phase transition and structural amorphization. However, for high temperature treatment, these changes are mainly related to the anharmonic fluctuations of the metal-halide bonds, spin-orbit coupling and electron-phonon coupling. These findings not only offer new strategies for the modulation and tuning of optical and electric properties of HDPs, but also provide novel insights into the structure-property relationship in HDPs. 


\section{Chapter 4 Crystal Synthesis and Characterization}

\section{Methods}

\subsection{Crystal Synthesis Methods}

To understand the intrinsic properties of HDPs materials, it is crucial to synthesize highquality single crystals, which are also important for single crystal device applications. In this chapter, various common techniques to grow the single crystal of halide perovskites are introduced, including the hydrothermal method, ${ }^{67}$ slow evaporation method, ${ }^{112}$ inversion temperature crystallization $\operatorname{method}^{113}$ and antisolvent vapor assisted method. ${ }^{114}$

\subsubsection{Hydrothermal (Solvothermal) Method}

Hydrothermal method is the most used technique to synthesize high-quality HDPs single crystals. In this method, the crystal growth is performed in a piece of equipment consisting of a steel pressure vessel called an autoclave, which can withstand high temperatures and pressures, as shown in Figure 4.1 a,b. Usually, the precursor materials have very poor solubility in the solvent at room temperature but can be fully dissolved under high temperature and high-pressure conditions. By decreasing the temperature of the precursor solution in the autoclave, the solubility of the solution gradually decreases and reaches supersaturation. Further decreasing the temperature of the precursor solution slowly, crystal nucleus forms and then grow into large crystals. For the growth of HDPs single crystals, a solvent (acid) is used instead of water in the synthesis process. We employed this method to synthesize most of HDPs crystals involved in this thesis, including $\mathrm{Cs}_{2} \mathrm{AgBiBr}_{6}, \mathrm{Cu}$-doped $\mathrm{Cs}_{2} \mathrm{AgBiBr}_{6}, \mathrm{Cs}_{2} \mathrm{AgIn}_{(1-\mathrm{x})} \mathrm{Fe}_{\mathrm{x}} \mathrm{Cl}_{6}$ and $\mathrm{Cs}_{2} \mathrm{NaFeCl}_{6}$ single crystals.
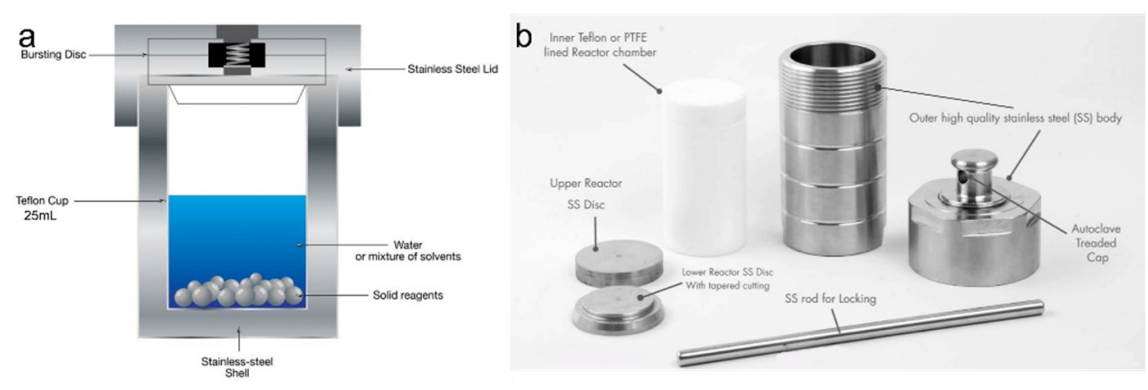

Figure 4.1 (a) Schematic diagram of Teflon lined stainless steel autoclave with inner components. The Teflon chamber is housed inside the stainless-steel chamber in which reaction is carried out. (b) The commercially available Teflon lined stainless steel autoclave. 


\subsubsection{Slow Evaporation Method}

Slow evaporation method is the simplest technique for growing single crystals of airstable materials. In this method, we need to choose a suitable solvent to prepare a nearly saturated precursor solution, and then slowly evaporate the solution to obtain single crystals, as shown in Figure 4.2a. The size of the perforations on the cap and the evaporation temperature are two experimental variables that depend to some extent on the volatility of the solvent. In this thesis, we employed this method to grow $\mathrm{Cs}_{2} \mathrm{AgBiBr} 6$ single crystals with different bandgaps by controlling the evaporation temperature (Figure 4.2b). The basic principle of crystal growth by slow evaporation method at different temperatures is almost the same, which is caused by the precipitation of solutes due to gradual evaporation of the solvent.
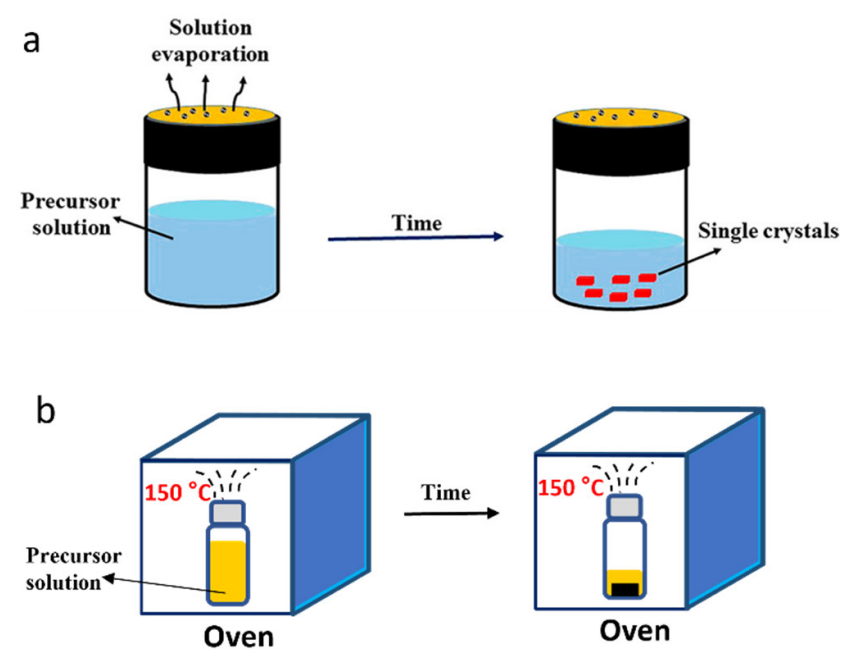

Figure 4.2 Schematic representation of crystal growth by slow evaporation method at room temperature (a) $)^{115}$ and high temperature (b).

\subsubsection{Inversion Temperature Crystallization Method}

Inversion temperature crystallization method is a general and simple method for synthesizing $\mathrm{Pb}$-based halide perovskite single crystals. This method requires the material to have inverse solubility in an appropriate solvent at high temperatures. As shown in Figure 4.3, the single crystals can be precipitated by annealing the precursor solution at a high temperature due to the decreased solubility of material at high temperatures. For example, $\mathrm{MAPbI}_{3}\left(\mathrm{MA}=\mathrm{CH}_{3} \mathrm{NH}_{3}{ }^{+}\right)$single crystals can be obtained by dissolving a stoichiometric molar ratio of salts $\mathrm{PbI}_{2}$ and MAI in $\gamma$ - butyrolactone (GBL) solution at room temperature, followed by heating the precursor solution at $120^{\circ} \mathrm{C}$ for several hours. 
Since most HDPs have solubility issues or lack of suitable solvent for HDPs with inverse solubility at high temperature, this method has not been adopted to grow HDPs single crystals.

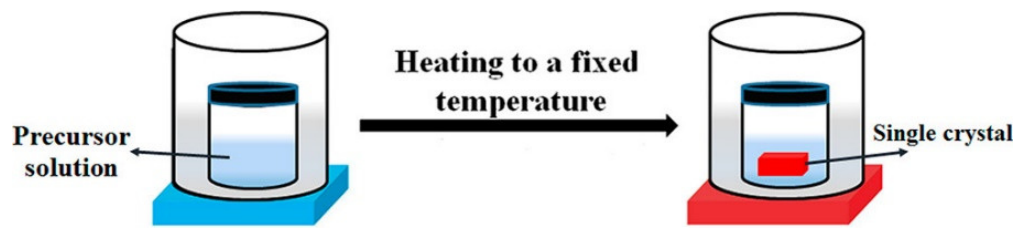

Figure 4.3 Schematic representation of the inversion temperature crystallization method in which the crystallization vial is immersed within a heating bath. ${ }^{115}$

\subsubsection{Antisolvent Vapor Assisted Method}

The critical part in this method is to choose two suitable solvents (solvent 1 and solvent 2). Solvent 1 is not or less volatile with a good solubility for the precursor materials. In contrast, solvent 2 is more volatile with extremely poor solubility of the precursor materials. For crystal growth, the precursor materials are dissolved in solvent 1 in a small vial, and then transferred to a sealed space with the solvent 2, as shown in Figure 4.4. Along with the slow diffusion of the solvent 2 into the precursor solution, single crystals would be formed.

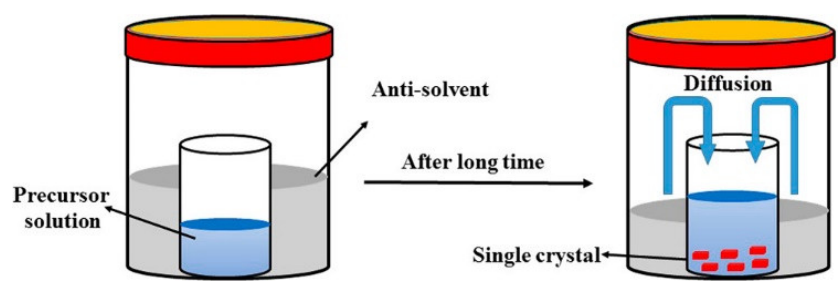

Figure 4.4 Schematic illustration of antisolvent method for single crystal growth. ${ }^{115}$

\subsection{Characterization Methods}

\subsubsection{X-ray Diffractometry (XRD)}

$\mathrm{X}$-ray diffraction (XRD) is the most used non-destructive technique to determine the crystallographic structure of a material. It works by irradiating a material with incident $\mathrm{X}$-rays and then measuring the intensities and scattering angles of the X-rays that are scattered by the material. Specifically, crystals are regular arrays of atoms, and X-rays can be considered waves of electromagnetic radiation. Crystal atoms can scatter incident X-rays mainly through interaction with the atoms' electrons, called elastic scattering. A regular array of scatterers (atoms) produces a regular array of spherical waves and then 
wave interference occurs. There are two different interference, constructive and destructive interference, of which only constructive interference can be detected in the X-ray detector. The constructive interference (diffraction) could occur in a special condition, as determined by Bragg's law:

$$
\mathrm{n} \lambda=2 \mathrm{~d} \sin \theta
$$

here $\mathrm{n}$ is an integer, $\lambda$ is the wavelength of the incident $\mathrm{X}$-ray, $\mathrm{d}$ is the spacing between diffracting planes and $\theta$ is the incident angle (Figure 4.5).

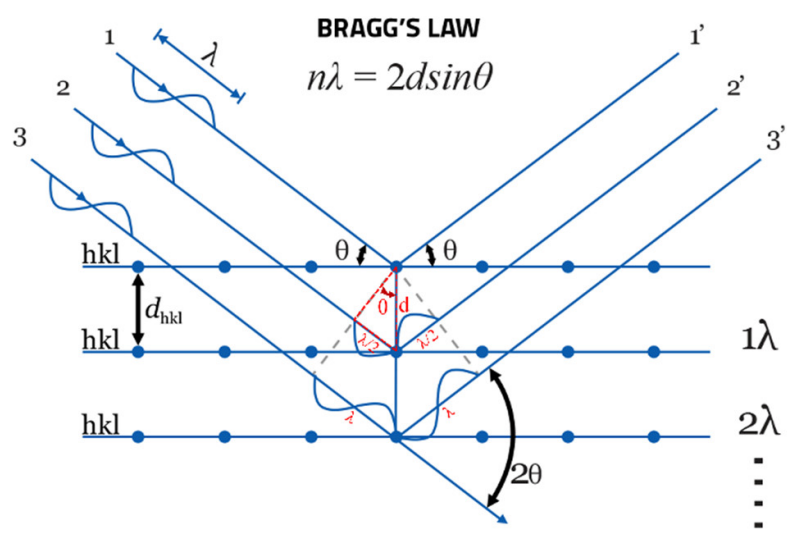

Figure 4.5 Bragg's law

XRD can be performed using single crystal (single-crystal XRD) or powder (powder XRD). Single-crystal XRD is mainly used to determine the absolute structure of a single crystal, including the exact atomic positions, unit cell dimensions, bond lengths, and bond-angles. Powder XRD measures samples of polycrystalline materials (polycrystals) and is therefore considered a bulk characterization technique. The powder XRD pattern is considered a "fingerprint" for a given material; it provides information about the bulk purity, crystallinity, and phase (polymorph) of the material.

\subsubsection{Ultraviolet and Visible Spectrophotometry (UV-Vis)}

Ultraviolet-visible spectrophotometry (UV-Vis) primarily refers to absorption spectroscopy or reflectance spectroscopy in the near-UV (180-390 nm) or visible (390-780 $\mathrm{nm}$ ) region. It measures the attenuation of a beam of light after it passes through a sample or after reflection from a sample surface. The absorbance of materials can be determined by using the Beer-Lambert law.

$$
A=\log _{10}\left(I_{0} / I\right)
$$


where $\mathrm{A}$ is the measured absorbance, $I_{0}$ is the intensity of the incident light at a given wavelength, $I$ is the intensity of light after passing through a sample. Since the ratio $I / I_{0}$ is transmittance $T$, the absorbance A could be converted by transmittance using the below equation.

$$
A=\log _{10}(1 / T)=-\log _{10} T
$$

It is noted that some powder or single crystal samples with the thick thickness could cause absorption saturation, that is, almost $100 \%$ of the light is absorbed. In this case, we could choose to measure the reflectance $R$ instead of the absorbance $A$.

$$
R=I^{\prime} / I^{\prime} 0
$$

Here $I^{\prime}$ is the intensity of light reflected from a sample, and $I^{\prime} 0$ is the intensity of light reflected from a reference material, such as spectralon or $\mathrm{BaSO}_{4}$. The reflectance spectra can be further converted to pseudo-absorbance spectra using the Kubelka-Munk transform.

$$
\alpha \approx(1-R)^{2} / 2 R
$$

where $\alpha$ is pseudo-absorbance and $R$ is reflectance. In addition, the direct and indirect optical bandgaps can be measured by taking the intercept upon extrapolation of the linear regions of $(\alpha h v)^{2} \mathrm{Vs} E(\mathrm{eV})$ and $(\alpha h v)^{1 / 2} \mathrm{Vs} E(\mathrm{eV})$ plots, respectively.

\subsubsection{Photoluminescence spectroscopy}

Photoluminescence (PL) is luminescence from materials after the absorption of photons. In semiconductors, PL is a basic and important property, which is a radiative recombination process of electron-hole pairs. Generally, PL in perovskite semiconductors mainly includes band-to-band luminescence and exciton luminescence. As shown in Figure 4.6, band-to-band luminescence is the radiative recombination between the electrons in the conduction band and holes in the valance band. Therefore, this type of luminescence can be employed to determine the bandgap of materials. Exciton luminescence means the emission of photons through exciton recombination. Exciton is a bound electron-hole pair, in which an electron and a hole are attracted to each other by Coulomb force. The exciton emission energy is usually slightly lower than the bandgap, and this energy difference is the exciton binding energy. It is noted that there is a special type of exciton luminescence, called self-trapped exciton (STE) luminescence, whose emission energy is much smaller than the bandgap (Figure 4.6). 


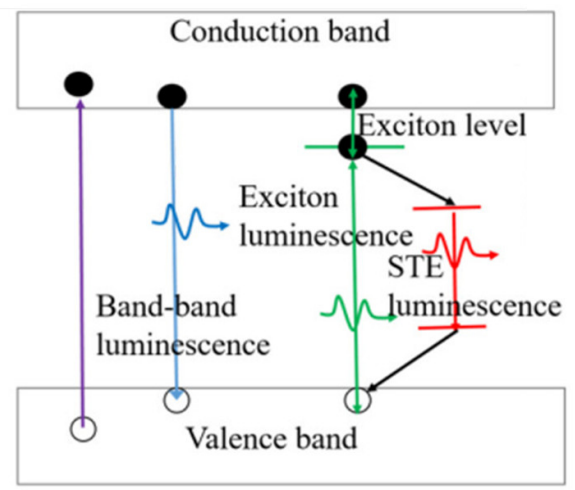

Figure 4.6 Schematic of various intrinsic photoluminescence phenomena, including band-to-band luminescence, exciton luminescence, and STE luminescence. ${ }^{69}$

\subsubsection{Solid-State Nuclear Magnetic Resonance (ssNMR)}

Solid-state nuclear magnetic resonance (ssNMR) spectroscopy is an atomic-level method to determine the chemical structure of solid materials, and it is a type of nuclear magnetic resonance (NMR) spectroscopy. NMR is the response of nuclei with non-zero spins in a magnetic field to resonant excitation by radiofrequency irradiation (Figure 4.7a). ${ }^{116}$ When atoms with nuclei spins are placed in an external magnetic field $B_{0}$, the degeneracy of the nuclear spin states is lifted (Figure 4.7b), leading to an energy difference $\Delta E$ given by below.

$$
\Delta E=\gamma h(1-\sigma) B_{0}
$$

where $\gamma$ is the gyromagnetic ratio, a fundamental property associated with each isotope; $h$ is Planck constant; $B_{0}$ is the strength of the external magnetic field; and $\sigma$ is the chemical shielding around a nucleus, which varies for different nuclei of a given isotope in a material. The transitions between these nuclear spin states induced by electromagnetic radiation are called resonance. The resonance frequencies are sensitive to the electron distribution around the nucleus, which shields the nucleus from the external magnetic field. Meanwhile, the electron distribution of the nucleus could be affected by a serious of couplings, including spin-spin scalar couplings dependent on covalent bonding, spinspin dipolar couplings dependent on internuclear distances, and quadrupolar couplings between the electric field gradient at the nucleus and the charge distribution of the nucleus for nuclear spins greater than $1 / 2$. Therefore, NMR frequencies can reveal the chemical environments of nucleus in material. For example, if nuclei are present in a compound in equivalent chemical environments, they will appear as one peak in the 
spectra. Multiple peaks will be observed when the nuclei exist in more than one chemical environment. Since the changes in NMR frequency are usually extremely small, NMR frequencies are commonly transferred to chemical shift $\delta$, which is the fractional difference between the frequency of a particular nucleus and a reference or standard compound such as tetramethylsilane. The unit of chemical shift $\delta$ is part per million (ppm).

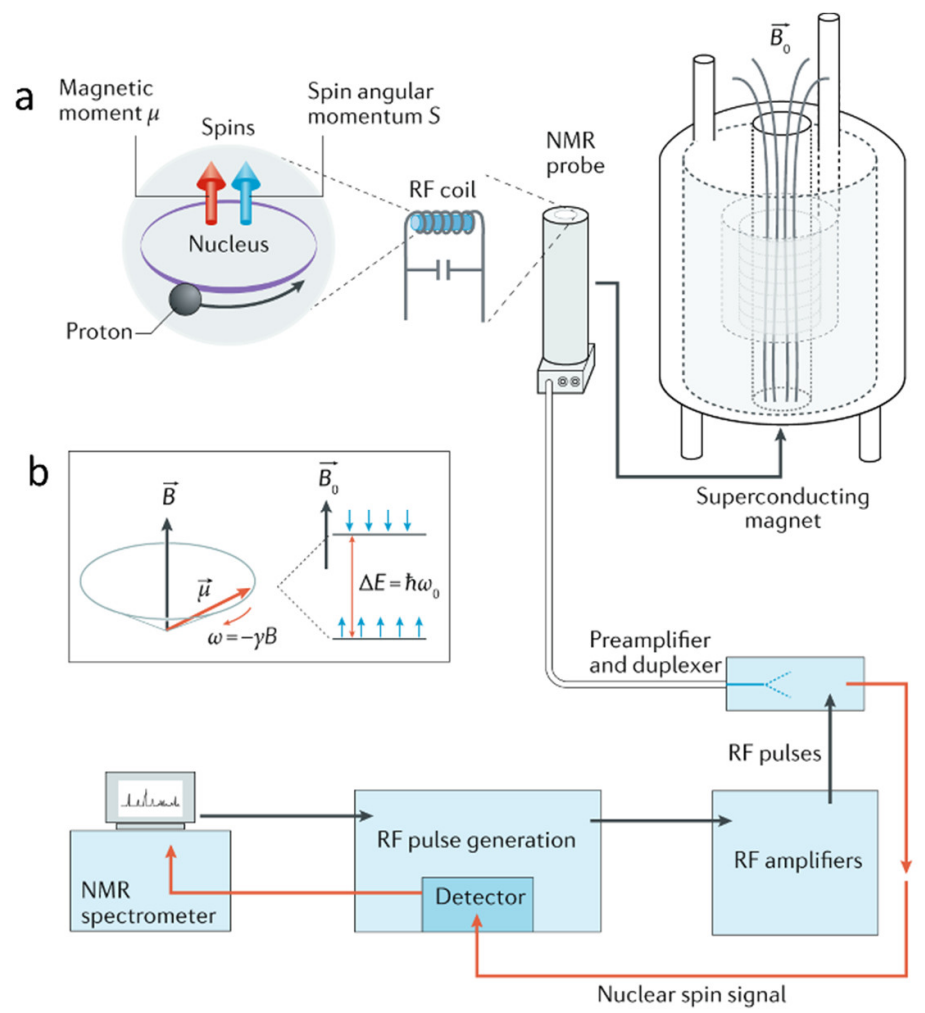

Figure 4.7 (a)(b) Nuclear spin magnetic dipole moments $(\mu$ ) precess around a static magnetic field $\left(B_{0}\right)$ at a frequency identical to the transition frequency between the energy levels of the spins $(\Delta E$ $\left.=\hbar \omega_{0}\right)$. A radiofrequency (RF) coil is wrapped around the sample at the top of a nuclear magnetic resonance (NMR) probe, which is inserted into the center of the magnet. The RF coil allows irradiation of the RF pulses as well as detection of the transition frequency of the nuclear magnetic moment. ${ }^{16}$ (b) Schematic diagram of nuclear spin energy level splitting under an external static magnetic field. Angular velocity, $\omega=-\gamma B{ }^{116}$

The frequency-domain ssNMR spectra are obtained from Fourier transformation of time-domain signals recorded after a radiofrequency pulse that perturbs the system from equilibrium. The return to equilibrium after excitation by the pulse is referred to as longitudinal relaxation. The relaxation time of nuclei in diamagnetic perovskite materials 
could be significantly shortened (up to 3-4 orders of magnitude) when paramagnetic ions such as some transition metal and lanthanide ions are introduced. This phenomenon called paramagnetic relaxation enhancements (PRE), arising from the electron spin-nuclear spin interactions between NMR active nuclei and unpaired electrons of the paramagnetic ion. ${ }^{117}$ PRE is a short-range effect and typically can be observed for distances up to around $20 \AA$ from the unpaired electron. Therefore, the relaxation-based data provide a straightforward and general approach to evidence and understand the distribution of paramagnetic alloying ions in host materials.

In addition, ssNMR spectra usually show broad peaks (Figure 4.8b), which are caused by the significant effects of anisotropic (orientation dependent) nuclear spin interactions. Unlike the more commonly used solution NMR, the anisotropic interactions are averaged due to the rapid tumbling of the molecules in solution, but molecules in solids cannot tumble a lot and the orientation matters. To obtain solid-state NMR spectra with higher resolution (narrow peaks), a commonly used approach is magic-angle spinning (MAS), where samples are physically spun around an axis that is tilted by $54.7^{\circ}$ from the static magnetic field to remove the anisotropic contribution (Figure 4.8a). ${ }^{118}$ The rate of MSA needs to be greater than (or equal to) the magnitude of the anisotropic interaction to average it to zero. Otherwise, a manifold of spinning sidebands becomes visible, which appear on either side of any large genuine peak at a separation of integer multiples to the spinning rate (Figure 4.8c,d). 


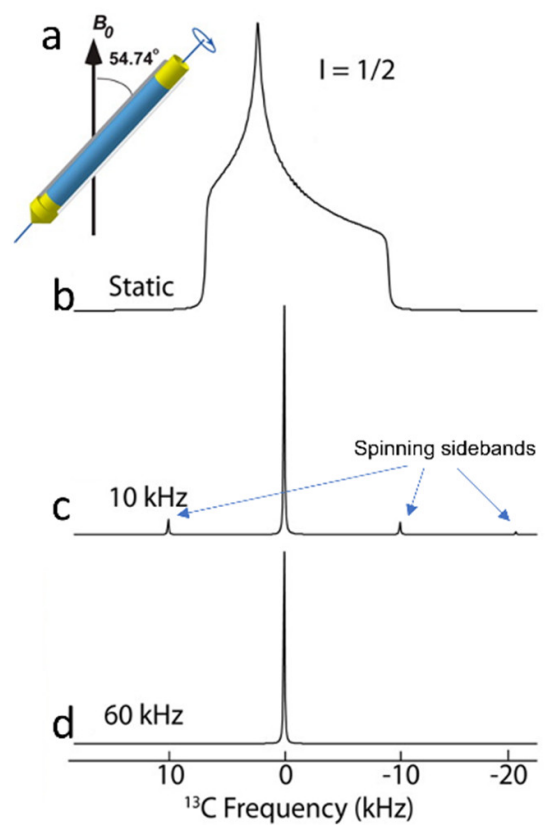

Figure 4.8 (a) Schematic representation of MAS NMR setup. ${ }^{118}$ The sample is placed into an NMR probe at the "magic" angle of $54.74^{\circ}$ with respect to the static magnetic field and spun rapidly. (b-d) Illustration of the effect of MAS on NMR line shapes in a spin- $1 / 2$ nucleus. The broad ${ }^{13} \mathrm{C}$ powder pattern resulting from chemical shift interaction in a static sample (b) is broken up into a series of spinning sidebands (c), which represent the Fourier components of the MAS frequency, and averaged out into an isotropic peak (d) when the MAS frequency exceeds the magnitude of the anisotropic interaction. ${ }^{118}$ 
52 


\section{Chapter 5 Summary and Outlook}

In this thesis, we aim to solve the large and/or indirect bandgap issues of HDPs by employing three strategies, including metal doping/alloying, crystallization control and structure engineering. We also discuss the intrinsic characteristics, optoelectronic applications, critical challenges, and opportunities of HDPs.

Metal doping/alloying can change the bandgap of the host HDPs by the introduction of the external dopant's orbital states in the host band structure with a modification of the CBM and VBM. A special example we discovered is $\mathrm{Cu}$-doped $\mathrm{Cs}_{2} \mathrm{AgBiBr}_{6}$. We found that $\mathrm{Cu}$ dopants barely affect the bandgap of the host; instead, it contributes to the noticeable near infrared (NIR) absorption by introducing defect states. More interestingly, this NIR absorption can generate band carriers upon excitation and thus demonstrate a novel approach for NIR detection in HDPs. In addition, the emission properties of host HDPs can also be changed, not only due to the bandgap modulation, but also caused by the dopant ions which emit light via their orbital transition emission, such as $\mathrm{Mn}^{2+}, \mathrm{Er}^{3+}$ and $\mathrm{Yb}^{3+}$. Moreover, a series of isovalent (monovalent and trivalent) and heterovalent (bivalent and tetravalent) metal ions can be doped or co-doped into HDPs lattice, further expanding the large family of HDPs. These results provide the possibility to fabricate various optoelectronic and multifunctional devices based on HDPs through doping/alloying different functional ions. However, due to the poor solubility of HDPs and the different crystallization process of thin films compared with single crystals, the formation of thin films of these materials is still challenging and requires further research.

The large bandgaps of HDPs can also be narrowed by crystallization control, which is possibly related to different degrees of $\mathrm{B}$-site $\left(\mathrm{B}^{\mathrm{I}} / \mathrm{B}^{\mathrm{III}}\right)$ disorder in the crystal under different crystallization processes. This has been verified by first-principles calculations, which clearly indicated that increasing B-site disorder has a huge impact on the band structure and could significantly reduce the bandgap. Unfortunately, there is still a lack of a promising approach to precisely control and detect the degrees of $\mathrm{B}^{\mathrm{I}} / \mathrm{B}^{\mathrm{III}}$ disorder in HDPs. Meanwhile, the formed anti-site defects by $\mathrm{B}^{\mathrm{I}} / \mathrm{B}^{\mathrm{III}}$ disorder are unfavorable for optoelectronic applications. Therefore, it is critical to find a balance between the decrease of bandgap and increase of anti-site defects in order to further utilize this orderto-disorder approach. Besides, the $\mathrm{B}^{\mathrm{I}} / \mathrm{B}^{\mathrm{III}}$ disorder in HDPs crystals or powders cannot be retained in thin films due to their different crystallization processes.

Structure engineering is another strategy to alter the band structure of HDPs by tuning the lattice structure through high-pressure or high-temperature physical treatment. 
The underlying mechanisms of these two treatments are different. Specifically, during high-pressure treatment, the octahedral contraction and distortion, phase transition and structural amorphization are responsible for the bandgap change in HDPs. The bandgap change during high-temperature treatment is associated with the anharmonic fluctuations of the metal-halide bonds, spin-orbit coupling and electron-phonon coupling. A drawback of these strategies is that the engineered bandgap is hardly to be reserved at ambient conditions. However, these reversible process (i.e. thermochromism) could open doors for new applications of HDPs, such as smart windows or visual thermometers. Moreover, such widespread and controllable physical treatments provide a powerful tool for understanding the basic structure-property relationship of HDPs without changing the chemical composition.

In addition to the issues of large and/or indirect bandgap, some other challenges in HDPs also require attention. For example, the poor solubility make it challenge to fabricate most Cl-based HDPs films using the solution method, which impedes their application in thin film devices. Thermal evaporation could be an alternative to prepare highquality thin films of HDPs with poor solubility. Additionally, no HDPs have emerged as a prospective solar absorber with promising photovoltaic properties similar to $\mathrm{Pb}$ based halide perovskites. Further efforts are required to explore new promising HDPs with suitable direct bandgaps for efficient photovoltaic applications. Fortunately, some HDPs have shown exciting optoelectronic properties in luminescence and photodetection, indicating promising applications of currently reported HDPs as photo/X-ray detectors or phosphors in down-conversion light-emitting-diodes.

In summary, environmentally friendly HDPs have become a promising alternative to $\mathrm{Pb}$ halide perovskites for optoelectronic applications, in terms of their excellent stability, a wide range of possible combinations, and rich substitutional chemistry. However, the research on HDPs is still at an early stage, and more efforts are desired to realize their full potential by understanding and modifying their fundamental properties, as well as exploring other new promising HDPs and new applications. 


\section{Reference:}

1 K. Hirose, R. Sinmyo and J. Hernlund, Science, 2017, 358, 734-738.

2 P. Szuromi and B. Grocholski, Science, 2017, 358, 732-733.

3 J. Suntivich, H. A. Gasteiger, N. Yabuuchi, H. Nakanishi, J. B. Goodenough and Y. Shao-Horn, Nature Chem, 2011, 3, 546-550.

4 R. E. Cohen, Nature, 1992, 358, 136-138.

5 H. Béa, M. Gajek, M. Bibes and A. Barthélémy, J. Phys.: Condens. Matter, 2008, 20, 434221.

6 Y. Guo, K. Kakimoto and H. Ohsato, Appl. Phys. Lett., 2004, 85, 4121-4123.

7 V. M. Goldschmidt, Naturwissenschaften, 1926, 14, 477-485.

8 B. Saparov and D. B. Mitzi, Chem. Rev., 2016, 116, 4558-4596.

9 C. Li, X. Lu, W. Ding, L. Feng, Y. Gao and Z. Guo, Acta Crystallogr B Struct Sci, 2008, 64, 702-707.

10 A. Kojima, K. Teshima, Y. Shirai and T. Miyasaka, J. Am. Chem. Soc., 2009, 131, 6050-6051.

11 M. M. Lee, J. Teuscher, T. Miyasaka, T. N. Murakami and H. J. Snaith, Science, 2012, 338, 643-647.

$12 \mathrm{https} / / / \mathrm{www} . \mathrm{nrel} . \mathrm{gov} / \mathrm{pv} / \mathrm{cell}-\mathrm{efficiency} . \mathrm{html}$

13 F. Igbari, R. Wang, Z.-K. Wang, X.-J. Ma, Q. Wang, K.-L. Wang, Y. Zhang, L.-S. Liao and Y. Yang, Nano Lett., 2019, 19, 2066-2073.

14 W. Ning, F. Wang, B. Wu, J. Lu, Z. Yan, X. Liu, Y. Tao, J.-M. Liu, W. Huang, M. Fahlman, L. Hultman, T. C. Sum and F. Gao, Advanced Materials, 2018, 30, 1706246.

15 J. Tong, Z. Song, D. H. Kim, X. Chen, C. Chen, A. F. Palmstrom, P. F. Ndione, M. O. Reese, S. P. Dunfield, O. G. Reid, J. Liu, F. Zhang, S. P. Harvey, Z. Li, S. T. Christensen, G. Teeter, D. Zhao and M. M. Al-Jassim, 2019, 6.

16 Y. Gao, K. Wang, M. Wang, J. I. Khan, A. H. Balawi, W. Liu, S. De Wolf and F. Laquai, Sol. RRL, 2020, 4, 2000072.

17 C. Ran, J. Xu, W. Gao, C. Huang and S. Dou, Chemical Society Reviews, 2018, 47, 4581-4610.

18 Z.-K. Tan, R. S. Moghaddam, M. L. Lai, P. Docampo, R. Higler, F. Deschler, M. Price, A. Sadhanala, L. M. Pazos, D. Credgington, F. Hanusch, T. Bein, H. J. Snaith and R. H. Friend, Nature Nanotech, 2014, 9, 687-692.

19 K. Lin, J. Xing, L. N. Quan, F. P. G. de Arquer, X. Gong, J. Lu, L. Xie, W. Zhao, D. Zhang, C. Yan, W. Li, X. Liu, Y. Lu, J. Kirman, E. H. Sargent, Q. Xiong and Z. Wei, Nature, 2018, 562, 245-248.

20 T. Chiba, Y. Hayashi, H. Ebe, K. Hoshi, J. Sato, S. Sato, Y.-J. Pu, S. Ohisa and J. Kido, Nature Photon, 2018, 12, 681-687.

21 W. Xu, Q. Hu, S. Bai, C. Bao, Y. Miao, Z. Yuan, T. Borzda, A. J. Barker, E. Tyukalova, Z. Hu, M. Kawecki, H. Wang, Z. Yan, X. Liu, X. Shi, K. Uvdal, M. Fahlman, W. Zhang, M. Duchamp, J.-M. Liu, A. Petrozza, J. Wang, L.-M. Liu, W. Huang and F. Gao, Nat. Photonics, 2019, 13, 418-424.

22 Y. Dong, Y.-K. Wang, F. Yuan, A. Johnston, Y. Liu, D. Ma, M.-J. Choi, B. Chen, M. Chekini, S.-W. Baek, L. K. Sagar, J. Fan, Y. Hou, M. Wu, S. Lee, B. Sun, S. Hoogland, R. Quintero-Bermudez, H. Ebe, P. Todorovic, F. Dinic, P. Li, H. T. Kung, 
M. I. Saidaminov, E. Kumacheva, E. Spiecker, L.-S. Liao, O. Voznyy, Z.-H. Lu and E. H. Sargent, Nat. Nanotechnol., 2020, 15, 668-674.

23 Y. Fang, Q. Dong, Y. Shao, Y. Yuan and J. Huang, Nature Photon, 2015, 9, 679686.

24 H. Zhu, Y. Fu, F. Meng, X. Wu, Z. Gong, Q. Ding, M. V. Gustafsson, M. T. Trinh, S. Jin and X.-Y. Zhu, Nature Mater, 2015, 14, 636-642.

25 D. Li, H.-C. Cheng, Y. Wang, Z. Zhao, G. Wang, H. Wu, Q. He, Y. Huang and X. Duan, Adv. Mater., 2017, 29, 1601959.

26 S. Yakunin, M. Sytnyk, D. Kriegner, S. Shrestha, M. Richter, G. J. Matt, H. Azimi, C. J. Brabec, J. Stangl, M. V. Kovalenko and W. Heiss, Nature Photon, 2015, 9, 444-449.

27 Y. He and G. Galli, Chem. Mater., 2014, 26, 5394-5400.

28 J. Choi, S. Park, J. Lee, K. Hong, D.-H. Kim, C. W. Moon, G. D. Park, J. Suh, J. Hwang, S. Y. Kim, H. S. Jung, N.-G. Park, S. Han, K. T. Nam and H. W. Jang, $A d v$. Mater., 2016, 28, 6562-6567.

29 C. C. Boyd, R. Cheacharoen, T. Leijtens and M. D. McGehee, Chem. Rev., 2019, 119, 3418-3451.

30 M.-G. Ju, M. Chen, Y. Zhou, J. Dai, L. Ma, N. P. Padture and X. C. Zeng, Joule, 2018, 2, 1231-1241.

31 Y. Rong, L. Liu, A. Mei, X. Li and H. Han, Adv. Energy Mater., 2015, 5, 1501066.

32 B. Conings, J. Drijkoningen, N. Gauquelin, A. Babayigit, J. D’Haen, L. D’Olieslaeger, A. Ethirajan, J. Verbeeck, J. Manca, E. Mosconi, F. D. Angelis and H.-G. Boyen, Adv. Energy Mater., 2015, 5, 1500477.

33 G. P. Nagabhushana, R. Shivaramaiah and A. Navrotsky, Proc Natl Acad Sci USA, 2016, 113, 7717-7721.

34 I. Chung, J.-H. Song, J. Im, J. Androulakis, C. D. Malliakas, H. Li, A. J. Freeman, J. T. Kenney and M. G. Kanatzidis, J. Am. Chem. Soc., 2012, 134, 8579-8587.

35 C. Liu, W. Li, C. Zhang, Y. Ma, J. Fan and Y. Mai, J. Am. Chem. Soc., 2018, 140, 3825-3828.

36 A. Babayigit, A. Ethirajan, M. Muller and B. Conings, Nature Mater, 2016, 15, 247251.

37 P. P. Fu, Q. Xia, H.-M. Hwang, P. C. Ray and H. Yu, Journal of Food and Drug Analysis, 2014, 22, 64-75.

38 L. Shi, M. P. Bucknall, T. L. Young, M. Zhang, L. Hu, J. Bing, D. S. Lee, J. Kim, T. Wu, N. Takamure, D. R. McKenzie, S. Huang, M. A. Green and A. W. Y. Ho-Baillie, Science, 2020, 368, eaba2412.

39 T.-B. Song, T. Yokoyama, C. C. Stoumpos, J. Logsdon, D. H. Cao, M. R. Wasielewski, S. Aramaki and M. G. Kanatzidis, J. Am. Chem. Soc., 2017, 139, 836-842.

40 T. Krishnamoorthy, H. Ding, C. Yan, W. L. Leong, T. Baikie, Z. Zhang, M. Sherburne, S. Li, M. Asta, N. Mathews and S. G. Mhaisalkar, J. Mater. Chem. A, 2015, 3, 23829-23832.

41 B.-W. Park, B. Philippe, X. Zhang, H. Rensmo, G. Boschloo and E. M. J. Johansson, Adv. Mater., 2015, 27, 6806-6813.

42 P. Karuppuswamy, K. M. Boopathi, A. Mohapatra, H.-C. Chen, K.-T. Wong, P.-C. Wang and C.-W. Chu, Nano Energy, 2018, 45, 330-336.

43 N. Sakai, A. A. Haghighirad, M. R. Filip, P. K. Nayak, S. Nayak, A. Ramadan, Z. Wang, F. Giustino and H. J. Snaith, J. Am. Chem. Soc., 2017, 139, 6030-6033. 
44 M. Chen, M.-G. Ju, A. D. Carl, Y. Zong, R. L. Grimm, J. Gu, X. C. Zeng, Y. Zhou and N. P. Padture, Joule, 2018, 2, 558-570.

45 W. Ning and F. Gao, Adv. Mater., 2019, 31, 1900326.

46 S. S. Shin, J. P. Correa Baena, R. C. Kurchin, A. Polizzotti, J. J. Yoo, S. Wieghold, M. G. Bawendi and T. Buonassisi, Chem. Mater., 2018, 30, 336-343.

47 B. Saparov, F. Hong, J.-P. Sun, H.-S. Duan, W. Meng, S. Cameron, I. G. Hill, Y. Yan and D. B. Mitzi, Chem. Mater., 2015, 27, 5622-5632.

48 P. C. Harikesh, H. K. Mulmudi, B. Ghosh, T. W. Goh, Y. T. Teng, K. Thirumal, M. Lockrey, K. Weber, T. M. Koh, S. Li, S. Mhaisalkar and N. Mathews, Chem. Mater., 2016, 28, 7496-7504.

49 F. Jiang, D. Yang, Y. Jiang, T. Liu, X. Zhao, Y. Ming, B. Luo, F. Qin, J. Fan, H. Han, L. Zhang and Y. Zhou, J. Am. Chem. Soc., 2018, 140, 1019-1027.

50 B. Vargas, E. Ramos, E. Pérez-Gutiérrez, J. C. Alonso and D. Solis-Ibarra, J. Am. Chem. Soc., 2017, 139, 9116-9119.

51 Z. Xu, X. Liu, Y. Li, X. Liu, T. Yang, C. Ji, S. Han, Y. Xu, J. Luo and Z. Sun, Angew. Chem. Int. Ed., 2019, 58, 15757-15761.

52 F. Giustino and H. J. Snaith, ACS Energy Lett., 2016, 1, 1233-1240.

53 A. H. Slavney, T. Hu, A. M. Lindenberg and H. I. Karunadasa, J. Am. Chem. Soc., 2016, 138, 2138-2141.

54 E. T. McClure, M. R. Ball, W. Windl and P. M. Woodward, Chem. Mater., 2016, 28, 1348-1354.

55 G. Volonakis, M. R. Filip, A. A. Haghighirad, N. Sakai, B. Wenger, H. J. Snaith and F. Giustino, J. Phys. Chem. Lett., 2016, 7, 1254-1259.

56 G. Volonakis, A. A. Haghighirad, R. L. Milot, W. H. Sio, M. R. Filip, B. Wenger, M. B. Johnston, L. M. Herz, H. J. Snaith and F. Giustino, J. Phys. Chem. Lett., 2017, 8, 772-778.

57 B. A. Connor, R.-I. Biega, L. Leppert and H. I. Karunadasa, Chem. Sci., 2020, 11, 7708-7715.

58 A. H. Slavney, L. Leppert, A. Saldivar Valdes, D. Bartesaghi, T. J. Savenije, J. B. Neaton and H. I. Karunadasa, Angew. Chem. Int. Ed., 2018, 57, 12765-12770.

59 T. T. Tran, J. R. Panella, J. R. Chamorro, J. R. Morey and T. M. McQueen, Mater. Horiz., 2017, 4, 688-693.

60 H. Yin, Y. Xian, Y. Zhang, W. Chen, X. Wen, N. U. Rahman, Y. Long, B. Jia, J. Fan and W. Li, Adv. Funct. Mater., 2020, 11.

61 Z. Xiao, W. Meng, J. Wang and Y. Yan, ChemSusChem, 2016, 9, 2628-2633.

62 R. L. Z. Hoye, L. Eyre, F. Wei, F. Brivio, A. Sadhanala, S. Sun, W. Li, K. H. L. Zhang, J. L. MacManus-Driscoll, P. D. Bristowe, R. H. Friend, A. K. Cheetham and F. Deschler, Adv. Mater. Interfaces, 2018, 5, 1800464.

63 M. Delor, A. H. Slavney, N. R. Wolf, M. R. Filip, J. B. Neaton, H. I. Karunadasa and N. S. Ginsberg, ACS Energy Lett., 2020, 5, 1337-1345.

64 W. Ning, X.-G. Zhao, J. Klarbring, S. Bai, F. Ji, F. Wang, S. I. Simak, Y. Tao, X.M. Ren, L. Zhang, W. Huang, I. A. Abrikosov and F. Gao, Advanced Functional Materials, 2019, 29, 1807375.

65 J. Luo, S. Li, H. Wu, Y. Zhou, Y. Li, J. Liu, J. Li, K. Li, F. Yi, G. Niu and J. Tang, ACS Photonics, 2018, 5, 398-405.

66 W. Meng, X. Wang, Z. Xiao, J. Wang, D. B. Mitzi and Y. Yan, J. Phys. Chem. Lett., 2017, 8, 2999-3007. 
67 F. Ji, F. Wang, L. Kobera, S. Abbrent, J. Brus, W. Ning and F. Gao, Chem. Sci., 2021, 10.1039.D0SC05264G.

68 J. Luo, X. Wang, S. Li, J. Liu, Y. Guo, G. Niu, L. Yao, Y. Fu, L. Gao, Q. Dong, C. Zhao, M. Leng, F. Ma, W. Liang, L. Wang, S. Jin, J. Han, L. Zhang, J. Etheridge, J. Wang, Y. Yan, E. H. Sargent and J. Tang, Nature, 2018, 563, 541-545.

69 S. Li, J. Luo, J. Liu and J. Tang, J. Phys. Chem. Lett., 2019, 10, 1999-2007.

70 J. Zhou, X. Rong, P. Zhang, M. S. Molokeev, P. Wei, Q. Liu, X. Zhang and Z. Xia, Advanced Optical Materials, 2019, 7, 1801435.

71 E. Greul, M. L. Petrus, A. Binek, P. Docampo and T. Bein, J. Mater. Chem. A, 2017, 5, 19972-19981.

72 B.F. Aull, H.P. Jenssen, Phys. Rev. B, 34 (1986), pp. 6647-6655

73 J. Yang, C. Bao, W. Ning, B. Wu, F. Ji, Z. Yan, Y. Tao, J. Liu, T. C. Sum, S. Bai, J. Wang, W. Huang, W. Zhang and F. Gao, Advanced Optical Materials, 2019, 1801732.

74 W. Pan, H. Wu, J. Luo, Z. Deng, C. Ge, C. Chen, X. Jiang, W.-J. Yin, G. Niu, L. Zhu, L. Yin, Y. Zhou, Q. Xie, X. Ke, M. Sui and J. Tang, Nature Photon, 2017, 11, 726-732.

75L. Zhou, Y.-F. Xu, B.-X. Chen, D.-B. Kuang and C.-Y. Su, Small, 2018, 14, 1703762.

76 X.-G. Zhao, D. Yang, J.-C. Ren, Y. Sun, Z. Xiao and L. Zhang, Joule, 2018, 2, $1662-$ 1673.

77 W. Gao, C. Ran, J. Xi, B. Jiao, W. Zhang, M. Wu, X. Hou and Z. Wu, ChemPhysChem, 2018, 19, 1696-1700.

78 C. Wu, Q. Zhang, Y. Liu, W. Luo, X. Guo, Z. Huang, H. Ting, W. Sun, X. Zhong, S. Wei, S. Wang, Z. Chen and L. Xiao, Adv. Sci., 2018, 5, 1700759.

79 M. Wang, P. Zeng, S. Bai, J. Gu, F. Li, Z. Yang and M. Liu, Sol. RRL, 2018, 2, 1800217.

80 Z. Li, P. Wang, C. Ma, F. Igbari, Y. Kang, K.-L. Wang, W. Song, C. Dong, Y. Li, J. Yao, D. Meng, Z.-K. Wang and Y. Yang, J. Am. Chem. Soc., 2021, 143, 2593-2600.

81 B. Wang, N. Li, L. Yang, C. Dall'Agnese, A. K. Jena, S. Sasaki, T. Miyasaka, H. Tamiaki and X.-F. Wang, J. Am. Chem. Soc., 2021, 143, 2207-2211.

82 N. N. K. and A. Nag, Chem. Commun., 2018, 54, 5205-5208.

83 M. B. Gray, J. D. Majher, T. A. Strom and P. M. Woodward, Inorg. Chem., 2019, 58, 13403-13410.

84 H. Arfin, J. Kaur, T. Sheikh, S. Chakraborty and A. Nag, Angew. Chem. Int. Ed., 2020, 59, 11307-11311.

85 Y. Xian, H. Yin, Y. Bao, Y. Xiao, S. Yuan, N. U. Rahman, Y. Yuan, Y. Zhang, X. Meng, S. Jin, W. Li and J. Fan, J. Phys. Chem. Lett., 2020, 11, 9535-9542.

86 X. Cao, L. Kang, S. Guo, M. Zhang, Z. Lin and J. Gao, ACS Appl. Mater. Interfaces, 2019, 11, 38648-38653.

87 S. E. Creutz, E. N. Crites, M. C. De Siena and D. R. Gamelin, Nano Lett., 2018, 18, $1118-1123$.

88 F. Wei, Z. Deng, S. Sun, F. Zhang, D. M. Evans, G. Kieslich, S. Tominaka, M. A. Carpenter, J. Zhang, P. D. Bristowe and A. K. Cheetham, Chem. Mater., 2017, 29, 1089-1094.

89 M. R. Filip, X. Liu, A. Miglio, G. Hautier and F. Giustino, J. Phys. Chem. C, 2018, 122, 158-170. 
90 D. J. Kubicki, M. Saski, S. MacPherson, K. Galkowski, J. Lewiński, D. Prochowicz, J. J. Titman and S. D. Stranks, Chem. Mater., 2020, 32, 8129-8138.

91 A. H. Slavney, L. Leppert, D. Bartesaghi, A. Gold-Parker, M. F. Toney, T. J. Savenije, J. B. Neaton and H. I. Karunadasa, J. Am. Chem. Soc., 2017, 139, 5015-5018.

92 F. Ji, Y. Huang, F. Wang, L. Kobera, F. Xie, J. Klarbring, S. Abbrent, J. Brus, C. Yin, S. I. Simak, I. A. Abrikosov, I. A. Buyanova, W. M. Chen and F. Gao, Adv. Funct. Mater., 2020, 30, 2005521.

93 Y. Xian, H. Yin, Y. Bao, Y. Xiao, S. Yuan, N. U. Rahman, Y. Yuan, Y. Zhang, X. Meng, S. Jin, W. Li and J. Fan, J. Phys. Chem. Lett., 2020, 11, 9535-9542.

94 K. Du, W. Meng, X. Wang, Y. Yan and D. B. Mitzi, Angewandte Chemie International Edition, 2017, 56, 8158-8162.

95 Y. Liu, L. Zhang, M. Wang, Y. Zhong, M. Huang, Y. Long and H. Zhu, Materials Today, 2019, 28, 25-30.

96 W. Ning, J. Bao, Y. Puttisong, F. Moro, L. Kobera, S. Shimono, L. Wang, F. Ji, M. Cuartero, S. Kawaguchi, S. Abbrent, H. Ishibashi, R. De Marco, I. A. Bouianova, G. A. Crespo, Y. Kubota, J. Brus, D. Y. Chung, L. Sun, W. M. Chen, M. G. Kanatzidis and F. Gao, Sci. Adv., 2020, 6, eabb5381.

97 A. Karmakar, G. M. Bernard, A. Meldrum, A. O. Oliynyk and V. K. Michaelis, J. Am. Chem. Soc., 2020, 142, 10780-10793.

98 W. Lee, S. Hong and S. Kim, J. Phys. Chem. C, 2019, 123, 2665-2672.

99 H. Arfin, J. Kaur, T. Sheikh, S. Chakraborty and A. Nag, Angew. Chem. Int. Ed., 2020, 59, 11307-11311.

100 K. P. Lindquist, S. A. Mack, A. H. Slavney, L. Leppert, A. Gold-Parker, J. F. Stebbins, A. Salleo, M. F. Toney, J. B. Neaton and H. I. Karunadasa, Chem. Sci., 2019, 10, 10620-10628.

101 A. Karmakar, M. S. Dodd, S. Agnihotri, E. Ravera and V. K. Michaelis, Chem. Mater., 2018, 30, 8280-8290.

102 J. D. Majher, M. B. Gray, T. A. Strom and P. M. Woodward, Chem. Mater., 2019, 31, 1738-1744.

103 J. Zhou, X. Rong, M. S. Molokeev, X. Zhang and Z. Xia, J. Mater. Chem. A, 2018, 6, 2346-2352.

104 W. Yuan, G. Niu, Y. Xian, H. Wu, H. Wang, H. Yin, P. Liu, W. Li and J. Fan, Advanced Functional Materials, 2019, 29, 1900234.

105 F. Ji, J. Klarbring, F. Wang, W. Ning, L. Wang, C. Yin, J. S. M. Figueroa, C. K. Christensen, M. Etter, T. Ederth, L. Sun, S. I. Simak, I. A. Abrikosov and F. Gao, Angew. Chem., 2020, 132, 15303-15306.

106 J. Yang, P. Zhang and S.-H. Wei, J. Phys. Chem. Lett., 2018, 9, 31-35.

107 J. Kim, H. Kim, M. Chandran, S.-C. Lee, S. H. Im and K.-H. Hong, APL Materials, 2018, 6, 084903.

108 Q. Li, Y. Wang, W. Pan, W. Yang, B. Zou, J. Tang and Z. Quan, Angewandte Chemie International Edition, 2017, 56, 15969-15973.

109 R. Fu, Y. Chen, X. Yong, Z. Ma, L. Wang, P. Lv, S. Lu, G. Xiao and B. Zou, Nanoscale, 2019, 11, 17004-17009.

110 C. Lv, X. Yang, Z. Shi, L. Wang, L. Sui, Q. Li, J. Qin, K. Liu, Z. Zhang, X. Li, Q. Lou, D. Yang, J. Zang, R. Liu, B. Liu and C.-X. Shan, J. Phys. Chem. C, 2020, 124, 1732-1738. 
111 L. Zhang, Y. Fang, L. Sui, J. Yan, K. Wang, K. Yuan, W. L. Mao and B. Zou, ACS Energy Lett., 2019, 4, 2975-2982.

112 W.-Q. Liao, Y. Zhang, C.-L. Hu, J.-G. Mao, H.-Y. Ye, P.-F. Li, S. D. Huang and R.-G. Xiong, Nat Commun, 2015, 6, 7338.

113 M. I. Saidaminov, A. L. Abdelhady, B. Murali, E. Alarousu, V. M. Burlakov, W. Peng, I. Dursun, L. Wang, Y. He, G. Maculan, A. Goriely, T. Wu, O. F. Mohammed and O. M. Bakr, Nat Commun, 2015, 6, 7586.

114 D. Shi, V. Adinolfi, R. Comin, M. Yuan, E. Alarousu, A. Buin, Y. Chen, S. Hoogland, A. Rothenberger, K. Katsiev, Y. Losovyj, X. Zhang, P. A. Dowben, O. F. Mohammed, E. H. Sargent and O. M. Bakr, Science, 2015, 347, 519-522.

115 R. Babu, L. Giribabu and S. P. Singh, Crystal Growth \& Design, 2018, 18, 26452664.

116 B. Reif, S. E. Ashbrook, L. Emsley and M. Hong, Nat Rev Methods Primers, 2021, $1,2$.

117 D. J. Kubicki, D. Prochowicz, A. Pinon, G. Stevanato, A. Hofstetter, S. M. Zakeeruddin, M. Grätzel and L. Emsley, J. Mater. Chem. A, 2019, 7, 2326-2333.

118 T. Polenova, R. Gupta and A. Goldbourt, Anal. Chem., 2015, 87, 5458-5469. 


\section{Papers}

The papers associated with this thesis have been removed for copyright reasons. For more details about these see:

http://urn.kb.se/resolve?urn=urn:nbn:se:liu:diva-178816 


\section{FACULTY OF SCIENCE AND ENGINEERING}

Linköping Studies in Science and Technology No. 2156

Department of Physics, Chemistry and Biology (IFM)

Linköping University

SE-581 83 Linköping, Sweden

www.liu.se 